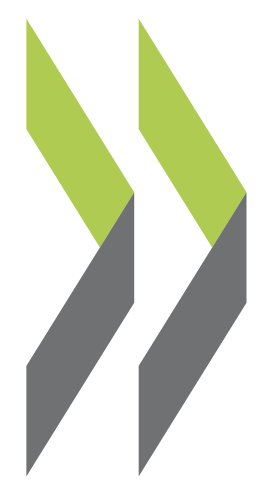

OECD Trade and Environment Working Papers 2014/03

\title{
The Stringency of Environmental Regulations and Trade in Environmental Goods
}

\section{Jehan Sauvage}




\section{OECD TRADE AND ENVIRONMENT WORKING PAPERS}

OECD Working Papers should not be reported as representing the official views of the OECD or of its member countries. The opinions expressed and arguments employed are those of the authors.

Working Papers describe preliminary results or research in progress by the author(s) and are published to stimulate discussion on a broad range of issues on which the OECD works. Comments on Working Papers are welcomed, and may be sent to the Trade and Agriculture Directorate, OECD, 2 rue André-Pascal, 75775 Paris Cedex 16, France or to the Environment Directorate, OECD, 2 rue André-Pascal, 75775 Paris Cedex 16.

The publication of this document has been authorised by Ken Ash, Director of the Trade and Agriculture Directorate.

This document and any map included herein are without prejudice to the status of or sovereignty over any territory, to the delimitation of international frontiers and boundaries and to the name of any territory, city or area.

The statistical data for Israel are supplied by and under the responsibility of the relevant Israeli authorities. The use of such data by the OECD is without prejudice to the status of the Golan Heights, East Jerusalem and Israeli settlements in the West Bank under the terms of international law.

This document has been declassified on the responsibility of the Joint Working Party on Trade and Environment under the OECD reference number COM/TAD/ENV/JWPTE(2013)33/FINAL.

Comments on the papers in this series are welcome and should be sent to env.contact@oecd.org or tad.contact@oecd.org.

\section{OECD TRADE AND ENVIRONMENT WORKING PAPERS}

are published on the OECD's trade (www.oecd.org/trade) and environment (www.oecd.org/environment) web pages, as well as on the OECD iLibrary web pages (www.oecdilibrary.org).

Ce document est également disponible en français sur le site Internet de l'OCDE à l'adresse URL suivante : www.oecd.org/trade/envtrade.

(c) OECD (2014)

You can copy, download or print OECD content for your own use, and you can include excerpts from OECD publications, databases and multimedia products in your own documents, presentations, blogs, websites and teaching materials, provided that suitable acknowledgment of OECD as source and copyright owner is given. All requests for commercial use and translation rights should be submitted to rights@oecd.org. 


\title{
Abstract \\ The Stringency of Environmental Regulations and Trade in Environmental Goods
}

\author{
Jehan Sauvage \\ OECD Trade Policy Analyst
}

\begin{abstract}
This report assesses conceptually and empirically the extent to which the stringency of environmental regulations drives international trade in environmental goods. Many of the measures governments adopt to address issues such as local air and water pollution or GHG emissions take the form of regulations that aim to change the behaviour of firms or households. Compliance by private actors with those regulations in turn generates a growing market for environmental goods and services that is increasingly international in scope as more countries tighten their environmental regulations. Regulatory stringency thus spurs the development of a market for a whole range of equipment specifically meant for preventing and abating pollution, with important implications for international trade in such equipment. The different indicators of regulatory stringency considered in the present analysis generally support the notion that the stringency of environmental regulations positively affects countries' specialisation in environmental products, even when considering specific sectors such as solid-waste management or wastewater treatment. While increased trade in environmental products is not an end in itself, the environmental benefits this entails can contribute to global improvements in environmental quality. By increasing demand for environmental products and technologies, environmental policy can complement trade policy in supporting pollution-reduction efforts not just domestically, but also abroad.
\end{abstract}

Keywords: Trade, Environment, Environmental Regulations, Environmental Goods, Comparative Advantage, Solid Waste Management, Wastewater Treatment.

JEL classification: F14, F18, Q53, Q56, Q58.

\section{Acknowledgments}

This paper was written by Jehan Sauvage of the Environment Policies Division of the OECD Trade and Agriculture Directorate under the supervision of Dale Andrew and Franck Jésus. The author wishes to thank Françoise Bénicourt and Theresa Poincet for their help in preparing the document for publication. The author's gratitude also goes to the following OECD staff members who provided helpful comments and suggestions: Silvia Albrizio, Peter Borkey, Julien Hardelin, Tomasz Kozluk, Jussi Lankoski, Sébastien Miroudot, Andrew Prag, Dorothée Rouzet, Raed Safadi, and Ronald Steenblik. In addition, the analysis greatly benefited from the insights of Grant Ferrier (principal, Environmental Business International Inc.).

Caroline Gomes Nogueira and Mark Mateo provided helpful statistical assistance. Excellent research assistance was also provided at different stages of the project by Livia Alfonsi, Assia Elgouacem, and Jocelyn van Berkel.

This paper was discussed by the Joint Working Party on Trade and Environment (JWPTE), which agreed to declassify the document under a written procedure. The author is grateful to the delegates for their many comments and suggestions. Any errors or omissions are the sole responsibility of the author. 


$\begin{array}{ll}\text { APC } & \text { Air pollution control } \\ \text { APEC } & \text { Asia-Pacific Economic Cooperation } \\ \text { BAT } & \text { Best available techniques } \\ \text { BRIICS } & \text { Brazil, Russia, India, Indonesia, China, South Africa } \\ \text { CLEG } & \text { Combined list of environmental goods } \\ \text { CO }_{2} & \text { Carbon dioxide } \\ \text { EBI } & \text { Environmental Business International Inc. } \\ \text { EBOPS } & \text { Extended balance of payment services } \\ \text { EEA } & \text { European Environment Agency } \\ \text { EGS } & \text { Environmental goods and services } \\ \text { EPS } & \text { Environmental policy stringency } \\ \text { ETS } & \text { Emissions trading system } \\ \text { GATS } & \text { General agreement on trade in services } \\ \text { GHG } & \text { Greenhouse gas } \\ \text { HS } & \text { Harmonized system } \\ \text { LBL } & \text { Load-based licensing } \\ \text { MSW } & \text { Municipal solid waste } \\ \text { NO } & \text { Nitrogen oxides } \\ \text { PEGS } & \text { Plurilateral agreement on environmental goods and services } \\ \text { PM } & \text { Particulate matter } \\ \text { RCA } & \text { Revealed comparative advantage } \\ \text { SO } & \text { Sulphur dioxide } \\ \text { Solar PV } & \text { Solar photovoltaic panel } \\ \text { US EPA } & \text { United States Environmental Protection Agency } \\ \text { USITC } & \text { United States International Trade Commission } \\ \text { UWWTD } & \text { Urban waste water treatment directive } \\ \text { VOC } & \text { Volatile organic compound } \\ \text { WEF } & \text { World Economic Forum } \\ \text { WHO } & \end{array}$




\section{Table of Contents}

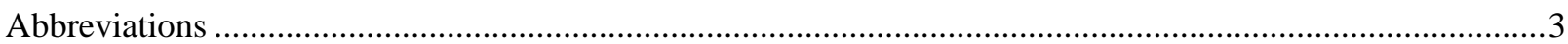

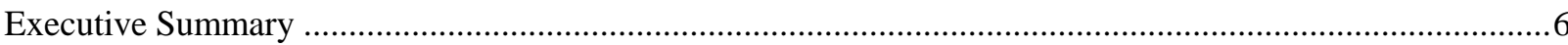

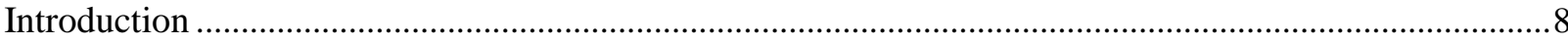

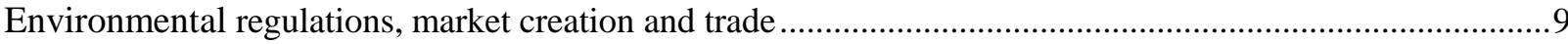

The purpose and scope of environmental regulations ..................................................................

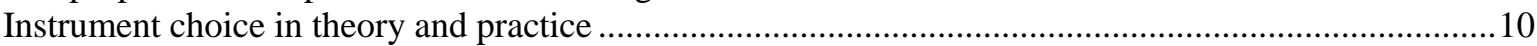

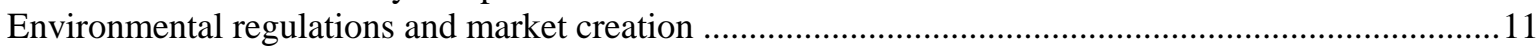

Market size and the direction of trade: a conceptual discussion ................................................. 13

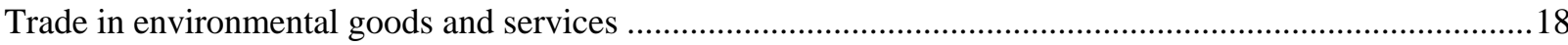

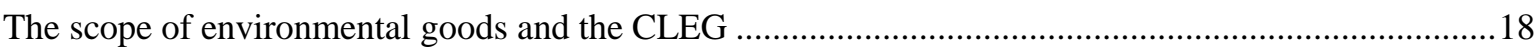

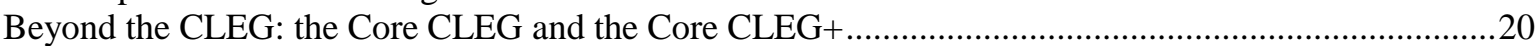

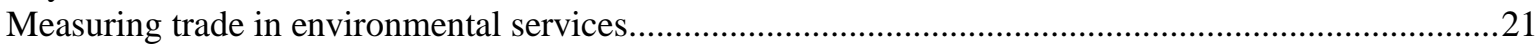

Recent trends in trade in CLEG products ..............................................................................22

Explaining patterns of trade in environmental goods: What role for environmental regulations? .................25

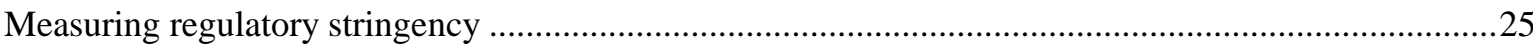

A broad-based analysis of comparative advantage in environmental products .................................27

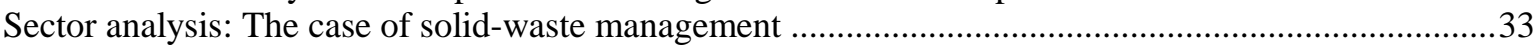

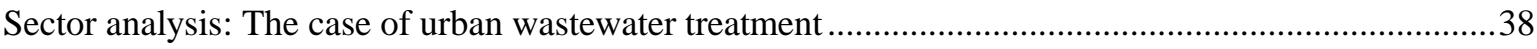

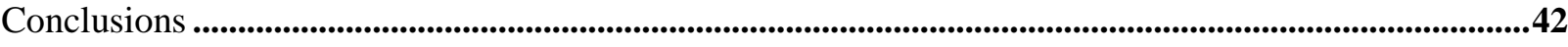

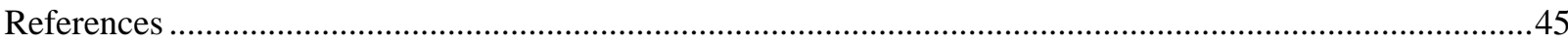

Annex 1: The Combined List of Environmental Goods (CLEG) used by the OECD ..................................50

Annex 2: Average import tariffs applied by a selection of countries on CLEG products by medium (2012) .57

Annex 3: Guidelines and binding concentration limits for selected pollutants, sectors, and OECD countries 58

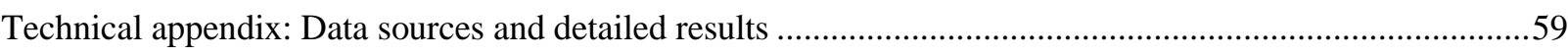

\section{Tables}

Table 1. Environmental themes and media in the CLEG ............................................................ 19

Table 2. World imports of environmental goods by environmental medium or theme.......................24

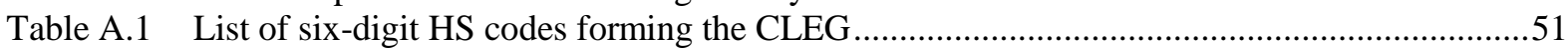

Table A.2. The EPS index and other determinants of RCA in CLEG products.....................................62

Table A.3. Additional results for CLEG products using the EPS index and average import tariffs .........63

Table A.4. The EPS index and other determinants of RCA in core CLEG products ..............................64

Table A.5. The EPS index and other determinants of RCA in core CLEG+ products..........................65

Table A.6. The EPS index and other determinants of RCA in energy-related CLEG products................66

Table A.7. The share of MSW landfilled and other determinants of RCA in solid-waste-related products67

Table A.8. The TRT indicator and other determinants of RCA in water-related products .......................68 


\section{Figures}

Figure 1. Intra-industry trade in environmental goods (2007-11) ........................................................16

Figure 2. World imports of environmental goods and merchandise goods .............................................23

Figure 3. Measuring the stringency of environmental policies at different points

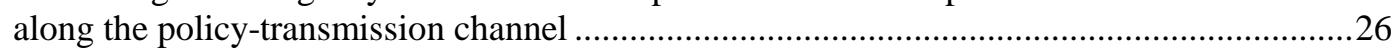

Figure 4. Aggregation structure of the composite indicator of environmental policy stringency

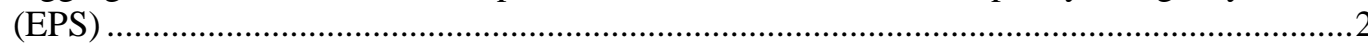

Figure 5. Environmental policy stringency and revealed comparative advantage in CLEG products

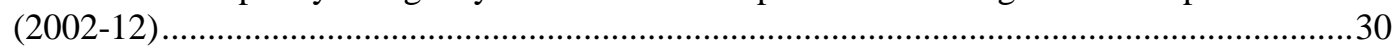

Figure 6. Environmental policy stringency and revealed comparative advantage in energy-related CLEG products (2002-12) ......................................................................... 32

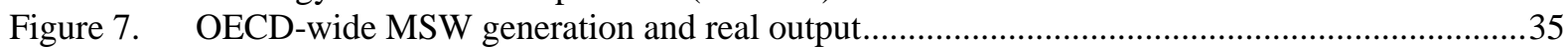

Figure 8. The waste management hierarchy …………......................................................................... 35

Figure 9. Landfilling of municipal solid waste and revealed comparative advantage in solid-waste-related products (2008-11) .............................................................................. 37

Figure 10. The level of wastewater treatment and revealed comparative advantage

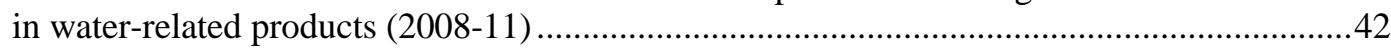

\section{Boxes}

Box 1. Regulating industrial emissions: the case of the EU ..........................................................11

Box 2. Market size, spillovers, and international trade: The example of Chile's EGS industry ..........17

Box 3. Tertiary treatment and the recovery of phosphate: The example of crystallisation technologies. 


\section{Executive Summary}

Governments in the OECD and elsewhere are increasingly taking action to mitigate the impacts that economic activity has on the environment, both locally and globally. Many of the measures they adopt to address issues such as local air and water pollution or GHG emissions take the form of regulations that aim to change the behaviour of firms or households. To comply with those regulations, private actors often acquire new techniques and equipment specifically meant for preventing and abating pollution. This generates in turn a growing market for environmental goods and services (EGS) that is increasingly international in scope as more countries tighten their environmental regulations.

Policy makers have, for many years, sought to liberalise EGS trade by means of tariff cuts and the removal of other impediments to trade in order to reap the economic and environmental benefits associated with a widespread international diffusion of EGS. Trade liberalisation alone may, however, not be enough in a context wherein demand for environmental products remains essentially determined by the stringency of environmental regulations. For that reason, this report assesses conceptually and empirically the extent to which the stringency of environmental regulations drives international trade in environmental products.

A goal of environmental regulation is to ensure that firms and households take into account the impacts that their decisions have on the environment, and indirectly on society. To do so, policy makers need to choose the best regulatory instruments available to them, which could include emission or ambient standards, technology requirements, pollution charges and taxes, tradable emission permits, or subsidies specifically related to the environment. If the regulation is effective, the instruments will, for example, prompt firms to modify their production techniques and adopt new, more environmentally friendly equipment. In that sense, environmental regulations spur the development of a market for a whole range of EGS that would otherwise likely be much smaller. An increased market size has in turn important implications for international EGS trade.

Several economic models of trade suggest that a larger home market increases exports more than imports in cases where products are differentiated. It is therefore plausible that stringent environmental regulations increase exports of environmental goods and services through the effect these regulations have on market size. To assess this channel empirically, this report uses a combined list of 248 environmental goods ("the CLEG") organised by environmental theme or medium. Challenges in defining and measuring environmental services make it difficult at this stage to include them in the analysis, however.

Results from a broad-based analysis using a composite index of the stringency of various environmental policy instruments (the EPS index) point to a clear positive relationship between a country's regulatory stringency and its relative share of world exports in environmental products. Further analysis goes on to find that the customs tariffs applied by a country on its imports of environmental products also have a small but detrimental impact on its exports of the same products, independent of the positive impact that regulatory stringency has. The indicators used in this analysis are, however, largely focussed on the power sector and air-pollution control, which makes it hard to generalise the findings to other areas. Besides, the indicator of regulatory stringency used here (the EPS index) covers a large set of energy-related policies that go beyond traditional pollution-abating instruments, including 
elements like public spending on renewable-energy R\&D and feed-in tariffs for solar and wind energy.

The remainder of the report therefore looks at two particular sectors in order to collect more focussed evidence, namely municipal solid-waste (MSW) management and wastewater treatment, two sectors that are major contributors to the global environmental industry. The regulations these sectors are subject to have also induced countries to collect data tracking the amounts of solid waste and wastewater generated and their subsequent treatment in dedicated facilities, thereby making them good candidates for quantitative analysis.

Because the limited use of landfills for treating waste tends to be closely associated with stringent regulations in the MSW sector, the analysis first uses the share of MSW landfilled as an indicator of regulatory stringency. The results thus obtained suggest that low shares of MSW landfilled tend to be associated with higher relative export shares of environmental products related to solid-waste management. Or, to put it differently, stringent regulations in the MSW sector are positively correlated with exports of MSW-related products even after controlling for the influence of other trade-related variables. The magnitude of the estimated coefficients is, however, much smaller than in the previous analysis for all CLEG products using the EPS index.

A similar analysis is then conducted for the wastewater-treatment sector, looking at trade in products related to water supply and sanitation. Using an indicator of the extent to which different countries treat their wastewater before release into water bodies, a correlation is found between the latter and countries' relative exports of water-related products, again suggesting that stringent regulations tend to be associated with better export performance in the relevant range of environmental products. Moreover, this last set of results appear more robust and of a larger magnitude than the previous ones concerning MSW, while falling roughly in the same range as those obtained using the EPS index for all CLEG products.

Overall, the variety of indicators considered in this report, together with the adoption of both a countrywide and a sector-level perspective, give considerable support to the argument that the stringency of environmental regulations positively affects trade in environmental products. While the scope of the report may appear limited in that it only looks at exports (and not imports) of environmental goods in particular sectors - and this in part due to data limitations for environmental services - , the consistency of the findings across the different indicators of stringency used still provides useful insights. Importantly, the analysis serves to highlight the peculiar nature of the market for environmental goods, and in particular the role that environmental regulations play in generating and sustaining demand, which in turn increases trade and export opportunities.

In this context, the removal of barriers to EGS trade forms but one of the drivers behind a greater diffusion of environmental technologies, so that current efforts to liberalise trade in environmental goods may need to be accompanied by parallel efforts to raise the level of ambition of environmental policy. By increasing demand for environmental products and technologies, environmental policy can thus complement trade policy in helping spread EGS more widely and support pollution-reduction efforts not just domestically, but also abroad. While increased EGS trade is not an end in itself, the environmental benefits this entails can, however, contribute to global improvements in environmental quality.

More generally, the supporting role that stringent environmental regulations play for EGS trade reveals areas of compatibility between trade and environmental policy objectives, which may help ease the apparent tension between environmental protection and economic competitiveness. Further consideration of the trade opportunities that can arise from the adoption of environmental regulations domestically could help counter-balance traditional concerns about the impacts these regulations have on pollution-intensive sectors. 


\section{Introduction}

As per capita incomes have grown rapidly in large emerging economies, so too have global environmental pressures despite some progress made in decoupling economic growth from pollution. Absent any changes to current policy, the OECD Environmental Outlook to 2050 's baseline scenario foresees the BRIICS ${ }^{1}$ accounting for more than $40 \%$ of world GDP and about 50\% of global greenhouse-gas (GHG) emissions by 2050 (OECD, 2012). Meanwhile, the World Health Organization recently estimated that outdoor air pollution had caused about 3.7 million premature deaths worldwide in 2012, most of them concentrated in the Western Pacific and Southeast Asian regions (WHO, 2014). Stress on water resources is also projected to increase in the coming decades for many regions, including Africa, Australia, some parts of South America, southern Europe, and the United States (World Bank, 2012).

Faced with such mounting challenges - and recognising the growing body of scientific evidence that many natural systems have "tipping points" (OECD, 2012) - governments in developing and developed countries alike are increasingly taking action to mitigate the impacts that economic activity has on the environment locally and globally. In the case of the People's Republic of China, these efforts have translated into, among other things: the introduction of $\mathrm{CO}_{2}$ emissions-trading schemes in seven pilot regions (starting with Shenzhen in June 2013); a gradual tightening of emissions standards for new motor vehicles; new rules requiring that industrial projects treat their wastewater and obtain a permit before release into sewage networks; and - starting on 1 January 2014 - the obligation for 15000 polluting firms to disclose in real time their emissions of air and water pollutants (OECD, 2013a; IPE, 2011; The Economist, 2014). Meanwhile, the US Federal Administration recently released a legislative proposal that would cut $\mathrm{CO}_{2}$ emissions from the country's existing power plants by $30 \%$ below 2005 levels by 2030 (US EPA, 2014). This proposal comes on top of steps taken a year before by the Administration to impose more stringent carbon-emission standards on newly built conventional power plants across the country (US EPA, 2013).

Many of the measures that governments adopt to address issues such as local air and water pollution or GHG emissions take the form of regulations that aim to alter the production or consumption decisions of private actors. In doing so, the expectation is that government intervention will help align the private costs that these decisions entail and their corresponding costs to society. However, the changes in behaviour that compliance with environmental regulations implies most often require that private actors adopt different techniques and new equipment helping to prevent and abate pollution. Environmental regulations thus create a need among regulated actors for new solutions. This need has generated over the years a growing market for environmental goods and services (EGS) that is increasingly international in scope as more countries tighten their environmental regulations.

The opening of EGS markets to international competition has brought many economic benefits in the form of increased efficiency, economies of scale, and easier access to the best available technologies. Predictably, it has also led to desirable environmental outcomes such as cleaner water, reduced air pollution, and a better use of natural resources. To ensure the continuation of these many benefits, policy makers have sought to further liberalise EGS trade by means of tariff cuts and the removal of other impediments to trade. Trade liberalisation alone may, however, not be enough in a context where demand for environmental products remains essentially determined by environmental regulations.

1. The BRIICS are Brazil, Russia, India, Indonesia, China, and South Africa. 
Because they partly determine the size of the market for EGS, environmental regulations likely have an important influence on trade in environmental products. Efforts to liberalise EGS trade may therefore need to be accompanied by parallel efforts to raise the level of ambition of environmental policy if EGS are to be diffused more widely. In this context, it is important that policy makers gain a better understanding of the way in which EGS trade is affected by regulatory stringency. The present report contributes to that goal by assessing conceptually and empirically the extent to which the stringency of environmental regulations drives exports of environmental goods.

\section{Environmental regulations, market creation and trade}

This first section provides the definitions and the conceptual background informing the analysis later conducted in this report. It starts by clarifying this paper's understanding of the purpose and scope of environmental regulations, with particular emphasis placed on the instruments through which regulations are generally applied and enforced. The remainder of the section then looks at the role that stringent environmental regulations play in creating a market for environmental goods and services, before discussing the implications this may have for international trade.

\section{The purpose and scope of environmental regulations}

Governments in the OECD and elsewhere usually adopt environmental regulations on the grounds that unregulated private actors generally do not take into account the adverse environmental impacts that their production and consumption decisions have on other actors. This class of market failures, known as negative externalities, implies that market forces can lead to socially sub-optimal outcomes, thereby providing a justification for government intervention. A goal of environmental regulation is thus to ensure that social welfare is maximised by aligning private and social costs, i.e. by requiring that private actors such as firms internalise the impacts that their decisions have on the environment, and indirectly on society. ${ }^{2}$

Given the set of goals to be pursued, policy makers then need to choose the best instrument available to achieve them. To that end, it is useful to make a distinction between the act of regulating an activity on the one hand, and the regulatory instruments available for that purpose on the other. In line with the literature ${ }^{3}$, "environmental regulation" is here broadly understood as the correction of an environmental externality while regulatory instruments are the different means through which this correction can be done. Those means are many and include measures such as emission standards, ambient standards, technology requirements, liability rules, information-disclosure measures, pollution charges and taxes, and tradable emission permits. A further distinction can also be made between those regulatory instruments that are command-and-control (or prescriptive), and those that are market-based in the sense that they allow for greater flexibility in the way private actors can abate pollution.

Subsidies could be considered a regulatory instrument under the above definition to the extent that they are used to correct an environmental externality, as is the case with taxes. This specificity requirement limits the scope of regulatory instruments to those that are specifically environmentally related, thereby excluding policy measures that are general in

2. Although economic efficiency is often used as the main criterion for evaluating the goals of environmental regulation, some would also argue for the inclusion of additional equity and fairness criteria. See Revesz and Stavins (2007) for a survey.

3. See Revesz and Stavins (2007), Wiener (1999), and Tietenberg (1990) for examples. 
their application such as value-added taxes levied on sales of petroleum products or general subsidies to businesses (e.g. R\&D tax credits). Setting such a perimeter around environmental regulation and its instruments is consistent with earlier work by the OECD on instruments used for environmental policy.

\section{Instrument choice in theory and practice}

The choice of which regulatory instrument to adopt in a given situation is a complex one as it involves trade-offs between different considerations (Box 1). Among these considerations, environmental effectiveness and the costs of meeting the target are probably the most frequently cited. Environmental effectiveness is self-explanatory since it refers to how effective an instrument is in correcting an environmental externality (e.g. how much pollution can be abated using a particular instrument). The costs of meeting the target are, on the other hand, more elusive as they encompass a wide range of monetary and non-monetary effects. In addition to the direct costs of compliance that different instruments impose on regulated actors are also costs such as those associated with monitoring and enforcement (e.g. how much information the government needs in order to apply a particular instrument). Economic theory offers some guidance in the case of compliance costs through the concept of "cost-effectiveness", which stresses the need to equalise marginal abatement costs across pollution sources. This ensures that the marginal cost of using a given instrument is as low as possible (OECD, 2007a).

In practice, the considerations that policy makers take into account in designing environmental regulations generally go beyond environmental effectiveness and compliance costs to include distributional effects and political feasibility. Emphasis is also sometimes put on an instrument's flexibility and the incentives it generates for research and innovation. There is, for example, evidence in the OECD context that environmentally-related taxes can induce innovation by firms seeking to minimise their tax burden (OECD, 2010). Still other considerations could include a jurisdiction's underlying legal institutions, as voting rules and implementation structures may influence the choice of the regulatory instrument (Wiener, 1999).

The problem at hand may also require more than one instrument, in which case potential interactions between instruments should be accounted for. This is the case where environmental externalities have multiple dimensions, so that not only the quantity of emissions but also their location and timing matter, or in situations where information is imperfect, so that additional instruments may be required for information gathering (OECD, 2007a). Most economic activities in the OECD are actually regulated using mixes of instruments. Sweden thus combines a permit system based on quantitative emission limits and a tax per $\mathrm{kg}$ emitted to regulate emissions of $\mathrm{NO}_{\mathrm{X}}$ from stationary combustion plants (Braathen, 2012). In the case of New South Wales in Australia, the government has adopted an integrated approach to the management and prevention of industrial emissions that relies on the total amount of pollution emitted each year by a licensed facility. This load-based licensing (LBL) approach uses both environmental performance standards and a fee structure to control pollutant releases into the air, the soil, and water bodies (NSW EPA, 2013).

In the case of policies seeking to limit GHG emissions, it can be especially difficult to isolate particular regulatory instruments impacting on these emissions. GHG emissions are prevalent across the entire economy and therefore affected by a wide range of policies and measures, many of which are not primarily aimed at controlling the release of GHGs into the

4. See the OECD/EEA database on instruments used for environmental policy and natural resources management, which is available at: www2.oecd.org/ecoinst/queries/. 
atmosphere, as in the case of policies seeking to increase energy security through investment in domestic, low-carbon energy sources or energy-efficient equipment. Macroeconomic changes, such as short-run fluctuations in economic activity, are also important determinants of GHG emissions as the 2008-09 financial and economic crisis shows (York, 2012).

\section{Box 1. Regulating industrial emissions: The case of the European Union}

The European Union sets the overarching framework regulating the emissions of pollutants from its member states' industrial facilities. Until recently, Directive 2008/1/EC concerning integrated pollution prevention and control (the "IPPC Directive") and a series of narrower sectoral directives established the conditions for granting environmental permits to about 52000 regulated installations. Those Directives have since been replaced by a single one, Directive 2010/75/EC (the "Industrial Emissions Directive"), to provide a more comprehensive framework regulating industrial emissions in the EU. Under this framework, environmental permits must "take into account the whole environmental performance of the plant, covering e.g. emissions to air, water and land, generation of waste, use of raw materials, energy efficiency, noise, prevention of accidents, and restoration of the site upon closure" (European Commission, 2013a). GHG emissions are, however, excluded from the scope of permits in cases where industrial facilities are already covered by the EU-ETS. This integrated approach to addressing industrial pollution - as opposed to separately controlling emissions into different environmental media - ensures that pollution is not shifted from one medium to another.

Under the rules set out in the Industrial Emissions Directive, environmental permits must include requirements reflecting the performance of the best-available techniques (BAT) as well as the corresponding emission limits for each pollutant concerned and the suitable emissions-monitoring methods. Emission limits should be set for each permit so that the regulated facility meets the emission levels prescribed in the associated BAT conclusions. To arrive at these BAT conclusions, the European Commission has put in place an information-exchange forum, which allows for member states and stakeholders to draw up industry-specific BAT reference documents (the so-called "BREF" documents). BAT conclusions form part of these documents, leading to the setting of industry-specific permit conditions that cover best-available techniques and the corresponding emission limits. As of August 2014, BAT conclusions exist for the following sectors: the manufacture of glass; the production of iron and steel, chlor-alkali, cement, lime, and magnesium oxide; and the tanning of hides and skins.

Starting in January 2014, the new Industrial Emissions Directive provides for a more harmonised and rigorous implementation of emissions limits associated with the cleanest available technologies (i.e. the BAT) across member states. Deviations from these standards are only permitted where local and technical characteristics would make their adoption disproportionately costly. As before, key parts of the necessary technical documents (the BAT conclusions) are to be adopted via implementing acts, and these conclusions shall serve as a reference in the drawing up of permit conditions.

Source: European Commission (2013a).

\section{Environmental regulations and market creation}

Regardless of the particular instrument mix eventually chosen by regulators, an effective regulation will most certainly aim to shift the behaviour of regulated entities, be they individuals or firms. For firms ${ }^{5}$ to internalise the impacts that their decisions have on the environment, environmental regulations thus need to alter input prices in such a way that producers economise on their use of the polluting input(s), with the latter understood here as an environmental "bad". 6 This change in input prices can either be explicit (using market-

5. This report mainly focusses on firms because they are generally by far the largest direct emitters of pollutants. Firms are also directly engaged in the conduct of international trade, either as exporters, importers or both.

6. This focus on input prices comes from the fact that economics generally treats pollution emitted as an input into the production process. A regulation-induced change in the way pollution is "priced" (e.g. taxed or charged) will therefore modify a firm's input mix other things being equal. In economic terms, this means that the new input prices must be such that firms choose a different point on their isoquant. 
based instruments) or implicit (in the case of command-and-control instruments), but will often require that firms modify their production techniques. The change in techniques will in turn necessitate the uptake of new processes and associated equipment for reducing the use of the regulated input(s) (e.g. air emissions of $\mathrm{SO}_{2}$ understood here as an input into the production process). In that sense, environmental regulations create a demand for a whole class of goods and services serving to prevent and abate pollution.

It is important to note that there would be little demand for most environmental goods and services (EGS) absent environmental regulations. As argued by Adlung (2009) in the case of environmental services:

In contrast to financial, telecommunications or transport services, there is no genuine demand for environmental services. Relevant markets are essentially created through government regulation. Who would purchase, for example, sewage or air-cleaning services out of sheer altruism?

The USITC (1996: 5-7) made a similar point earlier, noting that "environmental regulation and enforcement will continue to drive the markets [for air-pollution control equipment] in both the developed countries and in the developing countries." More recently, a case study of Chile's EGS industry found that many firms operating in the sector tended to cite the enforcement of environmental laws and regulations as the single most important market driver (USAID, 2011; Box 2). Similar examples abound illustrating that environmental regulations play a decisive role in creating demand for EGS. Provided they do not impose an excessive and disproportionate burden driving polluters out of business, stringent environmental regulations thus increase demand for EGS since a tightening of regulations effectively calls for bigger adjustments in a firm's production techniques. An increased market size for EGS has in turn important implications for innovation, the productivity of firms, and a country's position in international EGS trade.

Several OECD studies have already examined the link between the stringency of environmental regulations and innovation, whether in the context of one particular instrument or using more aggregate measures of regulatory stringency. One such study (OECD, 2010) focussed on the impacts that environmentally-related taxes have on research and innovation activities undertaken by polluting firms or by third-party innovators. In the particular case of the United Kingdom, it found that firms subject to the full rate of the Climate Change Levy patented significantly more than firms subject to a largely reduced rate, ${ }^{7}$ even after controlling for various firm characteristics (e.g. economic performance). Using firm-level interviews, the same study concluded that Switzerland's federal tax on volatile organic compounds (VOCs) ${ }^{8}$ had encouraged innovation in both small and larger firms subject to the tax, though only the latter had formalised $R \& D$ programmes in place.

Looking beyond environmentally-related taxes, another recent study (OECD, 2011a) found evidence supporting the view that the stringency of environmental regulations affects the rate and direction of innovation in relation to environmental technologies. Using the World Economic Forum's (WEF) index of businesses' perceptions of environmental regulations, the results suggest that perceived stringency has a significant and positive impact of its own on environmental patent activity.

7. Under the Climate Change Levy (CCL) system introduced in 2001, large energy-intensive firms entering into voluntary Climate Change Agreements can benefit from a reduced rate of CCL in return for meeting specified energy-savings targets.

8. VOCs are solvents used in activities such as paint-making (e.g. benzene, methylene chloride, and acetone). They contribute to the formation of smog and can adversely affect human health. 
In a similar vein, the OECD has recently started empirical work looking at the impacts that environmental policies have on productivity growth in the context of the Organisation's New Approaches to Economic Challenges (NAEC) initiative. Following the production of a literature review on the links between environmental policies and productivity (Koźluk and Zipperer, 2013), ${ }^{9}$ the project then turned to the collection of information on actual environmental regulations in OECD countries. Data were thus collected for several policies such as taxes on air pollutants and diesel fuel, renewable-energy certificates, feed-in tariffs for solar- and wind-based energy, and emission limit values for $\mathrm{SO}_{2}, \mathrm{NO}_{\mathrm{X}}$, and $\mathrm{PM}$, and subsequently combined into an index of environmental policy stringency (the EPS index). This EPS index was then used in econometric analysis, which concluded to the absence of lasting effects (positive or negative) of environmental regulatory stringency on multi-factor productivity growth at the macro, sector, and firm level over the period 1990-2010 ${ }^{10}$ (OECD, 2014a). While giving an important weight to the energy sector, the results suggest, nonetheless, that stringent environmental policies do not generally have detrimental effects on productivity.

Turning to international trade, the academic literature has generally tended to focus on the relationship between the stringency of environmental regulations and the competitiveness of pollution-intensive industries. Particular attention has notably been devoted to the issue of pollution leakage, ${ }^{11}$ whereby stringent environmental regulations in one jurisdiction lead to the relocation of pollution-intensive industries in another jurisdiction with laxer regulations, so that pollution is shifted from one place to the other (i.e. pollution "leaks" across borders). Examples would include Broner et al. (2012), which argues that environmental regulations may help explain why certain countries specialise in polluting industries, or Cole and Elliott (2003), who used a bilateral model of trade and found evidence consistent with the existence of a pollution-leakage effect. ${ }^{12}$ Because they are essentially concerned with the impacts that environmental regulations have on domestic, pollution-intensive industries, those studies focus by necessity on cases where the environmental regulatory process undermines countries' export performance.

Much less attention has, to date, been devoted to the impacts that the stringency of environmental regulations may have on EGS trade specifically, and on the trade opportunities that could arise from the environmental regulatory process more generally. Of the academic articles the OECD has had the opportunity to review, only Costantini and Mazzanti (2012) focus on the relationship between environmental policies and exports of environmental goods. Using a gravity model of trade, the authors' findings suggest that environmental and energy taxes in EU-15 countries have been associated with higher exports of environmental goods over the 1996-2007 period. Those results concern, however, a small number of exporters and of regulatory instruments (i.e. environmental and energy taxes), making it hard to generalise the findings.

\section{Market size and the direction of trade: a conceptual discussion}

To understand the impacts that the stringency of environmental regulations may have on international trade in EGS, one needs to start with the impacts that regulatory stringency has

9. Readers interested in the so-called "Porter hypothesis" and its empirical validity are encouraged to consult this literature review as it provides an up-to-date overview of relevant findings.

10. The sample covers the years 2000-09 only in the case of firm-level data.

11. The literature also often speaks of the "pollution-haven hypothesis".

12. A more comprehensive review of the literature on this topic can be found in Brunel and Levinson (2013) and in Condon and Ignaciuk (2013). 
on market size. Most models of international trade often treat the size of the home market as given (i.e. exogenous), usually equating it with a country's factor endowments or its population size. In the case of EGS, however, one would also hypothesise the size of the home market to be a function of the stringency of a country's environmental regulations. This is consistent with an early USITC study that identified environmental protection and economic growth as being the two fundamental drivers of market growth in the case of airpollution control equipment (USITC, 1996). In other words, the scale of a country's production or economic activity interacts with regulations to jointly determine the size of the home market for EGS.

Whether a larger home market for EGS increases exports more than imports - or the reverse - depends upon a variety of factors, including the degree and nature of competition prevailing in the EGS industry, not only domestically but also globally. There are indications that competition in the EGS market tends to involve a significant number of firms competing in dimensions other than just prices, such as quality, flexibility in production, and the ability to adapt products to client needs (OECD, 1996; USITC, 1996, 2013; Ecorys, 2009). ${ }^{13}$ This is particularly the case where companies provide integrated solutions to pollution prevention and abatement that involve the joint provision of a range of goods and services (e.g. the integrated design, installation and operation of a facility). In this context, products are differentiated in the sense that different firms produce different varieties of goods and services serving the same end-purpose since clients place a premium on variety and customisation. To better understand the implications this has for international trade, the next paragraph introduces the concept of monopolistic competition.

The concept of monopolistic competition is the cornerstone of so-called "new trade theory". ${ }^{14}$ It describes a setting wherein firms are able to differentiate their products so that each producer enjoys some degree of market power in pricing (i.e. firms are price makers rather than price takers). Free entry drives economic profits ${ }^{15}$ to zero, however. Under such conditions, ${ }^{16}$ trade flows are generally intra-industry rather than inter-industry, in the sense that countries end up importing and exporting products classified under the same HS headings but having properties that make them different in the eyes of the consumers, such as with different varieties of cars or wine. This contrasts with theories of trade centred on productivity differences or factor endowments, and which usually result in countries importing and exporting very different goods (e.g. goods classified under different HS headings) due to their high degree of product specialisation.

Whether goods are differentiated or not has in turn important implications for the effects of market size on the direction of trade. With firms tending to locate their operations in larger markets to benefit from economies of scale, the number of product varieties a country

13. The data reported by Ecorys (2009) and the USITC (2013) both indicate that SMEs $(<500$ employees) make up the majority of companies operating in the EGS industry but that exporters tend to be large firms providing a wide range of goods and services.

14. An introduction to new trade theory and models of international trade using monopolistic competition can be found in chapter 5 of Feenstra (2004).

15. Not to be confused with "accounting profit", the more common meaning of "profit". Economic profit is generated when revenues earned exceed the opportunity cost of inputs. Consequently, a firm can register a large accounting profit with little or no economic profit.

16. New-trade-theory models of trade also typically assume the existence of increasing returns to scale in production (i.e. economies of scale), which cause a firm's average costs to decrease with output. USITC (2013) suggests the presence of significant economies of scale in sectors such as waste management. 
produces increases more rapidly than the size of the home market. The combination of monopolistic competition and transportation costs may thus result in larger countries becoming net exporters of the differentiated goods (Krugman, 1980). This theoretical result - known as the "home market effect" - thus suggests that those countries having larger home markets for EGS (e.g. more stringent environmental regulations) may end up exporting EGS on a net basis, provided EGS trade is of the intra-industry kind (i.e. provided that environmental goods and services are sufficiently differentiated).

There is empirical evidence suggesting that the degree of product differentiation does in fact determine the way market size affects the direction of trade. Feenstra et al. (2001) used bilateral goods trade data to show that exports tend to increase more than proportionately with the exporting country's GDP (a proxy for the size of the home market) in the case of differentiated products, but that this result is reversed in the case of homogeneous goods, ${ }^{17}$ with exports increasing less than proportionately with the exporting country's GDP. In other words, the more differentiated products are, the larger the impact of market size on exports. This is because "the disproportionately high entry of firms [...] more than offsets the higher demand in the larger country, so that net exports are positive" where goods are differentiated (Feenstra et al., 2001: 434). Hanson and Xiang (2004) similarly found strong evidence of a home-market effect in the case of OECD countries' exports of differentiated products with relatively high transportation costs. It follows that understanding the impacts of domestic demand on trade requires a prior understanding of the type of competition prevailing in the market of interest.

While comparable evidence does not yet exist in the particular case of EGS, trade patterns for a selection of environmental goods seem to display some of the characteristics of intraindustry trade in differentiated products. Figure 1 shows average values of the Grubel-Lloyd index of intra-industry trade for OECD countries, where a value of one indicates that imports in the products considered are perfectly balanced by exports - that is to say, intra-industry trade is taking place. Conversely, a value of zero indicates perfectly unbalanced trade in the products considered, i.e. that all trade involves products of different industries and that there is no two-way trade of products from the same industries. ${ }^{18}$ Although average values for this index need to be interpreted with caution since they may conceal considerable variation between and within different six-digit HS groups (for example, HS 8541.40, which includes both light-emitting diodes and solar photovoltaic cells and modules), the data suggest that trade in environmental goods is often of the intra-industry kind in many OECD countries. That is to say, many OECD countries are both importers and exporters of environmental goods classified under the same six-digit HS commodity code. This indicates some degree of product differentiation among environmental goods, thereby making the home-market effect a real possibility. ${ }^{19}$

17. Feenstra et al. (2001) defined homogeneous goods as those goods that are "traded in an organized exchange".

18. The formula used here to calculate the Grubel-Lloyd index of intra-industry trade is $I I T_{i j k}=1-$ $\left(\left|X_{i j k}-M_{i j k}\right| /\left(X_{i j k}+M_{i j k}\right)\right)$, where $X_{i j k}$ denotes exports of product $k$ from country $i$ to country $j$, and $M_{i j k}$ denotes imports of product $k$ by country $i$ from country $j$.

19. Using narrower lists of environmental goods such as those described in the next section of the report (i.e. the Core CLEG and the Core CLEG+) does not alter results for the Grubel-Lloyd index; it even reinforces them for some countries. The estimates reported in Figure 1 place CLEG products in the upper range of values traditionally found for the Grubel-Lloyd index when calculated at the six-digit HS level. Occurrence of a home-market effect would, nevertheless, be clearly contingent upon environmental regulations in the importing countries being designed in a 
Figure 1. Intra-industry trade in environmental goods (2007-11)

( 1 = full intra-industry trade; 0 = full inter-industry trade)

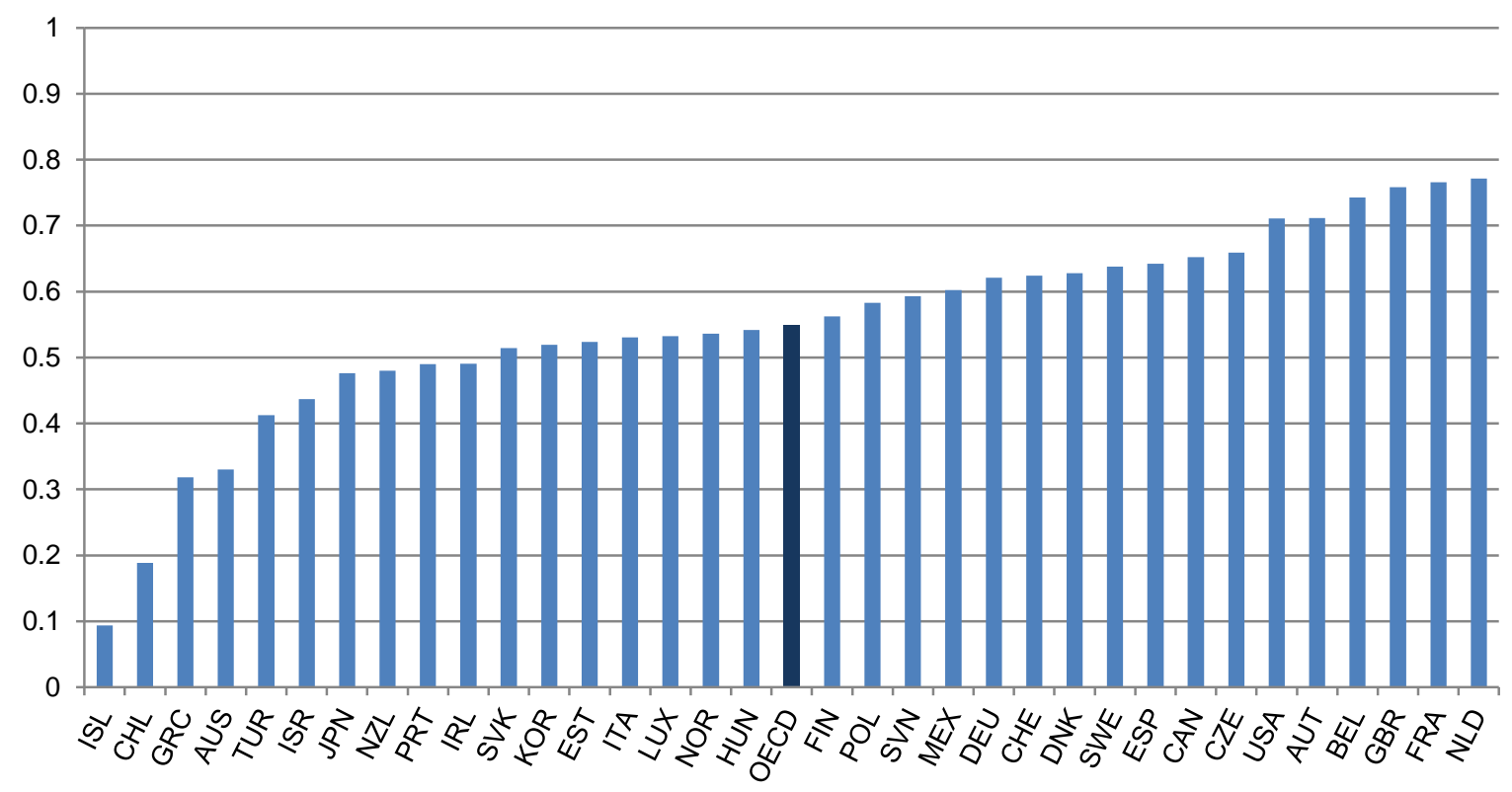

Note: The Grubel-Lloyd index is here calculated using the rest of the world as the partner country; the values reported above are trade-weighted averages of the index across products and years. Environmental goods are here taken to comprise all 248 six-digit HS codes included in the CLEG (see Annex 1).

Source: OECD based on data obtained from the UN Comtrade database.

Going one step further, additional insights can be gained by adopting a more dynamic approach and introducing a time dimension into the market-creation and trade nexus. This is particularly the case where learning-by-doing processes result in firms' costs diminishing over time. Under such conditions, domestic EGS-producing firms may, through experience, accumulate know-how and expertise that will later translate into higher productivity and exports. ${ }^{20}$ There is evidence that such processes have occurred in the particular case of the wind-turbine industry. Looking at the evolution of US wind-turbine projects between 2001 and 2009, Anderson (2012) found that firm-level learning-by-doing processes had played a role in reducing costs, albeit a modest one. In the case of Western Europe in the 1990s, Ek and Söderholm (2010) provide clearer evidence in favour of global learning-by-doing effects, with results pointing to wind turbines experiencing a $17 \%$ cost reduction for every doubling of output. A case study of the Dutch wind-turbine industry in the 1970s and 1980s paints a more contrasted picture, suggesting that a small market size and low feed-in tariffs did not allow significant learning processes to take place at that time in the Netherlands (Kamp, 2007). In this context, competition from neighbouring Denmark in export markets such as California resulted in the progressive decline of the Dutch wind industry. This further

manner that does not discriminate against foreign products and technologies, thereby highlighting the need for well-designed regulations.

20. Formally, learning-by-doing processes can be modelled using a measure of cumulative output or production, as in Grossman and Helpman (1995), or cumulative gross investment as in Arrow (1962). 
underlines the importance of market size for trade. It also serves to highlight the role that firstmover advantages sometimes play in shaping trade patterns. ${ }^{21}$

The role of experience and learning in lowering costs may, however, be dampened where spillovers induce the transfer of know-how and technology across firms. Such spillovers can either be local, national, or international in scale, with very different effects in each case. Local spillovers occur where experience and learning in one firm benefits other firms through positive externalities that are circumscribed to one particular area or cluster of firms (e.g. the Silicon Valley). Typical examples of externalities would include the creation of a pool of skilled labour force or the transfer of knowledge through specialised networks of suppliers. As Grossman and Helpman (1995: 1300-1301) put it, "if a country initially produces a large quantity of any one good in a cluster, then the learning spillovers from this activity will tend to confer a dynamic comparative advantage in other industries in the same cluster." At the other extreme, the existence of complete international spillovers would result in the experience of domestic producers fully benefitting foreign producers, meaning that "learning neither strengthens nor weakens the forces of intrinsic comparative advantage" (ibid.: 1294).

Whether, and at what scale, spillovers exist clearly has some importance for the relationship between market size and international trade (Box 2). Answering this question empirically is, however, difficult and would likely go beyond the scope of this report. The analysis that follows therefore looks directly at trade flows since they constitute one observable outcome of the learning process. To the extent that learning-by-doing processes do translate into higher exports, they should be reflected in trade data.

Box 2. Market size, spillovers, and international trade: The example of Chile's EGS industry

Chile combines a relatively open trade and investment regime and a commitment to protecting the environment as embodied in the General Environmental Framework Law of 1994 (Law No. 19.300), which - among other things - established the National Environment Commission (CONAMA) and introduced the notion of responsibility for environmental damage. The adoption in January 2010 of Law No. 20.417 further reinforced this framework through the creation of the Ministry of Environment (Ministerio del Medio Ambiente), the Council of Ministers for Sustainability (Consejo de Ministros para la Sustentabilidad), the Service for Environmental Assessment (Servicio de Evaluación Ambiental), and the Superintendency for the Environment (SuperIntendencia del Medio Ambiente), with each institution having its own set of functions and responsibilities. Together with the continued strengthening of environmental regulations, these factors contributed to making Chile's EGS market a relatively well-developed one in Latin America. This is most evident in the context of water and wastewater projects, where the country's large mining industry generates a sustained demand for water-related equipment and services such as environmental consulting and engineering.

Those conditions made it attractive for foreign EGS firms to invest and establish a local presence, including through partnerships with Chilean firms. This is, for example, the case of the Australian engineering company WorleyParsons, which in 2006 partnered with Santiago-based ARA (Arze, Recine y Asociados, Ingenieros Consultores) to establish an operating base for conducting business throughout the region (e.g. Argentina, Ecuador, Paraguay, and Peru). In wastewater treatment, the Barcelona-based Agbar group (Sociedad General de Aguas de Barcelona) now serves around six million customers across the country, including through the La Farfana advanced-treatment plant it operates near Santiago. This plant - the largest wastewater treatment plant in Latin America in terms of capacity ( $8.8 \mathrm{~m} 3$ per second) - was itself built by the Paris-based firm Degrémont Industry, a subsidiary of Suez Environnement.

Continued

21. See Brandt and Svendsen (2006) for a discussion of first-mover advantages in the context of Denmark's wind-turbine industry. 
The example of Chile provides useful insights into the relationship between the stringency of environmental regulations and international trade in EGS. By opening itself to foreign competition while tightening its environmental regulations, the country initially experienced an increase in its imports of environmental equipment and higher inflows of foreign investment, from Europe and North America mostly. Environmental gains quickly materialised as the imported equipment and associated services provided access to advanced technologies in domains like water treatment. The Superintendencia de Servicios Sanitarios (SISS, the national regulatory agency for water supply and sanitation) thus reports that in 2012 virtually all of the country's urban population had access to the potable-water network and was connected to wastewater-collection systems, a large share of which use tertiary treatment (see Box 3 ).

Although Chile depends a lot on imported environmental equipment, its position as one of Latin America's most dynamic EGS markets has also made the country a regional hub as it now increasingly exports environmentally related goods and services to neighbouring Argentina, Bolivia, Colombia, and Peru. In particular, the establishment of foreign EGS firms in Chile has led to local job creation and transfers of knowledge and technology, which in turn have contributed to making the country a regional leader in the provision of environmental consulting and engineering services. It is thus noteworthy that leading firms providing such services in Chile now comprise "an equal mix of independent Chilean enterprises and foreign-owned firms manned principally by Chilean nationals" (USAID, 2011:21).

This example illustrates the role that spillovers (e.g. transfers of know-how and technology) can play in translating market size into a comparative advantage. It also serves as a reflection on the homemarket effect in a context wherein EGS firms operating in Chile often cite the enforcement of environmental laws and regulations as the main market driver. ${ }^{1}$

1. A survey of EGS firms operating in Chile found that $55 \%$ of respondents cited the "enforcement of federal environmental laws and regulations" as the most important market driver, trumping other factors such as the "international standards of multinational corporations", "domestic public pressure and environmental NGO activity", and "regional agreements through APEC or free trade agreements" (USAID, 2011).

Sources: USAID (2011), OECD (2005), and SISS (2012).

\section{Trade in environmental goods and services}

This second section clarifies the contours of the analysis as it sets to describe the universe of products that are here considered environmental. The first two parts briefly discuss the various lists of environmental goods that have been negotiated or crafted in recent years, before turning to the lists compiled by the OECD for the purpose of the analysis undertaken in this report. The third part then focusses on the challenges involved in measuring international trade in environmental services, before suggesting a way forward for future work on the topic. Finally, the remainder of the section puts environmental goods trade into perspective by looking at recent trends in world trade and trade barriers.

\section{The scope of environmental goods and the CLEG}

There is no internationally agreed list of environmental goods and services, and the universe of products that fall under this umbrella is potentially very large. This absence of agreement is due in no small part to the many practical difficulties one encounters when trying to devise a comprehensive list. Steenblik (2005) lists many such difficulties in the case of environmental goods, including: the lack of specificity of existing classifications, such as the Harmonized System (HS) at the six-digit level; the existence of products with multiple uses, some of which are not environmental; and the problem of goods defined in terms of their relative environmental performance in use, something that may require chasing a moving target as technology improves over time. The inclusion of both intermediate and finished products in lists of environmental goods further complicates matters since their coverage in the HS classification often differs by industry, with some finished products like wind- 
generating sets having their own distinct code (HS 8502.31 - Other electric generating sets: wind-powered) and others not (like certain waste- or water-treatment plants for instance).

Despite these difficulties, there have been several attempts to draw up lists of environmental goods that could be used in trade negotiations. ${ }^{22}$ An early such effort in the OECD context was the list contained in Annex 2 of OECD/Eurostat (1999), which comprises as many as 132 unique six-digit HS codes covering environmental media or themes such as air pollution control or solid waste treatment. Another more recent example is the OECD's indicative list of climate-change-relevant goods for a plurilateral environmental goods and services (PEGS) agreement, which covers more than 150 products but focuses mainly on goods of relevance to combatting climate change. ${ }^{23}$

Lists themselves are often the subject of trade negotiations, as evidenced by the many submissions countries have made to the WTO Committee on Trade and Environment meeting in Special Session (CTE-SS) pursuant to Paragraph 31 (iii) of the Doha Declaration. Of the more than 400 individual products listed in these submissions, the subset of 154 products that was circulated by members of the "Friends group" ${ }^{24}$ is one of the most frequently cited (see WTO, 2009). On the plurilateral side, the 2011 Honolulu summit of APEC countries resulted in an agreement "to reduce by the end of 2015 [APEC countries'] applied tariff rates to 5\% or less" on a set of environmental goods, for which a list of 54 products was then released at the 2012 Vladivostok summit (APEC, 2012). More recently, a coalition of 14 economies $^{25}$ committed in January 2014 in Davos to start negotiations with a view to concluding a plurilateral agreement that would build on the APEC initiative. Those negotiations were then formally launched in Geneva in July 2014.

Table 1. Environmental themes and media in the CLEG

\begin{tabular}{clc}
\hline Code & \multicolumn{1}{c}{ Environmental theme or medium } & $\begin{array}{c}\text { Share of HS } \\
\text { lines }\end{array}$ \\
\hline APC & Air pollution control & $5 \%$ \\
CRE & Cleaner or more resource efficient technologies and products & $19 \%$ \\
EPP & $\begin{array}{l}\text { Environmentally preferable products based on end use or disposal } \\
\text { characteristics }\end{array}$ & $2 \%$ \\
HEM & Heat and energy management & $10 \%$ \\
MON & Environmental monitoring, analysis and assessment equipment & $15 \%$ \\
NRP & Natural resources protection & $<2 \%$ \\
NVA & Noise and vibration abatement & $<2 \%$ \\
REP & Renewable energy plant & $22 \%$ \\
\hline SWM & Management of solid and hazardous waste and recycling systems & $10 \%$ \\
\hline SWR & Clean up or remediation of soil and water & $<2 \%$ \\
WAT & Waste water management and potable water treatment & $13 \%$ \\
\hline
\end{tabular}

Note: A detailed list of the 248 products included in the CLEG is available in Annex 1.

22. What follows should not be considered an exhaustive catalogue of attempts to come up with a list of environmental goods.

23. This PEGS list was initially prepared by the OECD for the 2010 Toronto summit of the G20.

24. The Friends group is composed of Canada, the European Union, Japan, Korea, New Zealand, Norway, Switzerland, Chinese Taipei, and the United States.

25. These 14 economies are: Australia; Canada; China; Costa Rica; the European Union; Hong Kong, China; Japan; Korea; New Zealand; Norway; Singapore; Switzerland; Chinese Taipei; and the United States. 
In the absence of an international consensus on the goods that should be considered environmental, and because negotiated lists may exclude some goods usually deemed environmental but not retained in the context of trade negotiations, this report combines three existing lists to arrive at a customised set of 248 products (see Annex 1). This set of products — which the OECD labelled the "CLEG" (Combined List of Environmental Goods) — uses the HS 2007 classification at the six-digit level ${ }^{26}$ and further divides goods according to their environmental theme or medium (Table 1).

\section{Beyond the CLEG: The Core CLEG and the Core CLEG+}

While broad-based lists such as the CLEG are relatively comprehensive in their coverage of products having environmental applications, they also face a higher risk of including products used for non-environmental purposes. This is partly because most HS do not uniquely and precisely identify all categories of traded goods, so that a given six-digit HS line may cover both products having environmental applications and others that do not. ${ }^{27}$ Many existing lists of environmental goods thus specify "ex-outs" or "ex" heading products that go beyond the six-digit HS descriptions (Steenblik, 2005). This level of specificity is, however, not available in the trade statistics commonly found for most countries as internationally comparable reporting generally does not extend beyond the six-digit HS level. Empirical analyses of trade in environmental goods thus face a trade-off between comprehensiveness and accuracy in defining the scope of their enquiry.

Recognising the need to balance comprehensiveness and accuracy, the empirical analysis in this report performs several robustness and sensitivity checks using alternative, narrower lists of environmental goods that seek to complement the main results obtained using the CLEG (see Annex 1). Those alternative lists of environmental goods, namely the Core CLEG (11 products) and the Core CLEG+ (40 products), were selected with expert advice from Environmental Business International Inc. (EBI). ${ }^{28}$ For each of the CLEG's 248 products, the OECD reassessed the likely environmental content of the corresponding HS line against proprietary data from EBI on the size of the global market for various environmental pieces of equipment. This exercise made it possible to ascertain which HS codes on the CLEG have a clear environmental content in terms of the value of the trade flows they measure. Results suggest that $11 \mathrm{HS}$ codes cover trade flows for which environmental products make up more than two thirds of all measured trade (the Core CLEG of 11 products). This number increases to $40 \mathrm{HS}$ codes where environmental products account for more than a third of all measured trade (the Core CLEG+ of 40 products).

Importantly, the inclusion of two narrower lists of environmental goods in the report is for analytical purposes only. It does not follow from this analysis that trade negotiations ought to consider narrower lists of environmental goods, especially as trade liberalisation obeys a

26. The choice of the 2007 version of the HS classification was dictated by data-availability concerns and the difficulties that are inherent to converting HS codes from one version to another.

27. This problem is compounded in the case of products characterised by multiple end-uses, as was already indicated in the previous sub-section.

28. Environmental Business International Inc. (EBI) was founded in 1988 to provide market intelligence on the EGS industry to companies, investors, and policy-makers alike. This is done mainly through the company's two flagship publications, the Climate Change Business Journal and the Environmental Business Journal, and the production of extensive data on the size of the US and global EGS markets. More information can be found on the company's website: http://ebionline.org/. 
different logic. The CLEG products that have been excluded from either the Core CLEG or the Core CLEG+ remain entirely appropriate from an environmental perspective since the corresponding HS codes do cover goods having important environmental applications, such as certain pieces of equipment used in separating, crushing or shredding waste and recyclable materials. The same could be said of several water pumps and valves that have applications other than wastewater treatment.

\section{Measuring trade in environmental services}

The practical difficulties mentioned above for goods are similarly making it difficult to draw comprehensive lists of environmental services, while regulatory reforms and technological change are also acting to increase the field of relevant activities (OECD, 2001a). From a narrow definition comprising pollution control, waste disposal, and water treatment, the scope of services related to the environment has now grown to cover a much broader range of products, most of which fall outside the GATS W/120 classification of "Environmental Services" (corresponding to code 94 in CPC Prov.). A recent OECD Working Paper showed that trade in a wide range of services is helping to mitigate greenhouse-gas (GHG) emissions by encouraging the adoption of more energy-efficient and low-carbon technologies (Steenblik and Geloso Grosso, 2011).

Difficulties in defining and measuring environmental services also arise in relation to the way services trade is conducted. Article 1 of the WTO's General Agreement on Trade in Services (GATS) defines the four modes through which services are generally supplied internationally, with mode 1 involving the service itself crossing the border (e.g. the remote monitoring of water networks), mode 2 the movement abroad of services consumers (e.g. ecotourism), mode 3 the commercial presence abroad of suppliers (e.g. the establishment of local branches abroad), and mode 4 the temporary presence abroad of natural persons supplying a service. In the case of environmental services, the USITC (2013) notes that international trade in wastewater-treatment services, water-utilities services, and solid and hazardous waste services occurs predominantly through mode 3 , i.e. the establishment by domestic firms of a commercial presence abroad. Coupled with data showing that water-treatment services and waste services together accounted for more than $80 \%$ of global environmental services revenue in 2010 (ibid.), this suggests a large role for mode 3. It should be stressed, however, that supplying services through one mode does not necessarily prevent firms from simultaneously using other modes too. The establishment by a services firm of a commercial presence abroad could thus be coupled with the temporary movement of natural persons, such as where specialised staff members from the headquarters are sent abroad on short-term assignments to share expertise with local subsidiaries (an example of mode 4 supply involving intra-corporate transferees).

The quality and availability of data on trade in environmental services varies considerably from mode to mode, though it remains poor overall. Some data for Mode 1 and 2 can be accessed through balance-of-payments statistics, ${ }^{29}$ which are available in a format that follows the Extended Balance of Payments Services (EBOPS) classification. But while the earlier 2002 version of EBOPS does have a designated category for "Waste treatment and depollution" services, the corresponding data are in practice only available for a few countries. Even where such data are available, the scope of this category is far too narrow since environmental services extend far beyond waste treatment and depollution, as argued above. The gradual adoption by countries of the 2010 version of EBOPS complicates the

29. Balance-of-payments statistics may also at times capture some services trade conducted through Mode 3 and 4 in the case of particular sectors such as construction services (OECD, 2008). 
situation further as waste treatment and depollution services now tend to be combined with agricultural and mining services for data-reporting purposes. ${ }^{30}$

Data for Mode 3 are equally hard to collect. The possible sources described in OECD (2008), which include data on foreign affiliate trade in services (FATS) and stocks of foreign direct investment (FDI), are generally not available at a level of detail that singles out environmental services. Firm-level databases and surveys constitute another potential data source that has yet to be drawn upon in the context of measuring trade in services relevant to the environment. However, readily available options, such as the OECD-ORBIS database, ${ }^{31}$ are not always satisfactory in their coverage of multi-national firms known to provide essential services such as environmental consulting and engineering.

In view of these issues of scope, coverage, and data, environmental services will be explored in a subsequent project. Extending the analysis to environmental services would likely require that data be collected by the OECD or others on a firm-level basis, focussing initially on the revenues generated in different countries by a set of representative multinational service suppliers. Services such as environmental consulting and engineering offer a promising avenue for conducting this exercise given that they are more trade-exposed than traditional municipal-based services like solid-waste management and water treatment. They also span a large range of environmental projects and themes, including air-pollution control, water management, natural-resources protection, and resource development, which in turn involve activities as diverse as permitting and licensing, design, construction, and remediation. The relatively high degree of concentration observed among firms providing environmental consulting and engineering services means that data collection could initially concentrate on the top 120 companies, which together account for roughly $70 \%$ of the global market for environmental consulting and engineering services and $90 \%$ of global trade in those same services. ${ }^{32}$

\section{Recent trends in trade in CLEG products}

World trade in environmental goods has grown rapidly in recent years, even when accounting for the abrupt decline in global trade and GDP that resulted from the financial and economic crisis of 2008-09 and the protracted recovery that ensued. With an increase in value exceeding 40\% between 2007 and 2011, world imports of environmental products (defined here as CLEG products) have, in aggregate, grown appreciably faster than total merchandise imports over the same period (Figure 2). Focussing on a narrower list of environmental goods does not change this observation, with the 11 Core CLEG products also recording a faster increase than total merchandise. For 2011, imports of CLEG products consisted mostly of products related to: renewable-energy plants (37\%); wastewater management and potable water treatment (19\%); environmental monitoring, analysis and assessment equipment (10\%); and solid- and hazardous-waste management and recycling systems (9\%) (Table 2). This predominance of products related to renewable-energy plants can largely be explained by the

30. See United Nations et al. (2011) for a presentation of the 2010 version of EBOPS.

31. This refers to ORBIS data that were manipulated by the OECD before October 2012. The OECD-ORBIS database that was thus derived contains structural and financial information for millions of firms worldwide. Each observation in the database "corresponds to one account published by a firm, for a given time period" (Ragoussis and Gonnard, forthcoming), which makes it an important source of micro-level data.

32. These estimates are based on unpublished data from EBI's annual model of the environmental consulting and engineering industry, which itself uses data derived from firm surveys and statistical sampling. 
impressive growth in global imports of solar photovoltaic panels, which alone accounted for about $18 \%$ of the total increase in world imports of CLEG products between 2007 and $2011 .^{33}$

Figure 2. World imports of environmental goods and merchandise goods

$$
(2007=100)
$$

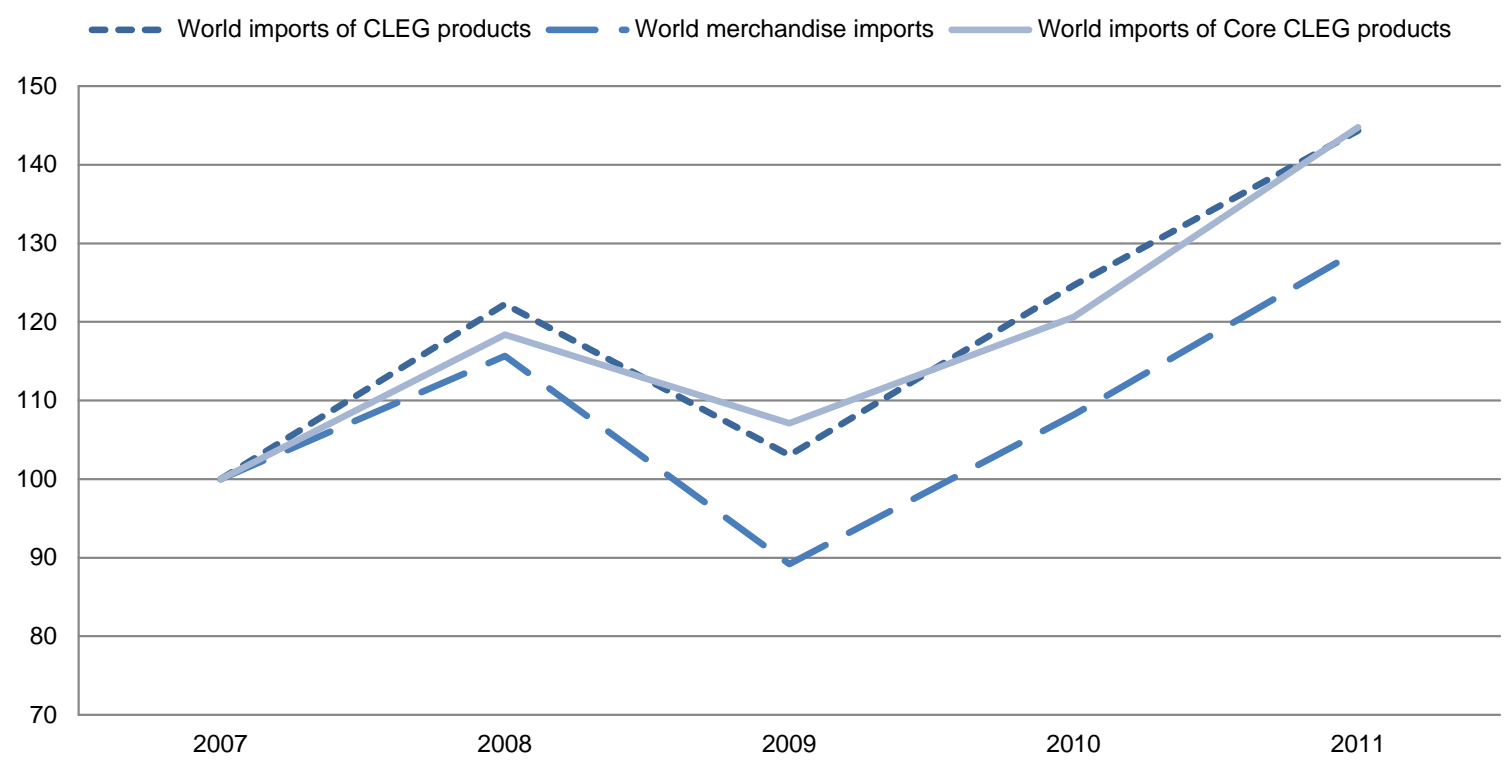

Note: Environmental goods are here taken to comprise all six-digit HS codes included in the CLEG (see Annex 1). Initial data are in current USD.

Source: OECD based on data obtained from the UN Comtrade database and WTO (2013).

As of 2011, OECD countries accounted for as much as $64 \%$ of world imports in CLEG products. This represents a significant decrease from $71 \%$ in 2007 and reflects the increasing participation of BRIICS countries (20\% in 2011) and other developing and emerging economies (16\% in 2011) in world EGS trade. Underlying this trend is China, which became in 2011 the world's single largest importer of CLEG products (13\%), followed by the United States (12\%), Germany (8\%), France (4\%), the United Kingdom (3\%), and Japan (3\%). Looking at world exports rather than world imports changes this picture a bit as OECD countries accounted for $72 \%$ of world CLEG exports in 2011, thereby making the OECD as a whole a net exporter of environmental products. In terms of individual countries, China (17\%) led the ranking again, followed by Germany (15\%), the United States (10\%), Japan (8\%), and Korea (5\%). While China's share of world trade in CLEG products is certainly impressive, it should be noted that this estimate does not significantly differ from that for China's share of world manufactures trade (16.8\% according to WTO, 2013).

33. HS 8541.40 (which includes solar photovoltaic cells and light-emitting diode lamps) and HS 8504.40 (which includes inverters used for solar PV arrays) record the two largest increases among all 248 CLEG products over the 2007-11 period. 
Table 2. World imports of environmental goods by environmental medium or theme

\begin{tabular}{lc}
\hline \multicolumn{1}{c}{ Environmental medium or theme } & $\begin{array}{c}\text { Share in world imports of } \\
\text { environmental goods (2011) }\end{array}$ \\
\hline Air pollution control (APC) & $7 \%$ \\
\hline Cleaner or more resource efficient technologies and products (CRE) & $6 \%$ \\
\hline $\begin{array}{l}\text { Environmentally preferable products based on end use or disposal } \\
\text { characteristics (EPP) }\end{array}$ & $<1 \%$ \\
\hline Heat and energy management (HEM) & $6 \%$ \\
\hline Environmental monitoring, analysis and assessment equipment (MON) & $10 \%$ \\
\hline Natural resources protection (NRP) & $<1 \%$ \\
\hline Noise and vibration abatement (NVA) & $6 \%$ \\
\hline Renewable energy plant (REP) & $37 \%$ \\
\hline Clean up or remediation of soil and water (SWR) & $1 \%$ \\
\hline Waste water management and potable water treatment (WAT) & $19 \%$ \\
\hline $\begin{array}{l}\text { Management of solid and hazardous waste and recycling systems } \\
\text { (SWM) }\end{array}$ & $9 \%$ \\
\hline
\end{tabular}

Note: Environmental goods are here taken to comprise all six-digit HS codes included in the CLEG (see Annex 1). Source: OECD based on data obtained from the UN Comtrade database.

Applied import tariffs on CLEG products are generally very low across OECD countries and a bit higher for BRIICS countries. Annex 2 provides data broken down by country and environmental medium on the (trade-weighted) average tariffs effectively applied on CLEG HS lines. As can be seen, tariff rates range from $0 \%$ to $12.8 \%$ and are slightly higher on average for products related to renewable-energy plants and wastewater management. However, although import tariffs may not be major impediments to CLEG trade, there is evidence that the measures introduced by some governments to support the deployment of renewable-energy equipment may effectively favour domestic producers over foreign ones (see, e.g. Bahar et al., 2013). Recent years have seen a proliferation of local-content requirements attached to the provision of support for renewable-energy sources across both BRIICS and OECD countries, the result of which has been the de facto introduction of new trade barriers for renewable-energy equipment. Moreover, there are indications that such practices go beyond renewable-energy equipment to affect markets for electric and hybrid cars and energy-efficient goods. ${ }^{34}$

The remainder of this report is concerned with the impacts that environmental regulations have had on the trends described above for trade in CLEG products. Gaining a better understanding of how environmental regulations affect trade in environmental goods is indeed central to understanding the impacts that barriers and their removal can have on trade in those goods. The regulation-led nature of the EGS industry means that trade-liberalisation efforts in this domain may not always have the effects one would normally expect in a more

34. This forms the subject of two forthcoming studies by the OECD, one of which concerns energyefficient goods and the other electric vehicles and batteries. 
conventional market. For that reason, the next section first discusses existing approaches to measuring the stringency of environmental regulations before conducting an empirical assessment of its relationship to exports of CLEG products.

Explaining patterns of trade in environmental goods: What role for environmental regulations?

\section{Measuring regulatory stringency}

Assessing the extent to which the stringency of environmental regulations affects trade in environmental goods first requires that some indicator of the former be available. Measuring regulatory stringency is, however, both conceptually and empirically difficult. Brunel and Levinson (2013) describe some of the challenges facing researchers and analysts attempting to do so, including the "multidimensionality" of environmental regulations (e.g. the fact that regulations vary by medium, pollutant and sector, and in the way they are enforced) and the "simultaneity" problem, whereby regulatory stringency is both affecting and affected by emissions of pollutants. This is, for example, the case where countries with degraded air quality react by imposing more stringent regulations. Conversely, countries or regions with large pollution-intensive industries may be subject to lobbying and decide to adopt lax environmental regulations or not to enforce them as strictly.

Recognising those difficulties, and in line with other OECD work (OECD, 2014a), one can identify at least four different methods for measuring the stringency of environmental regulations, each corresponding to a particular point along the policy-transmission channel (Figure 3). Because those methods are not exclusive vis-à-vis one another, and because each has its own advantages and limitations, it may be preferable not to restrict the analysis to one method in particular, and instead attempt to determine whether the results they give rise to all point in the same direction. What follows discusses each method in the context of empirically analysing the relationship between regulatory stringency and trade in environmental goods.

A first such method relies on the direct observation of environmental regulations (bubble 1 in Figure 3). It is, in that sense, the most policy-relevant method, though not necessarily the most tailored to quantitative analysis. Putting aside the challenges of aggregating different regulatory instruments into one composite index (a direct consequence of the multidimensionality problem mentioned by Brunel and Levinson, 2013), ${ }^{35}$ there remains the problem of coming up with a set of indicators that vary significantly across countries and years. The extent to which this latter problem is severe will depend on the particular set of regulations considered. Market-based regulatory instruments such as $\mathrm{CO}_{2}$ and fuel taxes or tradable emissions permits impose an explicit price per unit of pollution emitted, and can offer significant geographical and time variation. On the contrary, prescriptive or command-and-control instruments (e.g. maximum allowable concentration limits) will tend to vary less, reflecting among other things the length and complexity of countries' legislative processes. The international guidelines (e.g. the WHO guidelines for drinking-water quality) or similar binding concentration limits (e.g. European directives such as 2000/76/EC on the incineration of waste) that countries adopt in relation to air and water pollution further reinforce that problem (see Annex 3).

35. OECD (2014a) offers one possible way for aggregating information on different environmental regulations into one composite indicator of environmental policy stringency (the EPS index). This particular approach builds on earlier OECD work undertaken in the context of the Product Market Regulation (PMR) index. 
Figure 3. Measuring the stringency of environmental policies at different points along the policy-transmission channel

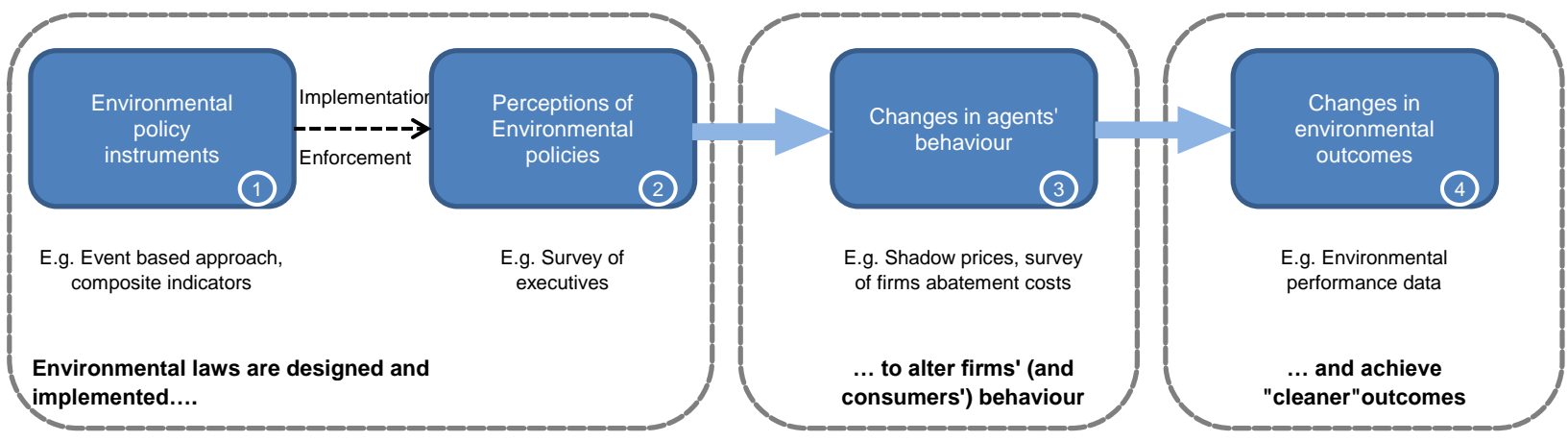

Source: OECD (2014a).

Importantly, a strict focus on actual regulations does not allow controlling for variations in implementation, enforcement, and local conditions, which are often crucial in determining how stringent a country's environmental regulations effectively are. This problem is most severe in those developing and emerging economies that lack the capacity to monitor and enforce regulations adequately. Duflo et al. (2013) provide evidence for India suggesting that the monitoring by third-party auditors of firms' compliance with environmental regulations resulted in "auditors systematically reporting plant emissions just below the standard, although true emissions were typically higher."

A second method uses the perceptions firms or households have of environmental policies to measure regulatory stringency (bubble 2 in Figure 3). This is most often done through opinion surveys that directly ask respondents how stringent they think environmental regulations are in certain countries or regions. Respondents are generally either business executives, as in the World Economic Forum's (WEF) Executive Opinion Survey, or households. The index that was developed by the WEF based on their survey of business executives is readily available for many countries but does not provide sector-level information, nor does it offer much variation across the years. As such, it only yields very general insights that may not always be representative of a country's actual regulations (a problem of identification, as mentioned in OECD, 2014a). In the case of households, the OECD has conducted several surveys in relation to the greening of household behaviour, with some questions relating to respondents' satisfaction with particular aspects of their local environment (e.g. local air and water quality and access to "green spaces") (OECD, 2013b). However, the surveys' focus on local outcomes makes it hard to draw clear conclusions about a country's environmental regulations. Given their subjectivity and their sometimes loose correlation with actual regulations, measures of stringency based on opinion surveys should preferably only be used if they can be complemented by other, more objective indicators.

The observation of changes in agents' behaviour provides a third avenue for measuring environmental regulatory stringency (bubble 3 in Figure 3). Here, the focus is on the reaction firms and households have to changes in their policy environment. This reaction can be gauged in several ways, including through surveys of pollution abatement costs and expenditures or through the estimation of "shadow input prices" using industry- or firm-level data (as in Van Soest et al., 2006). In most cases, the data would thus allow the analysis to be conducted at the sector or sub-sector level. A focus on changes in behaviour also makes it possible to account for local conditions and issues of implementation, enforcement, and interaction among regulatory instruments. A drawback is that the method does not provide a 
clear sense of which regulations in particular are responsible for the observed changes (another instance of the identification problem highlighted in OECD, 2014a).

Most of the features mentioned above for changes in agents' behaviour equally apply to measures of regulatory stringency relying on observed environmental outcomes such as air emissions or water quality (bubble 4 in Figure 3). Outcome-based measures have, in addition, the advantage of being more readily available since the enforcement of environmental regulations usually requires that data be collected on emissions of pollutants at a relatively disaggregated level. ${ }^{36}$ These measures also make it possible to account for investments that were undertaken primarily for cost reasons but that nonetheless contribute to pollution control or abatement, a problem that often plagues surveys of pollution abatement costs and expenditures (Brunel and Levinson, 2013). In a similar fashion, looking at actual environmental outcomes makes the distinction between end-of-pipe measures and changes to integrated processes irrelevant, since a given improvement in air quality could equally come from newly-installed filters or a more efficient use of polluting inputs. The identification problem is, however, potentially acute in that case since it may be hard to control for the impacts that factors other than regulations have on observed environmental outcomes.

Regardless of which of the above measures of regulatory stringency is used, the limited availability of information may sometimes prompt analysts to use proxies, or proxy variables, on the assumption that they are sufficiently correlated with environmental regulations and their effects. The literature points to a number of country-specific proxies that have been used with varying degrees of success, ${ }^{37}$ such as the lead content of gasoline, the number of multilateral environmental agreements (MEAs) signed, the share of environmentally related taxes in total tax revenues, or the number of active environmental NGOs in the country. The challenge in that case is to identify the type of information that will reflect actual regulations or their effects to the best extent possible. This can prove particularly difficult when the analysis is to be conducted at the sector or sub-sector level.

The limitations mentioned above suggest that a focus on one particular method may not prove satisfactory, thereby requiring that several approaches be tested. This report uses two such methods to arrive at more robust results, namely a composite index of the stringency of actual environmental policy instruments (the EPS index described in OECD, 2014a) and two different outcome-based measures applying to particular sectors. All three indicators are successively described in the next three sub-sections where their relationship to exports of CLEG products is assessed statistically.

\section{A broad-based analysis of comparative advantage in environmental products}

The focus of the analysis in this report is on a country's environmental regulations and its total exports of specific environmental goods, i.e. exports to the rest of the world, regardless of which country imports the exported environmental goods. In this context, attention is paid to environmental regulations applying in the exporting country rather than in the importing countries. The reasons for doing so are twofold. First is the presumption that regulations in the exporting country matter more for that country's total volume of exports than for the geographical breakdown of these exports. Understanding that breakdown would be a different exercise altogether and would require collecting a comprehensive set of indicators on the stringency of environmental regulations in all importing and exporting countries. Such indicators are, however, typically only available for most OECD countries and a restricted set of non-member economies. In addition, a focus on total exports is clearly better suited for

36. Implementing an emissions trading scheme requires, for example, that the emissions themselves be adequately monitored and verified in the first place.

37. See the literature review in Brunel and Levinson (2013) for examples. 
assessing the degree to which different countries specialise in environmental goods. While one would expect most countries adopting stringent environmental regulations to import some environmental products, little can be said a priori as to whether those regulations will stimulate exports. ${ }^{38}$ Together, these considerations contribute to making an analysis centred on total exports a more fruitful exercise. To that end, use is made of a standard index of revealed comparative advantage (RCA).

RCA indices have been used frequently in trade analysis, including in the OECD context, to provide a concise picture of a country's export performance in various sectors or industries. Using data on actual trade flows, they compare a country's share of world exports for a particular set of goods to that country's share of world exports for all goods. ${ }^{39}$ In that sense, RCA indices bear little theoretical relationship to the Ricardian concept of comparative advantage, which emphasises relative production costs in an autarky setting, and instead serve to describe the sectors in which a country exports more or less than average (OECD, 2011b). They can therefore be used "as a guide to what causes actual trade patterns", including "policies that may not be intended to influence trade, but that might do so unintentionally" (ibid). This description fits this report's focus on the impacts that environmental regulations have on patterns of trade in environmental goods. ${ }^{40}$

Lack of data prevents the empirical analysis in this report from looking beyond exports of environmental goods to include exports of environmental services. The reasons for this were mentioned in the previous section, where it is explained that currently available data sources do not provide sufficient coverage of trade in services related to the environment. Data limitations make it similarly impossible at this stage to adopt a perspective looking at global value chains for environmental products, whereby the analysis would investigate the interrelation between imports and exports in determining countries' competitive position in the global EGS industry. While these aspects are clearly important and deserve further attention, they are not considered in the context of the present empirical analysis.

The empirical analysis presented in this report first combines an RCA index for all CLEG products (see the list in Annex 1) with an indicator of overall environmental policy stringency (EPS) developed in the context of related OECD work on environmental policies and productivity growth (OECD, 2014a). This indicator was constructed as a composite measure of the relative stringency of different regulatory instruments applying to a selection of pollutants, industries, and media, with the underlying assumption being that a stringent approach to the latter is indicative of "a general preoccupation with environmental issues across all domains" (ibid.: 13). For each instrument included in the composite EPS index, the information collected was normalised and scored on a 0-6 scale, and subsequently aggregated using equal weights to arrive at a single value for each country and year (Figure 4). ${ }^{41}$ The resulting data are available for 26 OECD countries over most of the period 1990-2012, though

38. The conceptual discussion above describes some of the conditions under which a larger home market for EGS may lead to larger exports of environmental products.

39. The formula used here to calculate the RCA index is $R C A_{i k}=100 \times\left(\left(X_{i k} / X_{w k}\right) /\left(X_{i .} / X_{w}\right)\right)$, where $X_{i k}$ denotes country $i$ 's exports of product $k, X_{w k}$ denotes world exports of product $k, X_{i}$. denotes country $i$ 's total exports, and $X_{w}$. denotes world total exports.

40. Using an RCA index does not, however, allow for a formal test of the home-market effect strictly speaking since that would require that the analysis focusses on net exports of CLEG products rather than gross exports.

41. Annex 2 of the cited report (OECD, 2014a) describes in detail the construction of the EPS index — including the particular regulatory instruments that were selected - and further tests for the sensitivity of the index to different weighting schemes (e.g. equal weights or random weights). 
the analysis in the present report covers only the years 2002 to 2012 due to data limitations on the trade side. The EPS index thus improves on other available measures of the general stringency of environmental regulations such as the WEF's index of perceived stringency in that it offers more time variation and does not suffer from identification problems, as explained in the previous sub-section. ${ }^{42}$

Figure 4. Aggregation structure of the composite indicator of environmental policy stringency (EPS)

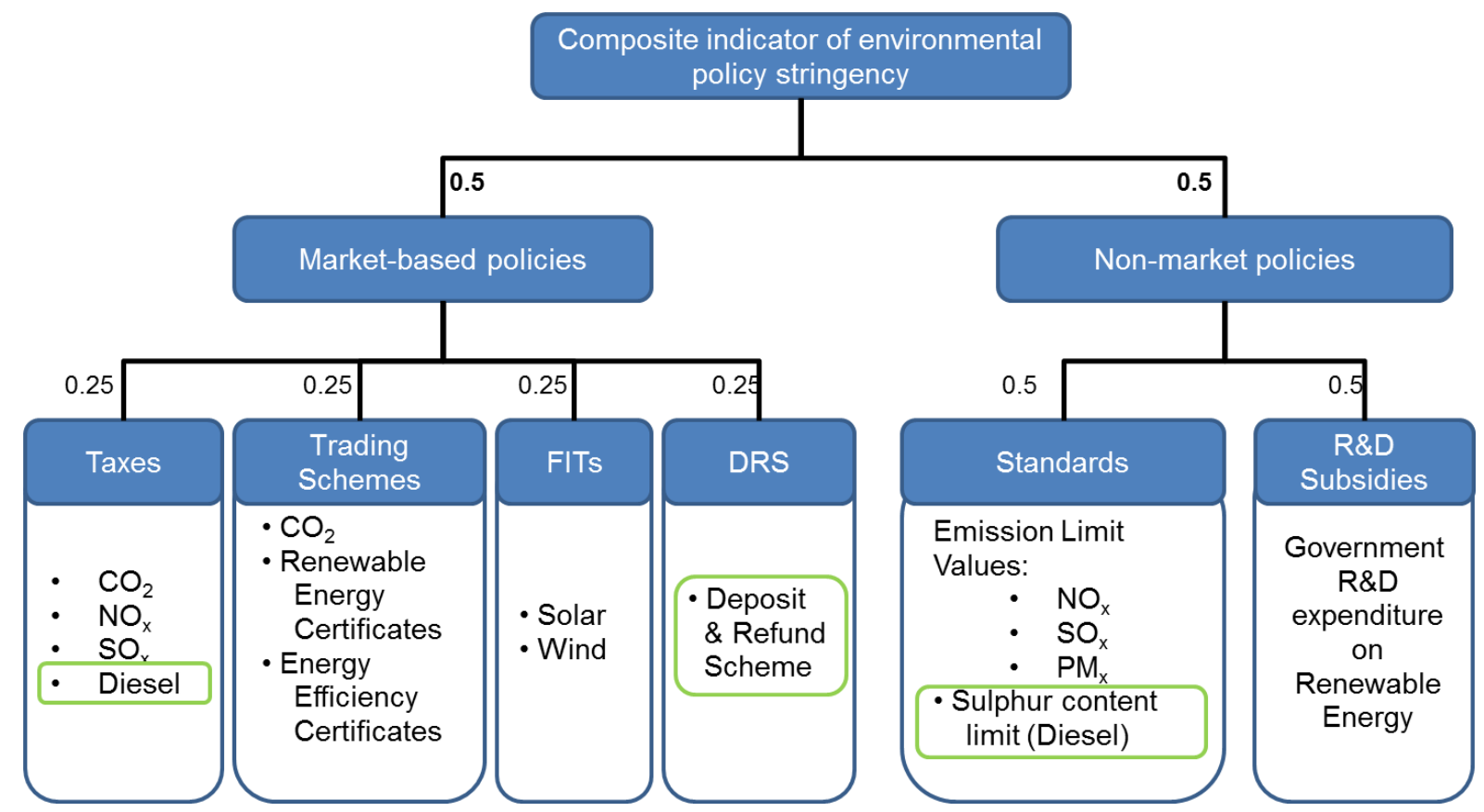

Note: Feed-in tariffs (FITs) concern only wind and solar energy and include feed-in premia. The policy instruments enclosed in lighter frames are the ones not related to the power sector.

Source: OECD (2014a).

A graphical display of the two variables over the 2002-12 period indicates a positive and significant correlation between the EPS index and revealed comparative advantage in all 248 CLEG products (Figure 5). This means that, on average, countries with stringent environmental regulations tend to be those that export relatively more environmental products. It could be, however, that countries with stringent regulations also happen to have better infrastructure and large endowments in those factors of production that are used intensively in the production of environmental products. More analysis is therefore needed to assess the role that other variables may play in shaping the observed trade patterns.

In what follows, the analysis controls for the impacts that other trade-relevant country characteristics may have on revealed comparative advantage in environmental products. Using data from the World Bank's World Development Indicators (WDI) database and UNCTAD, this report looks at three such country characteristics: the degree of export diversification; the capital-labour ratio; and the share of the labour force with at least

42. Earlier analyses using the WEF index and the revenues of environmentally related taxes (expressed as a share of GDP) as measures of stringency were conducted for the purpose of this report but did not prove very conclusive due to a lack of variation across time and to identification issues. 
secondary education (a measure of human capital). ${ }^{43}$ The capital-labour ratio and the secondary-education ratio are meant to control for the intensity with which factors of production are used in different countries. While those indicators may seem very broad for the purpose of explaining exports of environmental goods, environmental products generally span a wide range of HS chapters, which in turn involve very different industrial activities. ${ }^{44}$ There is also ample evidence suggesting that factor endowments — as measured using capital per worker or the share of skilled workers in the total labour force - are important sources of comparative advantage in many traditional manufacturing industries (Chor, 2010; OECD, 2011b). To the extent this is the case for CLEG-producing industries, the capital-labour ratio and the secondary-education ratio should help control for that. The capital-labour ratio can also help control for countries' level of development given that it correlates strongly with GDP per capita.

Figure 5. Environmental policy stringency and revealed comparative advantage in CLEG products (2002-12)

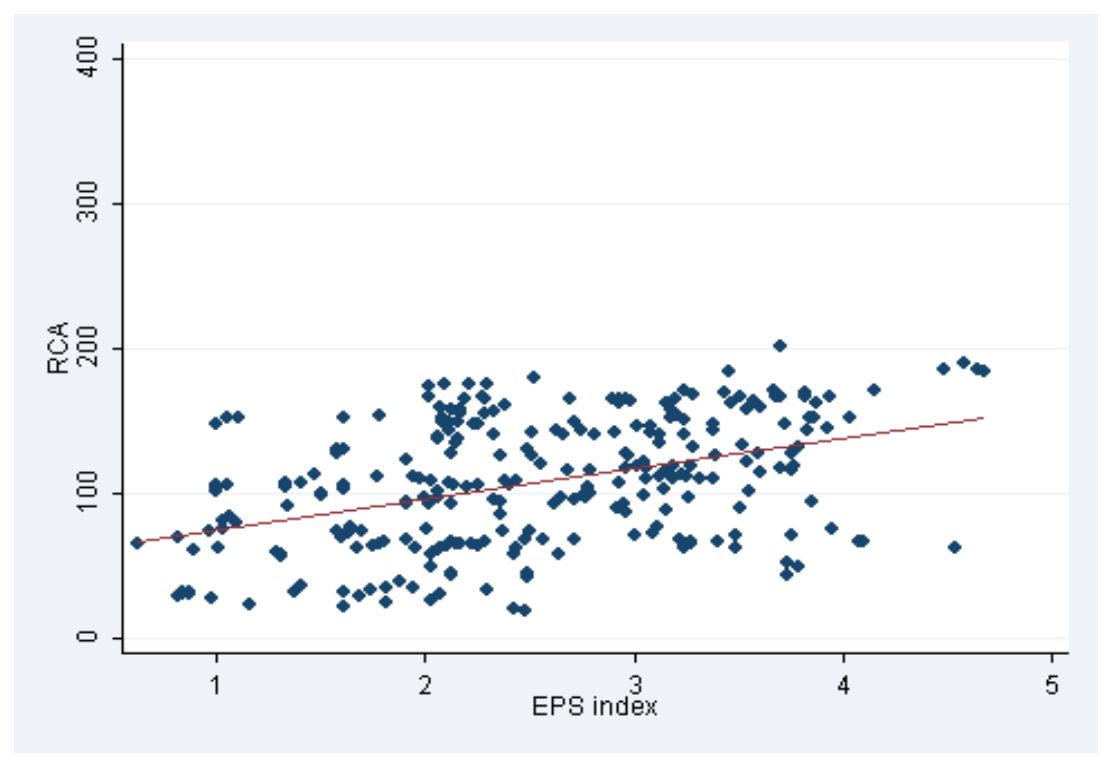

Source: OECD based on the data described in the Technical Appendix.

The degree of diversification of a country's exports is an important characteristic in this context as well. As indicated earlier in Figure 1, there are large differences in the extent to which OECD countries import and export CLEG products, which in turn reflect the extent to which these countries are narrowly specialised. It is thus no accident that countries with the lowest values for the Grubel-Lloyd index of intra-industry trade tend to be resource-oriented or relatively remote (e.g. Australia, Chile, and Iceland). In a similar fashion, and noting again that CLEG products span a wide range of industrial activities, one might expect narrowly specialised countries (i.e. countries with a low degree of export diversification) to have a lower revealed comparative advantage in environmental products, all else being equal.

43. A detailed description of the variables and the corresponding sources is available in the Technical Appendix.

44. Converting the CLEG from HS 2007 to SITC Rev.4 reveals that environmental goods cover activities as diverse as "cork and wood manufactures", "power-generating machinery and equipment", "general industrial machinery and equipment", "plastics in non-primary forms", "non-metallic mineral manufactures" or "textile yarn, fabrics, etc." 
While there are many other country characteristics that have the potential to affect countries' exports in general, the use of an RCA index centred on CLEG products makes their inclusion unnecessary since this index relates a country's share of world exports for CLEG products to that country's share of world exports for all goods. Hence, to the extent that some particular country characteristic results in a country exporting more of all goods (e.g. owing to better infrastructure or a low incidence of corruption), this would equally affect the numerator (i.e. exports of CLEG products) and the denominator (i.e. exports of all products), thereby cancelling out the effect. Given the resulting need for controls that bear some specificity with regards to the RCA index for CLEG products, one might also consider including some indicator of a country's technological advancement in the particular domain of pollution prevention and abatement. R\&D statistics are, however, not available at that particular level of detail. Meanwhile, past OECD work indicates that the stringency of environmental regulations may be an important predictor of environmentally friendly innovation, as measured using the number of patent applications in selected areas of environmental technology (OECD, 2011a). These results make the inclusion in the same regression of both stringency indicators and environmentally related patents difficult as the resulting estimates would likely suffer from acute multicollinearity between regressors.

The detailed results presented in Table A.2 in the Technical Appendix suggest the existence of a significant positive correlation between the index of environmental policy stringency and exports of CLEG products that is independent of the country characteristics included here. That is, the correlation holds when controlling for the capital-labour ratio, the level of education of the labour force, and the degree of export diversification. The magnitude of the estimated coefficients ranges between 0.61 and 0.69 , meaning that a $10 \%$ increase in the EPS index is associated with a 6.1-6.9\% increase in the RCA index for CLEG products in statistical terms. Importantly, the results do not seem very sensitive to the use of lagged values for the EPS index, which allow for a three- to five-year lag in the effects environmental stringency may have on trade. In other words, the results do not vary much when older regulations are used to account for variations in exports of CLEG products. The analysis also uses year dummies to control for factors such as the 2008-09 economic crisis or changes in world resource prices but this does not alter the results either.

Because some countries may use import tariffs and other trade barriers as a means to insulate local firms from international competition and spur the development of a larger home market (the so-called "infant-industry" argument), further analysis is then conducted using the average import tariff applied on CLEG products in the exporting country as an additional control variable (Table A.3 in the Technical Appendix). Contrary to the argument that protecting domestic firms increases exports through learning-by-doing effects, the results indicate that, on average, import tariffs applied by a country have a small but detrimental impact on its exports of environmental products, thereby suggesting that countries protecting their EGS industry by means of tariffs do not export more. This negative impact is, importantly, distinct from the positive impact of the EPS index ${ }^{45}$ indicating that the stringency of environmental regulations and trade barriers have opposite effects on exports of CLEG products. A reason for this could be that higher import tariffs on CLEG products are indicative of a more general inclination toward protectionism and of a lesser degree of competition domestically. In a context of global value chains, where imports increasingly comprise intermediate goods that undergo further processing before being re-exported, import barriers can thus damage a country's export competitiveness since they raise the cost of inputs. In addition, Figure 1 above has already shown that many OECD countries happen to

45. The data presented in the Technical Appendix show little correlation between average import tariffs applied on CLEG products and the EPS index. 
be both importers and exporters of the same CLEG products, which further suggests that exports and imports of environmental goods form two sides of the same coin.

As a robustness check, the analysis is also performed using the narrower lists of environmental products described in the previous section, namely the Core CLEG (11 products) and the Core CLEG+ (40 products). ${ }^{46}$ Table A.4 and Table A.5 in the Technical Appendix show the results obtained for the Core CLEG and the Core CLEG+ respectively. Interestingly, there still seems to be a positive association between the EPS index and countries' export performance in environmental goods, though this association does appear weaker in some cases. This weaker correlation is likely due to the weight the EPS index gives to the energy sector and air-pollution control, and the fact that Core CLEG and Core CLEG+ products include predominantly pieces of equipment used in water and waste treatment.

To account for this possibility, a similar econometric analysis is then conducted using only those CLEG products classified under the media "APC", "MON", and "REP", i.e. hose products listed in Annex 1 that relate to air-pollution control, environmental monitoring and analysis, and renewable-energy plants. Together, these 103 products make up a set of energyand APC-related goods that are presumably well-suited for an analysis using the EPS index. Figure 6 illustrates graphically the positive correlation between RCA in those energy-related CLEG products and the EPS index. As expected, the econometric results presented in Table A.6 are stronger and statistically more significant than those for Core CLEG and Core CLEG+ products, thereby reinforcing the presumption that the previous results above were driven to a significant extent by their energy- and APC-related component.

Figure 6. Environmental policy stringency and revealed comparative advantage in energy-related CLEG products (2002-12)

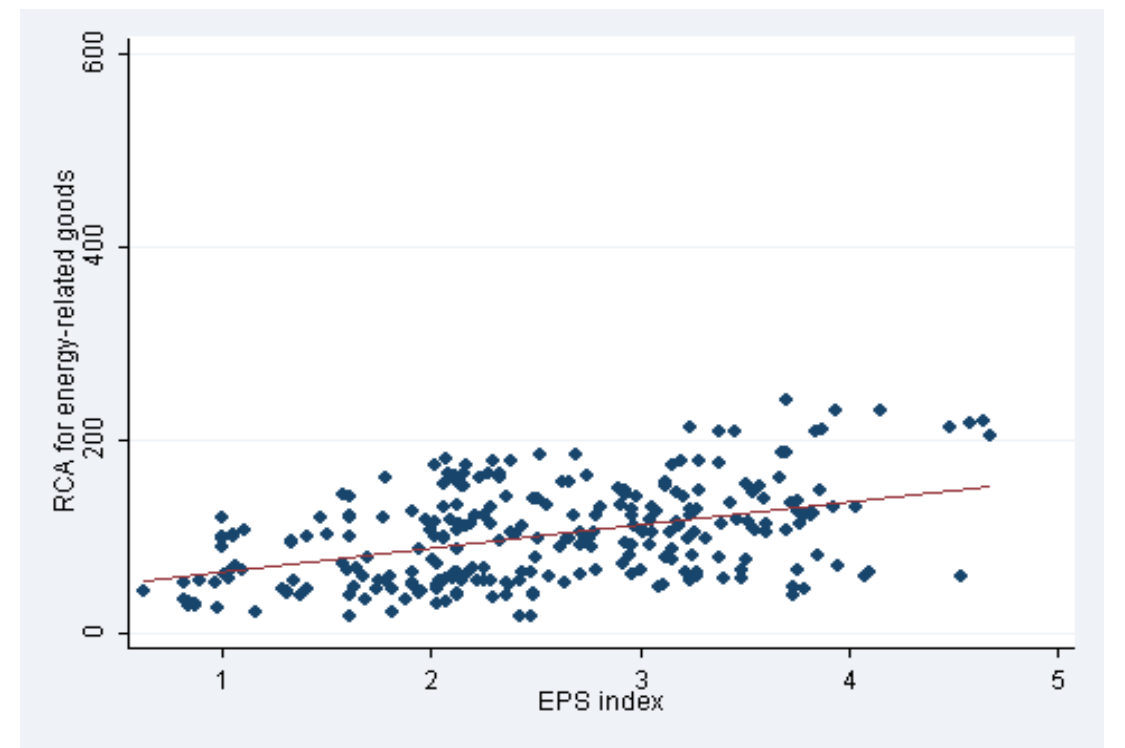

Source: OECD based on the data described in the Technical Appendix.

46. Some more tests were also run, such as replacing the capital-labour ratio with GDP per capita, but these did not change the results much. 
Although the analysis above seems to indicate that countries with stringent environmental regulations export relatively more environmental products, the indicator used for measuring regulatory stringency (i.e. the EPS index) remains broad in scope - including elements like public spending on renewable-energy $\mathrm{R} \& \mathrm{D}$ and feed-in tariffs for solar and wind energy while the regressions likely omit important country characteristics. It is also likely that the resulting estimates are driven largely by the power sector since the EPS index has a bias toward renewable-energy sources and the regulation of air emissions from conventional power plants and waste incinerators (Figure 4). More focussed evidence is therefore required if the analysis is to be considered valid beyond the energy sector and policy instruments such as renewable-energy subsidies. In the following sub-sections, the report turns to two particular sectors for which the analysis uses outcome-based indicators of stringency.

\section{Sector analysis: The case of solid-waste management}

To complement the above broad-based analysis, this sub-section adopts a sector-level perspective and focusses on municipal solid-waste (MSW) management. The OECD has produced over the years a large body of work on solid-waste management policies, focussing on, among other things, best practices and guidelines in the area of waste prevention and minimisation and the environmentally sound treatment of waste. ${ }^{47}$ To support this work, large quantities of data are regularly collected that track the amount of MSW generated and the various ways in which it is then treated. Even though it accounts for about $10 \%$ of global waste generation, the availability and transparency of the data thus make the MSW sector an appealing option for quantitative analysis. The MSW management sector also represents a major segment of the broader EGS industry, accounting for as much as 30\% of total ecoindustry turnover in the European Union (Ecorys, 2009) and 28\% of global revenues for all environmental services (USITC, 2013). ${ }^{48}$ From a trade angle, CLEG products classified under the medium "SWM" (solid- and hazardous-waste management) make up 10\% of all CLEG HS lines and account for about 9\% of world imports of environmental goods (the fourthlargest product group after REP, WAT, and MON). ${ }^{49}$ For these reasons, this report looks at the stringency of regulations in the MSW management sector and their relationship to revealed comparative advantage in CLEG products classified under the "SWM" heading, i.e. environmental goods of relevance to the management of solid and hazardous waste and recycling systems. ${ }^{50}$

OECD countries generate annually over 660 million tonnes of municipal solid waste, most of it in the form of food wastes, paper, cardboard, plastics, textiles, leather, and rubber. Although this represents about half of global MSW generation (Hoornweg and Bhada-Tata, 2012), the past 20 years have seen waste generation in the OECD growing much slower than real output (Figure 7). This decoupling between economic growth and MSW generation may, in part, reflect the efforts governments deploy in the area of waste prevention and

47. See OECD (2013c) for an overview of work in this area.

48. These shares concern only municipal solid-waste management and thus exclude the recycling industry and the management of hazardous waste. Their inclusion would increase the shares even more.

49. See Table 1 and Table 2. Looking only at trade in goods related to waste management probably downplays the importance of a sector where services account for the bulk of revenues.

50. While the SWM heading also encompasses products related to the management of hazardous waste, none of the products listed in the CLEG pertain specifically to this latter application. Rather, most listed products seem general enough to be equally used in solid-waste management and recycling. Examples include landfill liners, covers for methane collection, waste containers, biomass boilers, sanitary landfill compactors, and shredders. 
minimisation, including through increasing emphasis placed on extended producer responsibility in the treatment of products at the post-consumer stage (OECD, 2001b). While the trend is encouraging, the large amounts of MSW generated every year continue to pose serious environmental challenges.

In practice, municipal solid waste is generally treated in either of four ways: landfilling, incineration (with or without recovery of energy and heat), recycling, or composting. The waste-management hierarchy ranks these alternatives in descending order, with landfilling and incineration without energy recovery standing at the bottom given their higher environmental costs (Figure 8). ${ }^{51}$ In particular, landfills may leak and contaminate groundwater where, for example, sites lack adequate landfill liners. Atmospheric pollution through emissions of methane, $\mathrm{CO}_{2}$, and even mercury may also result from the decomposition of waste and chemical reactions, thereby requiring that landfills be equipped with proper monitoring and gas-collection systems. Methane, a greenhouse gas, takes on particular importance since it is about 20 times more potent than $\mathrm{CO}_{2}$ in warming the atmosphere, and landfills account for about $12 \%$ of global methane emissions (Hoornweg and Bhada-Tata, 2012). Finally, landfills also pose a host of land-use problems, including the difficulty of finding an adequate site that both meets a certain set of geological and environmental criteria and is acceptable by neighbouring residents. ${ }^{52}$

There are several instruments available to governments for regulating the management of solid waste. The OECD's Guidance Manual on Environmentally Sound Management of Waste (OECD, 2007b) recommends that member countries "provide incentives to take part in environmentally sound recycling schemes" using measures such as collection schemes for recyclables, landfill taxes, landfill bans for certain wastes, recycling targets, and eco-labels among others. Efforts have been made in that respect as the share of MSW landfilled tends to follow a downward trend in most OECD economies, with a large decrease observed in several European countries over the 1995-2011 period (e.g. Austria, Belgium, Germany, the Netherlands, Norway, and Sweden).

Because the regulation of the MSW management sector involves many different instruments, measuring the overall level of stringency this generates can prove challenging. Interactions between regulatory instruments are also pervasive. Landfill taxes or bans may, for example, divert MSW away from landfills and into incinerators, which are themselves often subject to numerous instruments regulating their atmospheric emissions of pollutants and disposal of residues. Positive incentives for recycling may also serve to reduce the amounts of MSW going into landfills independently of the effects of landfill taxes and bans. Moreover, countries differ in the range of instruments they adopt in order to meet a given policy goal. As an example, the Netherlands used to charge the delivery of waste to landfills at rates exceeding EUR 80 per tonne while Germany chose to directly ban landfilling instead. The end result is, however, very close, with both countries landfilling less than $1 \%$ of their MSW.

51. While clearly the worst alternative from an environmental standpoint, the wild dumping of waste does not involve any treatment per se and does not form part of the waste-management hierarchy.

52. This constitutes one classical example of the NIMBY ("Not-In-My-Backyard") problem. 
Figure 7. OECD-wide MSW generation and real output

$(1995=100)$

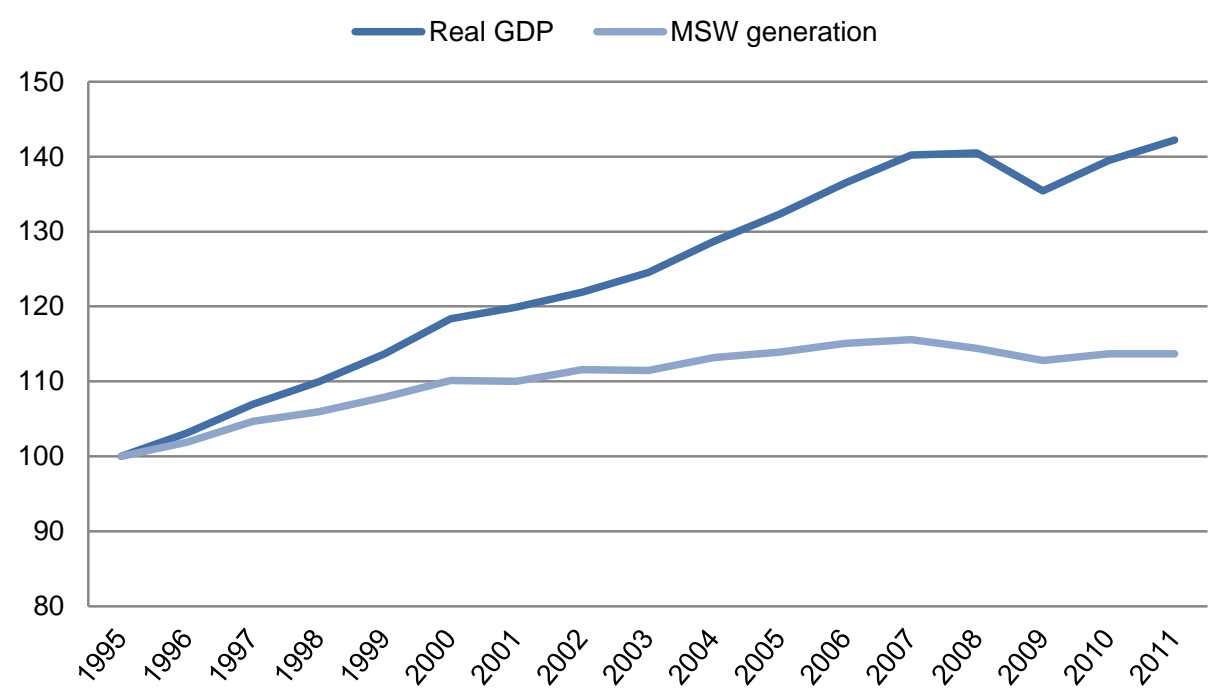

Figure 8. The waste management hierarchy

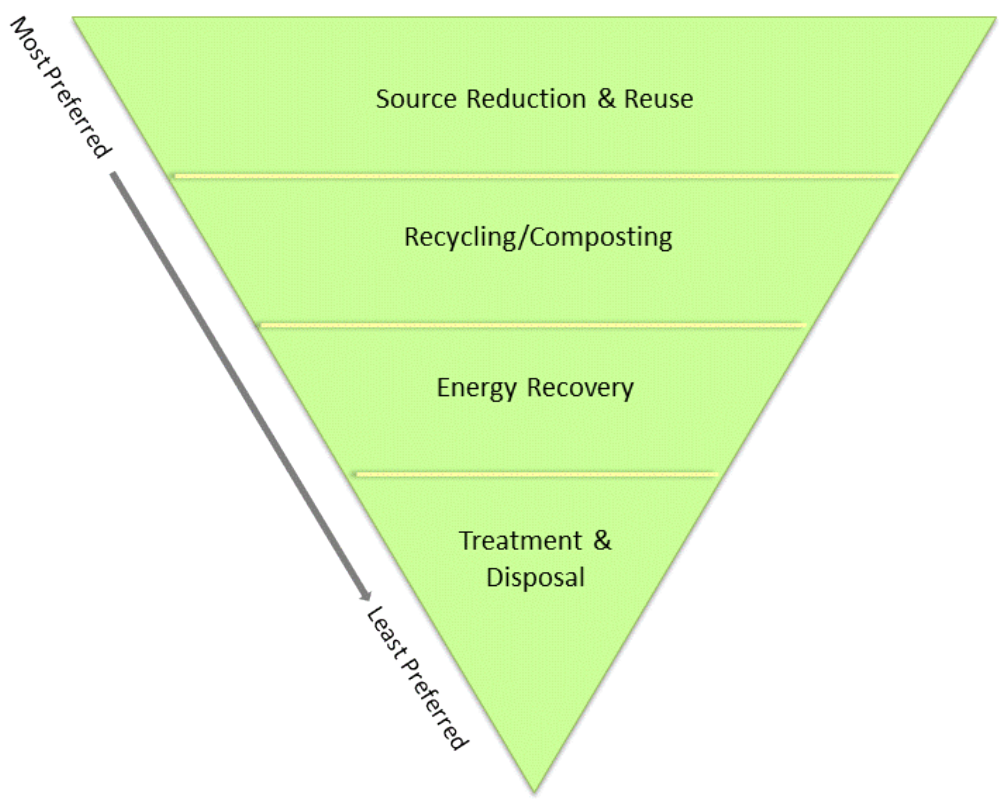

Source: OECD based on U.S. EPA. 
The analysis that follows therefore focusses on the outcomes of the regulatory process. It uses the share of MSW landfilled as an indicator of regulatory stringency in the MSW management sector on the grounds that governments often consider landfilling the worst alternative. Hence, the assumption made is that the lower the share of MSW landfilled, the more stringent environmental regulations are in the MSW management sector. While this indicator does not account for the substitution that may take place between landfilling and incineration (in particular incineration without energy recovery), data for most OECD countries show this shift to be limited. In 1995, the OECD-wide share of MSW landfilled reached $60.3 \%$ while MSW incinerated stood at $19.8 \%$. In 2011, these shares were $45.7 \%$ and $21.2 \%$ respectively, with recycling and composting accounting for most of the decrease in landfilling. Only in Austria, Finland, Italy, and Norway has incineration increased significantly over the whole period, the bulk of it in the form of incineration with energy and heat recovery. Even then, waste incineration in OECD countries is usually subject to strict regulations that significantly reduce the amounts of pollutants emitted into the air (see Annex 3). In the case of Denmark, for example, the Danish Environmental Economic Council (2014: 6) recently noted that "incineration has to live up to strong emission targets in Denmark for air pollutants and emissions are therefore low."

A recent USITC report (2013: xv) provides further evidence in support of the argument that a decrease in landfilling is associated with more stringent regulations, which in turn may increase demand for MSW-related goods and services:

Regulations mandating the collection and treatment of solid and hazardous waste also spur demand for waste treatment services in many countries. Further, within the past decade, both the United States and the European Union have adopted regulations requiring a reduction in the amount of waste going into landfills, thereby increasing the demand for recycling and composting services in those countries.

Whether the adoption of such regulations results from countries' geographical characteristics or the social preferences and attitudes of their citizens does not change the end result that stringent regulations generally decrease the amount of waste going into landfills, which in turn increases the demand for associated equipment and services. In other words, the fact that geographical factors may push certain countries to reduce landfilling through stricter regulations does not invalidate the initial argument that this increases the size of the home market for waste-related goods and services. Even then, the data do not necessarily show a strong correlation between countries' population density or land availability and the share of MSW they landfill, with small insular economies like Cyprus and Malta landfilling in 2011 as much as $80 \%$ and $88 \%$ of their MSW respectively. The remainder of this sub-section thus assesses empirically the relationship between the share of MSW landfilled and revealed comparative advantage in CLEG products related to solid-waste management (SWM).

Using annual data on the share of MSW landfilled, a negative correlation is observed between the latter and RCA in SWM products (Figure 9), implying that countries landfilling little of their MSW are also those that export relatively more waste-management-related equipment. As in the case of the broad-based analysis conducted above, caution should, however, be exercised when interpreting this result. Because the share of MSW landfilled may reflect unobserved country characteristics driving the correlation, the analysis next controls for other trade-related variables, a description of which is available in the Technical Appendix. As before, those variables are: the degree of export diversification; the capitallabour ratio; and the share of the labour force with at least a secondary education. 
Figure 9. Landfilling of municipal solid waste and revealed comparative advantage in solid-waste-related products (2008-11)

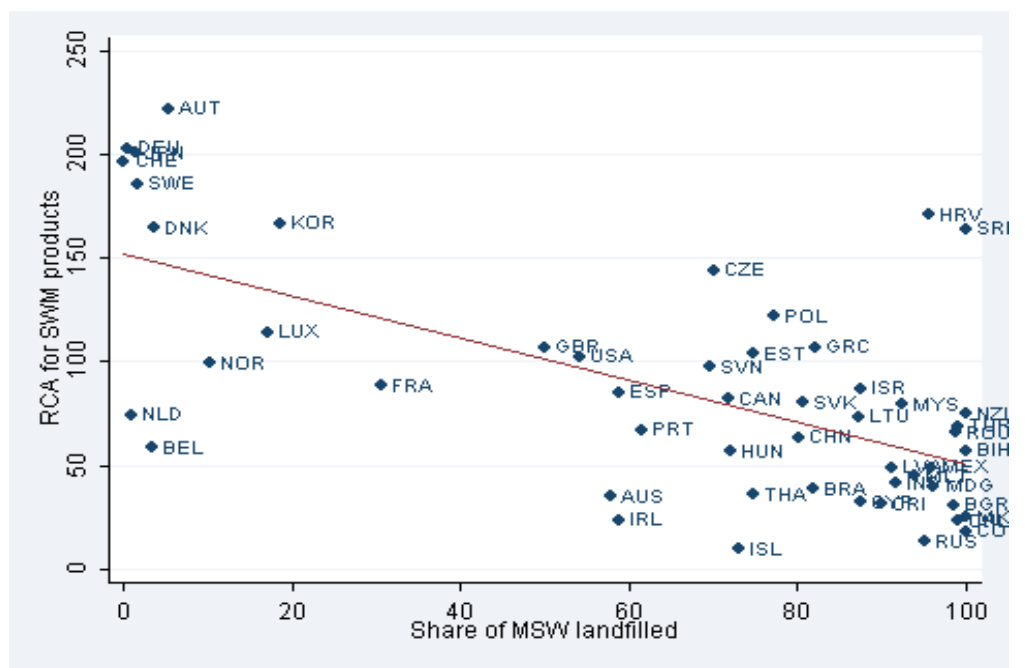

1. Note by Turkey: The information in this document with reference to "Cyprus" relates to the southern part of the Island. There is no single authority representing both Turkish and Greek Cypriot people on the Island. Turkey recognises the Turkish Republic of Northern Cyprus (TRNC). Until a lasting and equitable solution is found within the context of the United Nations, Turkey shall preserve its position concerning the "Cyprus issue."

2. Note by all the European Union Member States of the OECD and the European Union: The Republic of Cyprus is recognised by all members of the United Nations with the exception of Turkey. The information in this document relates to the area under the effective control of the Government of the Republic of Cyprus.

Source: OECD based on the data described in the Technical Appendix.

The results shown in Table A.7 in the Technical Appendix indicate that countries with a lower share of MSW landfilled tend to have a higher revealed comparative advantage in CLEG products related to solid-waste management. Coefficients on the MSW-landfilled variable are all negative and highly significant statistically, thereby lending support to the argument that low shares of MSW landfilled reflect stringent solid-waste regulations, which are in turn associated with higher relative exports of solid-waste-related products. This remains true when controlling for country characteristics like export diversification or physical- and human-capital intensity. While landfilling appears strongly correlated with the capital-labour ratio (itself strongly correlated with GDP per capita), the estimated coefficient does not vary much across the different specifications, including those that exclude the capital-labour ratio. The estimated coefficients are similarly not much affected by the use of three- and five-year lags on landfill rates.

The relationship between landfill shares and the RCA index appears, however, relatively modest in size compared with that for other variables like education or the degree of export diversification. The estimated coefficients thus imply that a $10 \%$ decrease in landfill rates is associated with a $0.4-0.6 \%$ increase in the RCA index. One explanation for this result could be that regulatory stringency in the waste-management sector takes more time to affect trade patterns than in other sectors. In that sense, the time span considered here (2002-11) may be too short to allow stringency to dramatically alter the content of exports. As discussed earlier in the context of learning-by-doing processes in the wind-turbine industry, it takes years for countries to develop an export capacity in a given domain so that adopting a longer-term view may yield additional interesting insights.

Another explanation for the small estimated coefficients could simply be that the share of MSW landfilled does not reflect regulatory stringency adequately. The Australian 
Productivity Commission (2006: LVI) has, for example, argued that "performance indicators of the amounts of waste being disposed to landfill or recovered have limited value because they do not provide any information on the costs and benefits of these options." While this clearly imposes limits on the use of landfill rates as measures of stringency, the implied bias would likely run the other way as countries with the most competitive MSW sectors would tend to be those with lower waste-recovery and recycling costs, making landfilling a less attractive waste-management option there and the estimated coefficient higher. Alternatively, a competing explanation would point to the small estimated coefficients and conclude that the stringency of regulations is not a major driver of trade in SWM-related products. While this may potentially be the case for SWM-related equipment, the present analysis does not cover trade in waste-management services, which presumably account for the bulk of revenues in the MSW sector. Moreover, it remains unclear whether a small estimated coefficient actually means a small impact in a context wherein the costs of managing MSW may evolve in a nonlinear fashion and regulations are developed only gradually.

\section{Sector analysis: the case of urban wastewater treatment}

Adding to the above sectoral evidence on the management of municipal solid waste, the analysis next turns to urban wastewater treatment, focussing on the discharges from treatment plants into water bodies. While most of the population in high-income countries is now connected to sewage networks, the extent to which urban wastewater is treated still differs considerably across jurisdictions. Some municipalities discharge their wastewater without any treatment, others opt for very limited treatment, and still others have adopted advanced technologies to remove substances like nutrients before wastewater is discharged into waterways (e.g. Amsterdam, Berlin, and Paris). In the case of the EU, the European Commission found that $82 \%$ of the wastewater generated by member states in 2009-10 received secondary, biological treatment but that this share dropped to $39 \%$ when considering only the 12 member states that joined in 2004 and 2007 (European Commission, 2013b). The situation is even more contrasted when looking at emerging economies like India, where a study of 908 cities having at least 50000 inhabitants was carried out by the country's Central Pollution Control Board in 2009, and found that treatment capacity in these cities could cope with only $31 \%$ of the total wastewater generated (CPCB, 2009).

Wastewater management constitutes a major segment of the broader EGS industry as it accounts for roughly $13 \%$ of total eco-industry turnover in the European Union (Ecorys, 2009). Estimates from EBI reported in USITC (2013) indicate that it stood at about a third of global EGS revenues in 2010. The same report also mentions that "the demand for wastewater services is [...] driven by federal, state, and local government regulations that require the treatment of wastewater for environmental and health reasons" (ibid.: xiv). Meanwhile, the European Environment Agency has estimated that the provision of wastewater treatment "has in fact accounted for as much as 50-60\% of the total investment for environmental protection in industrialised countries since 1970" (EEA, 2005: 11). Together with the fact that waterrelated products ${ }^{53}$ make up a fifth of global trade in CLEG products (Table 2), this points to wastewater management as a good candidate for further sectoral analysis.

The wastewater-treatment sector is also highly relevant from an environmental standpoint. Untreated discharges of wastewater into water bodies can severely affect the ecosystem, human health, and the economic sectors that depend on water as a resource. Impacts would

53. Water-related products include both wastewater and potable-water equipment since the HS does not make it possible to operate a distinction at the six-digit level. Examples of products included under this heading comprise activated carbon, pumps for liquids, filters, cast-iron pipes, and sludge driers. 
include the direct effects that certain heavy metals (e.g. lead and mercury) have on aquatic organisms to the indirect damages that nutrients (e.g. nitrogen and phosphorus) cause through eutrophication. ${ }^{54}$ The extent to which these adverse impacts are mitigated will, in turn, depend on the type of treatment adopted. One usually distinguishes between three levels of wastewater treatment, starting with so-called primary treatment, which mainly consists in the removal of inorganic material and heavier organic solids through physical processes (e.g. sedimentation and skimming). Next is secondary treatment using chemical and biological processes, whereby bacteria and algae serve to digest the organic matter that remains after primary treatment. Finally, tertiary treatment goes further as it seeks to remove nutrients and other dissolved and suspended substances through a variety of techniques such as chemical precipitation (Box 3). This third level of treatment is generally costly ${ }^{55}$ but may be essential in areas that are particularly sensitive to eutrophication.

The scope of urban wastewater treatment makes the sector well-suited for cross-country analysis given that it concerns all countries, and in particular those like OECD members whose population is concentrated in urban areas. A drawback is, however, that it does not capture directly the extent to which industrial water users abate their emissions of water pollutants. This is because most of the water used in industrial processes tends to be pretreated on-site before it is released into water bodies or sewage networks, thereby reducing the need for further wastewater treatment downstream. This reflects the separate set of regulations that apply to industrial users ${ }^{56}$ in part as "pollution reduction in industry is often cheaper if source-related in-house or in-plant measures are used, rather than the passive end-of-pipe process or sewage treatment" (EEA, 2005: 17). Looking at urban wastewater treatment therefore makes it more difficult to derive indicators of the stringency of environmental regulations applying to most industrial water users. It does, however, provide indications as to how far countries go in treating (or not) the urban wastewater they generate before it is released into water bodies.

Because this report focusses on environmental regulations and their connection to trade in environmental goods and services, it does not attempt to estimate the degree of stringency of regulations pertaining to drinking-water supply. While wastewater is generally destined to be released into water bodies, and thus has a direct relevance for the environment, the supply of potable water obeys a different logic where health considerations tend to predominate. In that sense, national regulations on drinking-water quality and international guidelines such as the WHO's (2011) are essentially health regulations more than environmental ones. ${ }^{57}$ Moreover, a cursory review of countries' drinking-water regulations shows them to be roughly equivalent across the OECD membership and high-income countries more generally, with

54. Eutrophication refers to the process by which a high concentration of nutrients causes algae and aquatic plants to develop excessively in a water body, thereby depriving it of the oxygen that is necessary to the preservation of fish and other aerobic life forms.

55. A report by the European Commission (2010) provides some estimates of the investment and operational costs that different treatment levels entail in the context of member states' compliance with the EU's Urban Waste Water Treatment Directive (91/271/EEC). See also the report by Ecorys (2009).

56. Box 1 discusses the regulation of industrial emissions in the case of the European Union, including industrial wastewater effluents.

57. This is not to deny that environmental and health considerations are closely related since a degraded environment often has adverse impacts on human health. See for example the latest WHO (2014) estimates indicating that outdoor air pollution may have caused 3.7 million premature deaths worldwide in 2012. 
concentration limits for heavy metals displaying, for example, very little variation around the levels specified in the WHO's (2011) guidelines (see Annex 3 for examples).

\section{Box 3. Tertiary treatment and the recovery of phosphate: The example of crystallisation technologies}

Concerns over the sustainable use of naturally occurring phosphate resources have led to the development of wastewater-treatment techniques seeking to recover phosphorus from wastewater so that it can later be used in other applications (e.g. as fertiliser in agriculture). Together with the fact that the removal of phosphorus from wastewater helps limit the eutrophication of water bodies into which the wastewater is to be discharged, this makes these techniques particularly attractive from an environmental standpoint.

One such technique is fluid-bed crystallisation, whereby solids are separated from liquids and the phosphate transformed into small, water-free crystals. The phosphate crystal pellets thus formed are of high purity and can be re-used in industrial processes. Crystallisation also improves on other treatment processes in that the crystal pellets it generates are much lighter and easier to handle than the sludge usually produced by conventional precipitation techniques, which needs to be dewatered and disposed of, as compost or through landfilling or incineration.

While there have been several pilot projects seeking to treat wastewater using crystallisation technologies, the costs involved can be high and have often prevented full-scale commercial applications. This may, however, change in the future as the costs of naturally occurring phosphate (a limiting nutrient) and fertilisers increase, thereby making phosphate-recovery technologies such as crystallisation more attractive economically. An increase in sludge-disposal costs would similarly raise the appeal of these technologies since they generate smaller amounts of sludge.

A sole focus on end-of-pipe technologies for removing nutrients may also exaggerate the costs of tertiary treatment in a context wherein agriculture contributes the bulk of total emissions of phosphorus and nitrogen. In the case of the greater Paris area, for example, it has been estimated that at least $10 \%$ of tertiary wastewater treatment costs for removing nitrogen can be ascribed to agriculture (Bommelaer and Devaux, 2011). Meanwhile, there is evidence for the Baltic region suggesting that achieving cost-effective nutrient reductions there would likely require targeting both agriculture and the treatment of wastewater, with wastewater treatment plants assuming a much bigger role in the case of phosphorus than in the case of nitrogen (Gren et al., 1997; Elofsson, 2010).

The example of crystallisation technologies thus illustrates concretely what tertiary treatment implies and the challenges its application faces in a setting wherein costs remain high and are partly due to agriculture's diffuse emissions of nutrients. Eutrophication and the depletion of naturally occurring phosphate resources make, however, such phosphate-recovering technologies environmentally appealing.

Sources: Berg et al. (2007), Bommelaer and Devaux (2011), Elofsson (2010), Giesen (1999), Gren et al. (1997), and Woods et al. (1999).

There are numerous regulatory instruments that can apply to the wastewater-treatment sector as a whole, including the imposition of tariffs or levies on water users, outright bans on the discharge of certain substances, minimum treatment requirements, and restrictions on the disposal of sludge. In the case of the European Union, Directive 91/271/EEC (the Urban Waste Water Treatment Directive, or UWWTD) forms the cornerstone of the region's approach to wastewater management since it effectively determines the extent to which member states need to treat their urban wastewater before release into water bodies. Under the UWWTD, member states are thus required to use at least secondary treatment for treating the wastewater from most agglomerations (Art. 4), except in a few specific cases where primary treatment may be acceptable (e.g. coastal waters, as per Art. 6). More advanced tertiary treatment is, however, required for designated "sensitive areas" (e.g. water bodies susceptible to eutrophication, as per Art. 5). The Directive also sets concentration limits for selected pollutants such as phosphorus that must be met in the discharges from urban wastewater treatment plants, thereby requiring member states to monitor the performance of their treatment plants but also that of the receiving waters. Canada's Wastewater Systems Effluent 
Regulations, which were developed in 2012 under the country's Fisheries Act, similarly set baseline effluent quality standards that require wastewater systems to use at least secondary or equivalent treatment (Canada Gazette, 2012). These regulations are currently being implemented in a phased manner, taking into account the risk profile of each wastewater system.

Meanwhile, the OECD has over the years issued a number of policy recommendations on several aspects of wastewater treatment, including the financing of sanitation services through water tariffs and taxes. A particular concern in that context has been to close the financing gap for ensuring adequate sanitation infrastructure, something which requires that countries set their water tariffs high enough to achieve full cost recovery (OECD, 2009). Most OECD countries now have some sort of tariff structure for covering the costs of wastewater treatment, the responsibility for which generally lies with local authorities. In the Netherlands, a forerunner in the implementation of the UWWTD, with $98 \%$ of its population connected to tertiary treatment plants in 2010, regional authorities collect a wastewater treatment levy (the Zuiveringsheffing) to cover the costs of treatment. Both households and businesses are subject to the levy at rates that averaged EUR 54 per population-equivalent, ${ }^{58}$ year, and entity in 2012 (OECD, 2014b). In the case of the Barcelona Metropolitan Area in Spain, the Catalan regional authority levies through the Catalan Water Agency (Agència Catalana de l'Aigua) a water tax that contributes to financing wastewater treatment plants in the region.

Given the variety of instruments used by different countries to regulate wastewater treatment and the different levels of government involved (national, provincial, municipal, etc.), it would likely be difficult to devise a comprehensive index based on actual policies that is comparable across countries. As done previously for the management of municipal solid waste, this report therefore uses an outcome-based measure of regulatory stringency, namely the share of a country's population that is connected to wastewater systems using at least secondary treatment (denoted TRT in what follows). As with most indicators that aim to infer the stringency of environmental regulations based on observed environmental outcomes, TRT does not adequately reflect the cost dimension of the measured environmental performance. Just like the share of MSW landfilled does not provide indications as to the relative costs and benefits of landfilling against other options (e.g. incineration), ${ }^{59}$ looking at the level of wastewater treatment does not reflect the costs of that treatment relative to the costs of efforts made upstream (e.g. measures that seek to reduce diffuse emissions of nutrients in agriculture). In that sense both measures fail to reflect the need to equalise marginal abatement costs across sources of pollution.

Notwithstanding those limitations, the TRT indicator has a number of properties that make it well-suited for the analysis that follows. First is the availability of data on the extent to which urban wastewater is treated in OECD countries, which stems from the need to monitor progress on the implementation of measures such as the UWWTD. This makes it possible to assemble datasets covering a significant number of countries and years. Second is the fact that a focus on (often local) environmental outcomes facilitates the aggregation of information at the national level, with a view to obtaining comparable country indicators that can be assessed against trade outcomes. By comparison, aggregating actual municipal, regional, provincial, and federal regulations into one country-level indicator that is internationally comparable would likely be extremely challenging and resource-intensive. This aspect is particularly

58. Population-equivalent is a standard measure of pollution loading in wastewater. For the purpose of the UWWTD, it is defined as "the organic biodegradable load having a five-day biochemical oxygen demand (BOD5) of $60 \mathrm{~g}$ of oxygen per day" (see Directive 91/271/EEC).

59. See the cited report by the Productivity Commission (2006) for a discussion of that particular aspect in the Australian context. 
salient in the case of wastewater treatment given the inherently local nature of the problem. Last, indicators such as TRT have a history in the OECD context, where they have been used for decades to track countries' environmental performance. ${ }^{60}$

As explained above in the context of the broad-based analysis, this report uses an indicator of revealed comparative advantage (RCA) to measure the extent to which countries export relatively more environmental products. This RCA index corrects for the size of countries since it takes into account their average weight in world trade, thereby providing a more accurate picture of trade specialisation than simple export shares. Plotting the TRT indicator previously described against the index of revealed comparative advantage for waterrelated products ${ }^{61}$ reveals a positive correlation (Figure 10), implying that countries where wastewater systems employ more advanced treatment procedures tend to export relatively more water-related products.

Figure 10. The level of wastewater treatment and revealed comparative advantage in water-related products (2008-11)

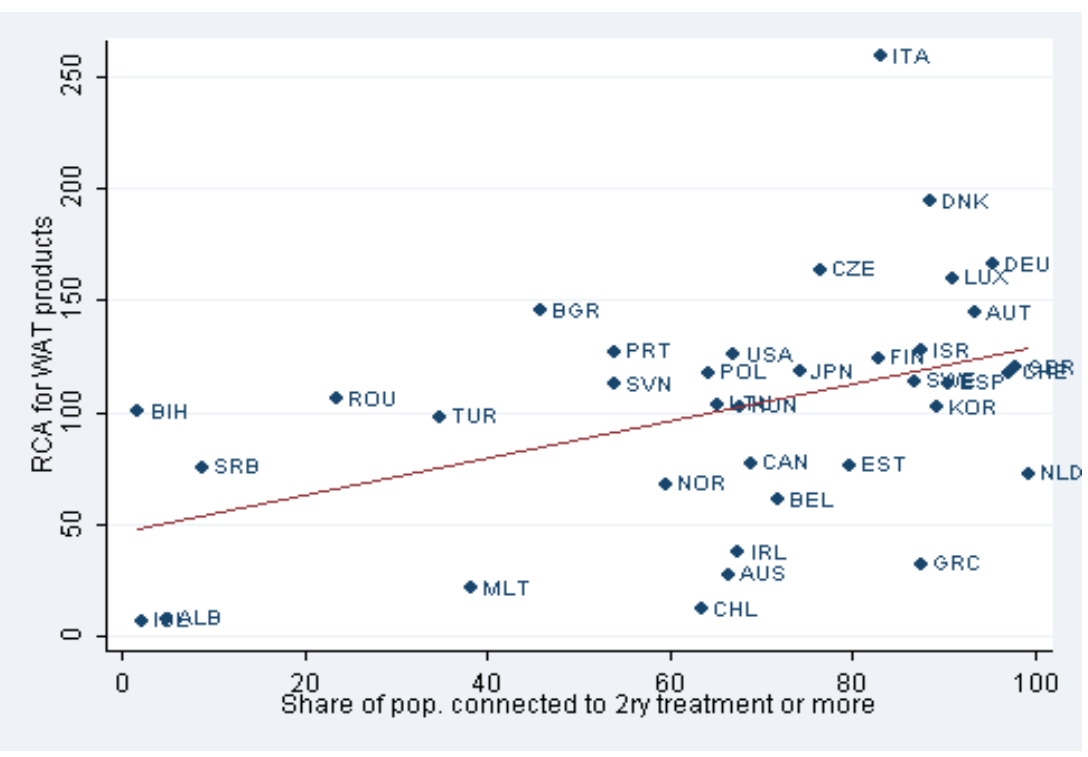

1. Note by Turkey: The information in this document with reference to "Cyprus" relates to the southern part of the Island. There is no single authority representing both Turkish and Greek Cypriot people on the Island. Turkey recognises the Turkish Republic of Northern Cyprus (TRNC). Until a lasting and equitable solution is found within the context of the United Nations, Turkey shall preserve its position concerning the "Cyprus issue."

2. Note by all the European Union Member States of the OECD and the European Union: The Republic of Cyprus is recognised by all members of the United Nations with the exception of Turkey. The information in this document relates to the area under the effective control of the Government of the Republic of Cyprus.

Source: OECD based on the data described in the Technical Appendix.

In line with the previous analyses conducted in this report, several trade-related country characteristics are then used to assess the extent to which this observed correlation is independent of the influence of factors such as capital and skill intensity or the degree of

60. See the latest brochure on OECD Work on Water available at: www.oecd.org/env/resources/OECD-Work-on-Water-Brochure.pdf.

61. Water-related products include all CLEG products classified under the medium "WAT", i.e. wastewater management and potable-water treatment (see Annex 1 and Table 1). 
export diversification. Table A.8 in the Technical Appendix reports the resulting estimates, which indicate that wastewater treatment as measured using the TRT indicator has indeed a correlation of its own with relative exports of water-related equipment. This relationship is robust across specifications, including the use of lags, and statistically significant despite a smaller sample size. In addition, the magnitude of the estimated coefficient for the TRT indicator roughly matches that for export diversification, meaning in this case that a $10 \%$ increase in the TRT indicator is associated with an increase of about 4-5\% in the RCA for water-related products. Note that this shows a correlation though, and not a direct causal mechanism. It is, nevertheless, possible to conclude from this analysis that more stringent regulations in the wastewater-treatment sector do correspond to higher relative exports of environmental goods related to the supply of water and sanitation.

\section{Conclusions}

Markets for environmental goods and services are essentially regulation-led in the sense that demand for EGS would likely be much smaller absent environmental regulations. The degree of stringency that characterises environmental regulations is thus a major driver of market size, with potentially large effects on trade flows of environmental products. The conceptual discussion in this report has suggested that a larger home market increases exports more than imports in cases where goods are differentiated. Provided they do not impose an excessive and disproportionate burden on polluters, it is therefore plausible that stringent environmental regulations increase exports of environmental goods through the effect these regulations have on domestic market size.

The analysis in this report has found empirical support for the argument that countries having stringent environmental regulations tend to be relatively larger exporters of environmental products. Using an index of revealed comparative advantage to measure countries' specialisation in environmental goods, the results indicate that regulatory stringency is indeed positively and significantly associated with higher exports of environmental products, even after controlling for the influence that country characteristics such as factor endowments and export diversification have on countries' exports. The findings are generally consistent across the three different measures of stringency used in this report, namely: (i) a composite index of the stringency of environmental policy instruments (the EPS index) that focusses largely on the power sector; (ii) the share of municipal solid waste that is landfilled in the case of trade in waste-management-related products; and (iii) the level of treatment of urban wastewater in the case of water-supply- and sanitation-related products.

The consistency of the findings across indicators and sectors suggests that environmental regulations play an important role in shaping patterns of trade in environmental goods that is distinct from more traditional trade forces, such as factor endowments and trade barriers. Better understanding this role could help policy makers in their efforts to promote trade in environmental goods and services. Efforts have until now aimed to reduce import tariffs or focussed on non-tariff barriers for a number of environmental products. The removal of barriers to trade in environmental goods forms, however, but one of the drivers behind a greater diffusion of environmental technologies, so that the liberalisation of trade needs to be considered alongside the level of ambition of environmental regulations. By increasing demand for environmental products and technologies, environmental policy can thus complement trade policy in helping spread environmental goods more widely and support pollution-reduction efforts worldwide. While increased trade in environmental products is not an end in itself, the environmental benefits this entails can, however, contribute to global improvements in environmental quality. The unbundling of value chains on a global scale could provide additional impetus to that movement by making it easier for developing countries to address their environmental externalities while also taking an active part in global EGS production networks, as the example of Chile shows (Box 2). In that respect, some of the 
results presented in the report do suggest that a lowering of a country's import tariffs serves to increase not only imports but also exports of environmental products.

More broadly, the positive impacts that the stringency of environmental regulations can have on trade in environmental products reveal areas of compatibility between trade and environmental policy objectives. Attention has, until now, largely focussed on issues where environmental goals either impede trade liberalisation (e.g. environmental policy measures as trade barriers) or hurt competitiveness. Emphasising the potential for market creation of welldesigned environmental regulations may therefore serve to cast a more positive light on the trade and environment debate by highlighting areas of common interest. Further consideration of the trade opportunities that can arise from the adoption of environmental regulations domestically could help counter-balance traditional concerns about the impacts these regulations have on pollution-intensive sectors. The findings also echo the conclusions from related OECD work on environmental policies and productivity growth (OECD, 2014a), which found that stringent environmental policies do not generally have detrimental effects on productivity, thereby providing additional evidence that stringent environmental regulations may not be as economically harmful as often assumed.

The empirical analysis in this report has essentially looked at environmental goods, focussing in the last two sub-sections on the particular cases of the management of municipal solid waste and the treatment of wastewater. Services play, however, a central and coordinating role since they form the basis on which rests most environmental projects, starting with permitting and design up to remediation activities. Lack of data has so far hampered work looking at trade in services relevant to the environment, and future work by the OECD or others should therefore seek to lay the groundwork for such analysis by collecting information on those particular firms that provide these services internationally. 


\section{References}

Adlung, Rudolf (2009), GATS' commitments on environmental services: 'hover through the fog and filthy air'?, chapter 13 in Thomas Cottier, Olga Nartova and Sadeq Z. Bigdeli (eds.) (2009), International Trade Regulation and the Mitigation of Climate Change: World Trade Forum, Cambridge University Press, Cambridge.

Anderson, John W. (2012), Experience and the Evolution of Wind Power Project Costs in the United States, mimeo.

APEC (2012), ANNEX C - APEC List of Environmental Goods, 2012 Leaders' Declaration, AsiaPacific Economic Cooperation, Vladivostok, Russia, 8-9 September 2012, available at: www.apec.org/Meeting-Papers/Leaders-

Declarations/2012/2012_aelm/2012_aelm_annexC.aspx.

Arcadis (2010), Leadership, Balance, Growth - Annual Report 2010, Arcadis NV, Amsterdam, available at:

www.arcadis.com/Content/ArcadisGlobal/docs/publications/AnnualReport2010.pdf.

Arrow, Kenneth J. (1962), "The Economic Implications of Learning by Doing”, The Review of Economic Studies, Vol. 29, No. 3, pp. 155-173.

Bahar, Heymi, Jagoda Egeland and Ronald Steenblik (2013), "Domestic Incentive Measures for Renewable Energy With Possible Trade Implications", OECD Trade and Environment Working Papers, 2013/01, OECD Publishing, Paris.

Berg, U., G. Knoll, E. Kaschka, P.G. Weidler and R. Nüesch (2007), "Is Phosphorus Recovery from Waste Water Feasible?", Environmental Technology, Vol. 28, No. 2, pp. 165-172.

Bommelaer, Olivier and Jérémy Devaux (2011), "Coûts des principales pollutions agricoles de l'eau", Études et documents, No.52, Service de l'économie, de l'évaluation et de l'intégration du développement durable, Commissariat Général au Développement Durable (CGDD), September 2011, Paris.

Braathen, Nils Axel (2012), Lessons in Environmental Policy Reform: The Swedish Tax on $N O_{x}$ Emissions, OECD, Paris.

Brandt, Urs S. and Gert T. Svendsen (2006), "Climate change negotiations and first-mover advantages: the case of the wind turbine industry", Energy Policy, Vol. 34, No.10, pp. 1175-1184.

Broner, Fernando, Paula Bustos and Vasco M. Carvalho (2012), "Sources of Comparative Advantage in Polluting Industries", NBER Working Paper Series, No. 18337, August 2012, National Bureau of Economic Research, Cambridge.

Brunel, Claire and Arik Levinson (2013), "Measuring Environmental Regulatory Stringency", OECD Trade and Environment Working Papers, 2013/05, OECD Publishing, Paris.

Canada Gazette (2012), Wastewater Systems Effluent Regulations, Fisheries Act, SOR/201213929 June 2012, Vol. 146, No. 15, 18 July 2012, available at: www.gazette.gc.ca/rppr/p2/2012/2012-07-18/html/sor-dors139-eng.html\#REF15 (accessed 14 April 2014).

Chor, Davin (2010), "Unpacking sources of comparative advantage: A quantitative approach", Journal of International Economics, Vol. 82, No. 2, pp. 152-167. 
Cole, Matthew A. and Robert J. Elliott (2003), "Do Environmental Regulations Influence Trade Patterns? Testing Old and New Trade Theories", The World Economy, Vol. 26, No, 8, pp 1163-1186.

Condon, Madison and Ada Ignaciuk (2013), "Border Carbon Adjustment and International Trade", OECD Trade and Environment Working Papers, 2013/06, OECD Publishing, Paris.

Costantini, Valeria and Massimiliano Mazzanti (2012), "On the green and innovative side of trade competitiveness? The impact of environmental policies and innovation on EU exports", Research Policy, Vol. 41, No. 1, pp. 132-153.

CPCB (2009), Status of Water Supply, Wastewater Generation and Treatment in Class-I Cities \& Class-II Towns of India, Control of Urban Pollution Series (CUPS/70/2009 - 10), Central Pollution Control Board, Ministry of Environment and Forests, Government of India, Delhi.

Danish Environmental Economic Council (2014), Summary of Latest Report Economy and Environment, Danish Economic Councils, available at: www.dors.dk/sw3018.asp (accessed 17 April 2014).

Duflo, Esther, Michael Greenstone, Rohini Pande and Nicholas Ryan (2013), "Truth-telling by Third-party Auditors and the Response of Polluting Firms: Experimental Evidence from India", NBER Working Paper Series, No. 19259, July 2013, National Bureau of Economic Research, Cambridge.

Ecorys (2009), Study on the Competitiveness of the EU eco-industry, Final Report - Part 1 , Report prepared for the European Commission's Directorate-General for Enterprise and Industry, 22 October 2009, Brussels.

Ek, Kristina and Patrik Söderholm (2010), "Technology learning in the presence of public R\&D: The case of European wind power", Ecological Economics, Vol. 69, No. 12, pp. 23562362.

Elofsson, Katarina (2010), "The Costs of Meeting the Environmental Objectives for the Baltic Sea: A Review of the Literature", Ambio, Vol. 39, No. 1, pp. 49-58.

European Commission (2010), Compliance Costs of the Urban Wastewater Treatment Directive, Final report, Directorate-General for the Environment, September 2010, Brussels.

European Commission (2013a), Summary of Directive 2008/1/EC concerning integrated pollution prevention and control (the IPPC Directive), Directorate-General for the Environment,

available at: http://ec.europa.eu/environment/air/pollutants/stationary/ippc/summary. htm (accessed 9 September 2013).

European Commission (2013b), Seventh Report on the Implementation of the Urban Waste Water Treatment Directive (91/271/EEC), Report from the Commission to the European Parliament, the Council, the European Economic and Social Committee and the Committee of the Regions, COM(2013) 574 final, 7 August 2013, Brussels.

EEA (2005), Effectiveness of urban wastewater treatment policies in selected countries: an EEA pilot study, European Environment Agency, EEA Report No. 2/2005, Copenhagen.

Feenstra, Robert C. (2004), Advanced International Trade: Theory and Evidence, Princeton University Press, Princeton, NJ.

Feenstra, Robert C., James R. Markusen and Andrew K. Rose (2001), "Using the gravity equation to differentiate among alternative theories of trade", Canadian Journal of Economics/Revue canadienne d'économie, Vol. 34, No. 2, pp. 430-447. 
Giesen, A. (1999), "Crystallisation Process Enables Environmental Friendly Phosphate Removal at Low Costs", Environmental Technology, Vol. 20, No. 7, pp. 769-775.

Gren, Ing-Marie, Katarina Elofsson and Paul Jannke (1997), "Cost-Effective Nutrient Reductions to the Baltic Sea", Environmental and Resource Economics, Vol. 10, No.4, pp. 341-362.

Grossman, Gene M. and Elhanan Helpman (1995), Technology and Trade, chapter 25 in Gene M. Grossman and Kenneth Rogoff (eds.) (1995), Handbook of International Economics - Volume 3, Elsevier.

Hanson, Gordon H. and Chong Xiang (2004), "The Home-Market Effect and Bilateral Trade Patterns”, The American Economic Review, Vol. 94, No. 4, pp. 1108-1129.

Hoornweg, Daniel and Perinaz Bhada-Tata (2012), What a Waste: A Global Review of Solid Waste Management, Urban Development Series, Knowledge Paper No. 15, March 2012, The World Bank, Washington, D.C.

IPE (2011), China drafts rules on urban drainage, sewage treatment, Institute of Public \& Environmental Affairs, Beijing, 6 December 2011, available at: www.ipe.org.cn/En/pollution/news_detail.aspx?id=10554 (accessed 24 April 2014).

Kamp, Linda M. (2007), "The Importance of Learning Processes in Wind Power Development", European Environment, Vol. 17, No. 5, pp. 334-346.

Koźluk, Tomasz and Vera Zipperer (2013), "Environmental Policies and Productivity Growth: A Critical Review of Empirical Findings", OECD Economics Department Working Papers, No. 1096, OECD Publishing, Paris.

Krugman, Paul (1980), "Scale Economies, Product Differentiation, and the Pattern of Trade", The American Economic Review, Vol. 70, No. 5, pp. 950-959.

NSW EPA (2013), Load-based licensing, NSW Environment Protection Authority, New South Wales Government, available at: www.epa.nsw.gov.au/licensing/lbl/lblicences.htm (accessed 6 September 2013).

OECD (1996), The Global Environmental Goods and Services Industry, OECD Publishing, Paris.

OECD (2001a), Environmental Goods and Services: The Benefits of Further Global Trade Liberalisation, OECD Publishing, Paris.

OECD (2001b), Extended Producer Responsibility: A Guidance Manual for Governments, OECD Publishing, Paris.

OECD (2005), OECD Environmental Performance Reviews - Chile, OECD Publishing, Paris.

OECD (2007a), Instrument Mixes for Environmental Policy, OECD Publishing, Paris.

OECD (2007b), Guidance Manual on Environmentally Sound Management of Waste, Guidance Manual for the Implementation of the OECD Recommendation C(2004)100 on Environmentally Sound Management (ESM) of Waste, OECD, Paris.

OECD (2008), Measuring Bilateral Trade in Services: A Note on the Data Collected and Estimated for the Services Trade Restrictiveness Index, OECD, Paris.

OECD (2009), Managing Water for All: An OECD Perspective on Pricing and Financing, OECD Studies on Water, OECD Publishing, Paris.

OECD (2010), Taxation, Innovation and the Environment, OECD Publishing, Paris.

OECD (2011a), Invention and Transfer of Environmental Technologies, OECD Studies on Environmental Innovation, OECD Publishing, Paris. 
OECD (2011b), Globalisation, Comparative Advantage and the Changing Dynamics of Trade, OECD Publishing, Paris.

OECD (2012), OECD Environmental Outlook to 2050, OECD Publishing, Paris.

OECD (2013a), OECD Economic Surveys: China 2013, OECD Publishing, Paris.

OECD (2013b), Greening Household Behaviour: Overview of 2011 Survey Data, OECD, Paris.

OECD (2013c), OECD's Work on Sustainable Materials \& Waste Management, OECD Policy Flyer, February 2013, available at: www.oecd.org/env/waste/OECD\%20Work\%20on\%20SMM_update\%2011-02-2013.pdf.

OECD (2014a), Do Environmental Policies Matter for Productivity Growth? Insights from new Cross-Country Measures of Environmental Policies, OECD, Paris.

OECD (2014b), Water Governance in the Netherlands: Fit for the Future?, OECD Studies on Water, OECD Publishing, Paris.

OECD/Eurostat (1999), The Environmental Goods and Services Industry: Manual for Data Collection and Analysis, OECD Publishing, Paris.

Productivity Commission (2006), Waste Management, Productivity Commission Inquiry Report No. 38, 20 October 2006, Australian Government, Canberra.

Ragoussis, Alexandros and Éric Gonnard (forthcoming), "The OECD-ORBIS database: Treatment and benchmarking procedures", OECD Statistics Working Papers, OECD Publishing, Paris.

Revesz, Richard L. and Robert N. Stavins (2007), Environmental Law, chapter 8 in A.M. Polinsky and S. Shavell (eds.) (2007), Handbook of Law and Economics - Volume 1, Elsevier.

SISS (2012), Informe anual de coberturas urbanas de servicios sanitários - 2012, Superintendencia de Servicios Sanitarios, Gobierno de Chile, available at: www.siss.gob.cl/577/articles-9886_recurso_1.pdf.

Steenblik, Ronald (2005), “Liberalising Trade in 'Environmental Goods': Some Practical Considerations", OECD Trade and Environment Working Papers, 2005/05, OECD Publishing, Paris.

Steenblik, Ronald and Massimo Geloso Grosso (2011), "Trade in Services Related to Climate Change: An Exploratory Analysis", OECD Trade and Environment Working Papers, 2011/03, OECD Publishing, Paris.

The Economist (2014), "Environmental accountability: Transparency in the haze", 8 February 2014, available at: www.economist.com/node/21595927.

Tietenberg, Thomas H. (1990), "Economic Instruments for Environmental Regulation", Oxford Review of Economic Policy, Vol. 6, No. 1, pp. 17-33.

United Nations, Eurostat, IMF, OECD, UNCTAD, UNWTO and WTO (2011), Manual on Statistics of International Trade in Services 2010, United Nations Publications, New York.

USAID (2011), Chile Environmental Industry 2011 - Case Study, report by Environmental Business International, Inc. and Nathan Associates Inc. for the United States Agency for International Development on behalf of the Asia-Pacific Economic Cooperation (APEC) forum, October 2011.

US EPA (2013), EPA Fact Sheet: Reducing Carbon Pollution From Power Plants, U.S. Environmental Protection Agency, 20 September 2013, Washington, D.C. 
US EPA (2014), EPA Proposes First Guidelines to Cut Carbon Pollution from Existing Power Plants/Clean Power Plan is flexible proposal to ensure a healthier environment, spur innovation and strengthen the economy, Press release, U.S. Environmental Protection Agency, 2 June 2014, Washington, D.C.

USITC (1996), Global Competitiveness of U.S. Environmental Technology Industries: Air Pollution Prevention and Control, Investigation No.332-361, Publication 2974, U.S. International Trade Commission, June 1996, Washington, D.C.

USITC (2013), Environmental and Related Services, Investigation No.332-533, Publication 4389, U.S. International Trade Commission, March 2013, Washington, D.C.

Van Soest, Daan P., John A. List and Tim Jeppesen (2006), "Shadow prices, environmental stringency, and international competitiveness", European Economic Review, Vol. 50, No. 5, pp. 1151-1167.

WHO (2011), Guidelines for Drinking-water Quality - Fourth Edition, World Health Organization, Geneva.

WHO (2014), Ambient (outdoor) air quality and health, Fact sheet No. 313, World Health Organization, Geneva, March 2014, available at: www.who.int/mediacentre/factsheets/fs313/en/ (accessed 11 April 2014).

Wiener, Jonathan B. (1999), “Global Environmental Regulation: Instrument Choice in Legal Context", The Yale Law Journal, Vol. 108, pp. 677-800.

Woods, N.C., S.M. Sock and G.T. Daigger (1999), "Phosphorus Recovery Technology Modeling and Feasibility Evaluation for Municipal Wastewater Treatment Plants", Environmental Technology, Vol. 20, No. 7, pp. 663-679.

World Bank (2012), Turn Down the Heat - Why a 4º C Warmer World Must be Avoided, A Report for the World Bank by the Potsdam Institute for Climate Impact Research and Climate Analytics, November 2012, The World Bank Group, Washington, D.C.

WTO (2009), Communication under paragraph 31 (III) of the Doha Ministerial Declaration, JOB(09)/132, Committee on Trade and Environment Special Session, World Trade Organization, 9 October 2009, Geneva.

WTO (2013), International Trade Statistics 2013, World Trade Organization, Geneva.

York, Richard (2012), "Asymmetric effects of economic growth and decline on $\mathrm{CO}_{2}$ emissions", Nature Climate Change, Vol. 2, pp. 762-764. 


\section{Annex 1. \\ The Combined List of Environmental Goods (CLEG) used by the OECD}

In the absence of an international consensus on the goods that should be considered environmental, and because negotiated lists may exclude some goods usually deemed environmental but not retained in the context of trade negotiations, the OECD has combined three existing lists (i.e. the Friends' list [WTO, 2009], the APEC list [APEC, 2012], and a modified version of the PEGS list ${ }^{62}$ ) to arrive at a customised set of 248 products. This set of products - named the "CLEG" (Combined List of Environmental Goods) - uses the HS 2007 classification at the six-digit level and further divides goods according to their environmental theme or medium (see Table A.1 below).

In addition, the OECD has reassessed the likely environmental content of each of the CLEG's HS lines against proprietary data from Environmental Business International Inc. (EBI) on the size of the global market for various environmental pieces of equipment. This exercise made it possible to ascertain which HS codes on the CLEG have a clear environmental content in terms of the value of the trade flows they measure. Results suggest that $11 \mathrm{HS}$ codes cover trade flows for which environmental products make up more than two thirds of all measured trade (the Core CLEG of 11 products). This number increases to $40 \mathrm{HS}$ codes where environmental products account for more than a third of all measured trade (the Core CLEG+ of 40 products). It should be stressed, however, that those two narrower lists are for analytical purposes only as they are simply meant to complement the main results obtained using the CLEG (as explained in more detail in the main body of the report). As such, they should be considered independent of trade negotiations related to EGS, especially given their very limited coverage of products having environmental applications.

62. The original PEGS list includes a number of six-digit HS codes for general cars and other road vehicles since these HS lines also include most hybrid electric vehicles and plug-in hybrid electric vehicles. The CLEG excludes these HS lines and only considers HS 8702.90 and HS 8703.90, i.e. vehicles using fuels other than gasoline or diesel fuel. 
Table A.1. List of six-digit HS codes forming the CLEG

\begin{tabular}{|c|c|c|c|c|c|c|}
\hline HS line (HS 2007) & Medium & Friends & PEGS & APEC & Core CLEG & $\begin{array}{c}\text { Core } \\
\text { CLEG+ }\end{array}$ \\
\hline 380210 & WAT & & $x$ & & & $x$ \\
\hline 390940 & HEM & & $x$ & & & \\
\hline 392010 & SWM & $x$ & $x$ & & & \\
\hline 392030 & HEM & & $x$ & & & \\
\hline 392111 & HEM & & $x$ & & & \\
\hline 392113 & HEM & & $x$ & & & \\
\hline 392510 & REP & & $x$ & & & \\
\hline 400259 & SWM & & $x$ & & & \\
\hline 441872 & EPP & & & $x$ & & \\
\hline 450410 & NVA & $x$ & $x$ & & & \\
\hline 450490 & HEM & & $x$ & & & \\
\hline 530310 & EPP & $x$ & & & & \\
\hline 530500 & EPP & $x$ & & & & \\
\hline 540500 & HEM & & $x$ & & & \\
\hline 560314 & WAT & $x$ & $x$ & & & \\
\hline 560721 & EPP & $x$ & & & & \\
\hline 560790 & EPP & $x$ & & & & \\
\hline 560811 & NRP & $x$ & & & & \\
\hline 560890 & NRP & $x$ & & & & \\
\hline 630510 & EPP & $x$ & & & & \\
\hline 680610 & HEM & & $x$ & & & \\
\hline 680690 & HEM & & $x$ & & & \\
\hline 680800 & HEM & & $x$ & & & \\
\hline 681011 & HEM & & $x$ & & & \\
\hline 681019 & HEM & & $x$ & & & \\
\hline 681091 & HEM & & $x$ & & & \\
\hline 691010 & WAT & $x$ & & & & \\
\hline 700800 & HEM & & $x$ & & & \\
\hline 700991 & REP & & $x$ & & & \\
\hline 700992 & REP & & $x$ & & & \\
\hline 701931 & HEM & $x$ & $x$ & & & \\
\hline 701939 & HEM & & $x$ & & & \\
\hline 730210 & CRE & & $x$ & & & \\
\hline 730230 & CRE & & $x$ & & & \\
\hline 730240 & CRE & & $x$ & & & \\
\hline 730290 & CRE & & $x$ & & & \\
\hline 730300 & WAT & $x$ & & & & $x$ \\
\hline 730431 & WAT & $x$ & & & & $x$ \\
\hline 730490 & WAT & $x$ & & & & $x$ \\
\hline 730630 & WAT & $x$ & & & & $x$ \\
\hline 730690 & WAT & $x$ & & & & $x$ \\
\hline 730820 & REP & $x$ & $x$ & & & \\
\hline
\end{tabular}




\begin{tabular}{|c|c|c|c|c|c|c|}
\hline HS line (HS 2007) & Medium & Friends & PEGS & APEC & Core CLEG & $\begin{array}{l}\text { Core } \\
\text { CLEG+ }\end{array}$ \\
\hline 730890 & REP & & $x$ & & & \\
\hline 730900 & WAT & $x$ & & & & $x$ \\
\hline 731010 & WAT & $x$ & & & & $x$ \\
\hline 731029 & WAT & $x$ & & & & $x$ \\
\hline 732111 & CRE & $x$ & $x$ & & & \\
\hline 732119 & REP & & $x$ & & & \\
\hline 732189 & REP & & $x$ & & & \\
\hline 732190 & CRE & $x$ & $x$ & & & \\
\hline 732490 & WAT & $x$ & & & & $x$ \\
\hline 732510 & WAT & $x$ & & & & \\
\hline 732690 & WAT & $x$ & & & & \\
\hline 761090 & REP & & $x$ & & & \\
\hline 761100 & REP & $x$ & $x$ & & & \\
\hline 761290 & SWM & $x$ & & & & $x$ \\
\hline 830630 & REP & & $x$ & & & \\
\hline 840219 & SWM & $x$ & & & & \\
\hline 840290 & SWM & $x$ & & $x$ & & \\
\hline 840410 & APC & $x$ & & $x$ & & X \\
\hline 840420 & APC & $x$ & & $x$ & & $x$ \\
\hline 840490 & APC & $x$ & & $x$ & & \\
\hline 840510 & APC & $x$ & 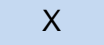 & & & X \\
\hline 840681 & REP & $x$ & $x$ & & & \\
\hline 840682 & REP & $x$ & $x$ & & & \\
\hline 840690 & REP & $x$ & $x$ & $x$ & & \\
\hline 840991 & NVA & $x$ & $x$ & & & \\
\hline 840999 & NVA & $x$ & $x$ & & & \\
\hline 841011 & REP & $x$ & $x$ & & & \\
\hline 841012 & REP & & $x$ & & & \\
\hline 841013 & REP & & $x$ & & & \\
\hline 841090 & REP & $x$ & $x$ & & & \\
\hline 841181 & REP & $x$ & $x$ & & & \\
\hline 841182 & REP & $x$ & $x$ & $x$ & & \\
\hline 841199 & REP & & & $x$ & & \\
\hline 841280 & REP & & $x$ & & & \\
\hline 841290 & REP & & $x$ & $x$ & & \\
\hline 841320 & WAT & $x$ & & & & \\
\hline 841350 & WAT & $x$ & & & & \\
\hline 841360 & WAT & $x$ & & & & \\
\hline 841370 & WAT & $x$ & & & & \\
\hline 841381 & WAT & $x$ & $x$ & & & \\
\hline 841410 & APC & $x$ & & & & $x$ \\
\hline 841430 & APC & $x$ & & & & \\
\hline 841440 & APC & $x$ & & & & \\
\hline
\end{tabular}




\begin{tabular}{|c|c|c|c|c|c|c|}
\hline HS line (HS 2007) & Medium & Friends & PEGS & APEC & Core CLEG & $\begin{array}{c}\text { Core } \\
\text { CLEG+ }\end{array}$ \\
\hline 841459 & APC & $x$ & & & & \\
\hline 841480 & APC & $x$ & & & & \\
\hline 841490 & APC & $x$ & & & & \\
\hline 841581 & REP & $x$ & $x$ & & & \\
\hline 841780 & SWM & $x$ & & $x$ & $x$ & $x$ \\
\hline 841790 & SWM & $x$ & & $x$ & $x$ & $x$ \\
\hline 841861 & REP & $x$ & $x$ & & & \\
\hline 841869 & REP & $x$ & $x$ & & & \\
\hline 841919 & REP & $x$ & $x$ & $x$ & & \\
\hline 841939 & WAT & $x$ & & $x$ & & \\
\hline 841940 & SWM & $x$ & & & & \\
\hline 841950 & HEM & $x$ & $x$ & & & \\
\hline 841960 & APC & $x$ & & $x$ & & \\
\hline 841989 & WAT & $x$ & $x$ & $x$ & & $x$ \\
\hline 841990 & REP & $x$ & $x$ & $x$ & & \\
\hline 842119 & SWR & $x$ & & & & \\
\hline 842121 & WAT & $x$ & & $x$ & $x$ & $x$ \\
\hline 842129 & WAT & $x$ & & $x$ & $x$ & $x$ \\
\hline 842139 & APC & $x$ & $x$ & $x$ & $x$ & $x$ \\
\hline 842191 & SWR & $x$ & & & & \\
\hline 842199 & WAT & $x$ & & $x$ & $x$ & $x$ \\
\hline 842220 & SWM & $x$ & & & & \\
\hline 842290 & SWM & $x$ & & & & \\
\hline 842833 & SWM & $x$ & & & & $x$ \\
\hline 842940 & SWM & $x$ & & & & \\
\hline 846291 & SWM & $x$ & & & & $x$ \\
\hline 846596 & SWM & $x$ & & & & \\
\hline 846599 & SWM & $x$ & & & & \\
\hline 846694 & SWM & $x$ & & & & \\
\hline 847420 & SWM & $x$ & & $x$ & & \\
\hline 847982 & SWM & $x$ & & $x$ & & $x$ \\
\hline 847989 & SWM & $x$ & $x$ & $x$ & & \\
\hline 847990 & SWM & $x$ & & $x$ & & \\
\hline 848110 & WAT & $x$ & & & & $x$ \\
\hline 848130 & WAT & $x$ & & & & $x$ \\
\hline 848140 & WAT & $x$ & & & & $x$ \\
\hline 848180 & WAT & $x$ & & & & \\
\hline 848190 & WAT & $x$ & & & & \\
\hline 848340 & REP & $x$ & $x$ & & & \\
\hline 848360 & REP & $x$ & $x$ & & & \\
\hline 850161 & REP & $x$ & $x$ & & & \\
\hline 850162 & REP & $x$ & $x$ & & & \\
\hline 850163 & REP & $x$ & $x$ & & & \\
\hline 850164 & REP & $x$ & $x$ & $x$ & & \\
\hline
\end{tabular}




\begin{tabular}{|c|c|c|c|c|c|c|}
\hline HS line (HS 2007) & Medium & Friends & PEGS & APEC & Core CLEG & $\begin{array}{c}\text { Core } \\
\text { CLEG+ }\end{array}$ \\
\hline 850220 & HEM & & $x$ & & & \\
\hline 850231 & REP & $x$ & 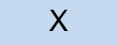 & $X$ & & \\
\hline 850239 & REP & $x$ & $x$ & $x$ & & \\
\hline 850300 & REP & $x$ & 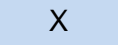 & $X$ & & \\
\hline 850421 & REP & & $x$ & & & \\
\hline 850422 & REP & & $x$ & & & \\
\hline 850423 & REP & & $x$ & & & \\
\hline 850431 & REP & & $x$ & & & \\
\hline 850432 & REP & & $\mathrm{X}$ & & & \\
\hline 850433 & REP & & $x$ & & & \\
\hline 850434 & REP & & $X$ & & & \\
\hline 850440 & REP & $x$ & $x$ & & & \\
\hline 850490 & REP & & & $\mathrm{X}$ & & \\
\hline 850590 & SWM & $x$ & & & & X \\
\hline 850680 & CRE & $\mathrm{x}$ & $\mathrm{x}$ & & & \\
\hline 850720 & REP & $x$ & $x$ & & & \\
\hline 850980 & CRE & $X$ & & & & \\
\hline 851410 & SWM & $x$ & & $x$ & & \\
\hline 851420 & SWM & $\mathrm{x}$ & & $x$ & & \\
\hline 851430 & SWM & $x$ & & $x$ & & \\
\hline 851490 & SWM & $\mathrm{x}$ & & $\mathrm{x}$ & & \\
\hline 851629 & SWR & $x$ & & & & \\
\hline 853010 & CRE & & $X$ & & & \\
\hline 853080 & CRE & & $x$ & & & \\
\hline 853090 & CRE & & $x$ & & & \\
\hline 853710 & REP & $x$ & $x$ & & & \\
\hline 853720 & REP & & $X$ & & & \\
\hline 853921 & HEM & & $x$ & & & \\
\hline 853931 & HEM & & $X$ & & & \\
\hline 853932 & HEM & & $x$ & & & \\
\hline 854140 & REP & $x$ & $x$ & X & & \\
\hline 854370 & WAT & $x$ & & & & \\
\hline 854390 & WAT & $x$ & & $x$ & & \\
\hline 860110 & CRE & & $x$ & & & \\
\hline 860120 & CRE & & $X$ & & & \\
\hline 860210 & CRE & & $x$ & & & \\
\hline 860290 & CRE & & $\mathrm{x}$ & & & \\
\hline 860310 & CRE & & $x$ & & & \\
\hline 860390 & CRE & & $\mathrm{x}$ & & & \\
\hline 860400 & CRE & & $x$ & & & \\
\hline 860500 & CRE & & $\mathrm{x}$ & & & \\
\hline 860610 & CRE & & $x$ & & & \\
\hline 860630 & CRE & & $\mathrm{x}$ & & & \\
\hline 860691 & CRE & & $x$ & & & \\
\hline
\end{tabular}




\begin{tabular}{|c|c|c|c|c|c|c|}
\hline HS line (HS 2007) & Medium & Friends & PEGS & APEC & Core CLEG & $\begin{array}{c}\text { Core } \\
\text { CLEG+ }\end{array}$ \\
\hline 860692 & CRE & & X & & & \\
\hline 860699 & CRE & & $x$ & & & \\
\hline 860711 & CRE & & $x$ & & & \\
\hline 860712 & CRE & & $x$ & & & \\
\hline 860719 & CRE & & $x$ & & & \\
\hline 860721 & CRE & & $x$ & & & \\
\hline 860729 & CRE & & $\mathrm{x}$ & & & \\
\hline 860730 & CRE & & $x$ & & & \\
\hline 860791 & CRE & & $x$ & & & \\
\hline 860799 & CRE & & $x$ & & & \\
\hline 860800 & CRE & & $x$ & & & \\
\hline 870290 & CRE & & $x$ & & & \\
\hline 870390 & CRE & & $\mathrm{x}$ & & & \\
\hline 871200 & CRE & & $x$ & & & \\
\hline 871411 & CRE & & $x$ & & & \\
\hline 871419 & CRE & & $x$ & & & \\
\hline 871420 & CRE & & $x$ & & & \\
\hline 871491 & CRE & & $x$ & & & \\
\hline 871492 & CRE & & $x$ & & & \\
\hline 871493 & CRE & & $x$ & & & \\
\hline 871494 & CRE & & $x$ & & & \\
\hline 871495 & CRE & & $x$ & & & \\
\hline 871496 & CRE & & $x$ & & & \\
\hline 871499 & CRE & & $x$ & & & \\
\hline 871639 & CRE & & $x$ & & & \\
\hline 890790 & SWR & $x$ & & & & \\
\hline 900190 & REP & $x$ & $x$ & & & \\
\hline 900290 & REP & $x$ & $x$ & & & \\
\hline 900580 & MON & & $x$ & & & \\
\hline 901380 & REP & & & $x$ & & \\
\hline 901390 & REP & & & $x$ & & \\
\hline 901530 & MON & $\mathrm{x}$ & $x$ & & & \\
\hline 901540 & MON & $x$ & & & & $x$ \\
\hline 901580 & MON & $x$ & & $x$ & & $x$ \\
\hline 901590 & MON & $x$ & $x$ & & & \\
\hline 902511 & MON & & $x$ & & & \\
\hline 902519 & MON & & $x$ & & & \\
\hline 902610 & MON & $x$ & $x$ & $x$ & & 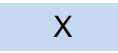 \\
\hline 902620 & MON & $x$ & $x$ & $x$ & & \\
\hline 902680 & MON & $x$ & $x$ & $x$ & & $x$ \\
\hline 902690 & MON & $x$ & $x$ & $x$ & & \\
\hline 902710 & MON & $x$ & $x$ & $x$ & $x$ & $x$ \\
\hline 902720 & MON & $x$ & $x$ & $x$ & $x$ & $x$ \\
\hline 902730 & MON & $x$ & $x$ & $x$ & $x$ & $x$ \\
\hline
\end{tabular}




\begin{tabular}{|c|c|c|c|c|c|c|}
\hline HS line (HS 2007) & Medium & Friends & PEGS & APEC & Core CLEG & $\begin{array}{c}\text { Core } \\
\text { CLEG+ }\end{array}$ \\
\hline 902750 & MON & $x$ & $x$ & $x$ & $x$ & $x$ \\
\hline 902780 & MON & $x$ & $x$ & $x$ & $x$ & $x$ \\
\hline 902790 & MON & $x$ & $x$ & $x$ & & \\
\hline 902810 & MON & $x$ & & & & $x$ \\
\hline 902820 & MON & $x$ & & & & $x$ \\
\hline 902830 & HEM & $x$ & $x$ & & & \\
\hline 902890 & HEM & $x$ & & & & \\
\hline 903010 & MON & $x$ & $x$ & & & \\
\hline 903020 & MON & $x$ & $x$ & & & \\
\hline 903031 & MON & $x$ & $x$ & & & \\
\hline 903032 & MON & $x$ & $x$ & & & \\
\hline 903033 & MON & $x$ & $x$ & & & \\
\hline 903039 & MON & $x$ & $x$ & & & \\
\hline 903084 & MON & $x$ & $x$ & & & \\
\hline 903089 & MON & $x$ & $x$ & & & \\
\hline 903090 & MON & $x$ & $x$ & & & \\
\hline 903110 & NVA & $x$ & & & & \\
\hline 903120 & MON & $x$ & $x$ & & & \\
\hline 903149 & MON & $x$ & $x$ & $x$ & & \\
\hline 903180 & MON & $x$ & $x$ & $x$ & & \\
\hline 903190 & MON & $x$ & $x$ & $x$ & & \\
\hline 903210 & MON & $x$ & $x$ & & & \\
\hline 903220 & MON & $x$ & $x$ & & & \\
\hline 903281 & MON & $x$ & $x$ & & & \\
\hline 903289 & REP & $x$ & $x$ & $x$ & & \\
\hline 903290 & MON & $x$ & $x$ & $x$ & & \\
\hline 903300 & MON & $x$ & $x$ & $x$ & & \\
\hline 940510 & HEM & & $x$ & & & \\
\hline 940520 & HEM & & $x$ & & & \\
\hline 940540 & HEM & & $x$ & & & \\
\hline 950720 & NRP & $x$ & & & & \\
\hline
\end{tabular}

Note: $\mathrm{APC}=$ Air pollution control; $\mathrm{CRE}=$ Cleaner or more resource efficient technologies and products; EPP $=$ Environmentally preferable products based on end use or disposal characteristics; HEM = Heat and energy management; MON = Environmental monitoring, analysis and assessment equipment; NRP = Natural resources protection; NVA = Noise and vibration abatement; REP = Renewable energy plant; SWM = Management of solid and hazardous waste and recycling systems; SWR = Clean up or remediation of soil and water; WAT = Waste water management and potable water treatment. 
Annex 2.

Average import tariffs applied by a selection of countries on CLEG products by medium (2012)

\begin{tabular}{|c|c|c|c|c|c|}
\hline Country & APC & MON & REP & SWM & WAT \\
\hline ARG & 3.07 & 5.46 & 8.40 & 6.06 & 8.12 \\
\hline AUS* & 2.51 & 0.27 & 1.86 & 2.56 & 2.54 \\
\hline AUT & 0.20 & 0.45 & 0.40 & 0.54 & 0.42 \\
\hline BEL & 0.18 & 0.44 & 0.39 & 0.64 & 0.51 \\
\hline BRA & 10.38 & 10.53 & 12.78 & 12.11 & 11.53 \\
\hline CAN & 0.00 & 0.08 & 0.08 & 0.08 & 0.13 \\
\hline $\mathrm{CHE}^{*}$ & 0.00 & 0.00 & 0.00 & 0.00 & 0.00 \\
\hline $\mathrm{CHL}$ & 0.80 & 1.08 & 0.98 & 0.66 & 1.41 \\
\hline $\mathrm{CHN}^{*}$ & 5.61 & 3.56 & 5.98 & 2.10 & 5.06 \\
\hline CZE & 0.17 & 0.37 & 0.41 & 0.62 & 0.45 \\
\hline DEU & 0.24 & 0.51 & 0.42 & 0.59 & 0.53 \\
\hline DNK & 0.23 & 0.42 & 0.36 & 0.72 & 0.42 \\
\hline ESP & 0.26 & 0.46 & 0.46 & 0.68 & 0.50 \\
\hline EST & 0.26 & 0.42 & 0.30 & 0.75 & 0.41 \\
\hline FIN & 0.24 & 0.46 & 0.36 & 0.71 & 0.46 \\
\hline FRA & 0.26 & 0.49 & 0.47 & 0.65 & 0.51 \\
\hline GBR & 0.25 & 0.68 & 0.63 & 0.79 & 0.63 \\
\hline GRC & 0.21 & 0.41 & 0.13 & 0.63 & 0.45 \\
\hline HKG & 0.00 & 0.00 & 0.00 & 0.00 & 0.00 \\
\hline HUN & 0.19 & 0.41 & 0.61 & 0.65 & 0.48 \\
\hline $\mathrm{IDN}^{*}$ & 2.02 & 3.34 & 2.69 & 2.96 & 3.26 \\
\hline $\mathrm{IRL}$ & 0.27 & 0.64 & 0.57 & 0.92 & 0.60 \\
\hline ISL & 0.38 & 0.00 & 0.14 & 0.14 & 0.19 \\
\hline ISR & 0.22 & 0.27 & 0.80 & 0.53 & 1.61 \\
\hline ITA & 0.22 & 0.43 & 0.41 & 0.61 & 0.47 \\
\hline JPN & 0.00 & 0.00 & 0.03 & 0.24 & 0.05 \\
\hline LUX & 0.32 & 0.59 & 0.48 & 0.68 & 0.44 \\
\hline NLD & 0.23 & 0.51 & 0.56 & 0.68 & 0.56 \\
\hline NOR & 0.00 & 0.00 & 0.00 & 0.00 & 0.00 \\
\hline POL & 0.21 & 0.44 & 0.42 & 0.69 & 0.44 \\
\hline PRT & 0.23 & 0.46 & 0.53 & 0.70 & 0.45 \\
\hline RUS & 0.57 & 1.65 & 3.45 & 1.56 & 4.12 \\
\hline SGP & 0.00 & 0.00 & 0.00 & 0.00 & 0.00 \\
\hline SVK & 0.19 & 0.44 & 0.29 & 0.64 & 0.44 \\
\hline SVN & 0.12 & 0.40 & 0.33 & 0.52 & 0.40 \\
\hline SWE & 0.22 & 0.42 & 0.42 & 0.62 & 0.44 \\
\hline TUR $^{*}$ & 0.20 & 0.27 & 0.25 & 0.17 & 0.33 \\
\hline USA & 0.32 & 0.56 & 0.60 & 0.69 & 0.95 \\
\hline ZAF & 0.52 & 0.06 & 1.60 & 1.06 & 3.65 \\
\hline
\end{tabular}

Average effectively applied tariffs by environmental medium are calculated using trade weights. A "*" indicates 2011 data.

$\mathrm{APC}=$ Air pollution control; MON = Environmental monitoring, analysis and assessment equipment; REP = Renewable energy plant; SWM = Management of solid and hazardous waste and recycling systems; WAT = Waste water management and potable water treatment.

Source: OECD based on the TRAINS database and the UN Comtrade database. 
Annex 3.

Guidelines and binding concentration limits for selected pollutants, sectors, and OECD countries

\begin{tabular}{|c|c|c|c|c|c|c|c|c|c|}
\hline & \multicolumn{9}{|c|}{ Sector or pollution source } \\
\hline & \multicolumn{2}{|c|}{ Transport fuels } & \multicolumn{3}{|c|}{ Drinking water } & \multicolumn{2}{|c|}{ Waste incineration (air) } & \multicolumn{2}{|c|}{$\begin{array}{l}\text { Effluents from the ferrous- } \\
\text { metals sector }\end{array}$} \\
\hline & $\begin{array}{l}\text { Lead content } \\
\text { of gasoline }\end{array}$ & $\begin{array}{l}\text { Sulphur } \\
\text { content of } \\
\text { diesel fuel }\end{array}$ & Arsenic & Lead & Mercury & $\mathrm{NO}$ and $\mathrm{NO}_{2}$ & $\mathrm{SO}_{2}$ & Lead & Mercury \\
\hline Australia & $5 \mathrm{mg} / \mathrm{L}$ & $10 \mathrm{mg} / \mathrm{kg}$ & $0.01 \mathrm{mg} / \mathrm{L}$ & $0.01 \mathrm{mg} / \mathrm{L}$ & $0.001 \mathrm{mg} / \mathrm{L}$ & $350 \mathrm{mg} / \mathrm{m}^{3}(1)$ & $100 \mathrm{mg} / \mathrm{m}^{3}(1)$ & $1 \mathrm{mg} / \mathrm{L}(2)$ & $0.01 \mathrm{mg} / \mathrm{L} \mathrm{(2)}$ \\
\hline Canada & $5 \mathrm{mg} / \mathrm{L}$ & $15 \mathrm{mg} / \mathrm{kg}$ & $0.01 \mathrm{mg} / \mathrm{L}$ & $0.01 \mathrm{mg} / \mathrm{L}$ & $0.001 \mathrm{mg} / \mathrm{L}$ & $190 \mathrm{mg} / \mathrm{m}^{3}(3)$ & $50 \mathrm{mg} / \mathrm{m}^{3}(3)$ & $0.2 \mathrm{mg} / \mathrm{L}$ & $0.01 \mathrm{mg} / \mathrm{L}$ \\
\hline European Union & $5 \mathrm{mg} / \mathrm{L}$ & $10 \mathrm{mg} / \mathrm{kg}$ & $0.01 \mathrm{mg} / \mathrm{L}$ & $0.01 \mathrm{mg} / \mathrm{L}$ & $0.001 \mathrm{mg} / \mathrm{L}$ & $\begin{array}{c}200-400 \\
\mathrm{mg} / \mathrm{m}^{3}\end{array}$ & $50 \mathrm{mg} / \mathrm{m}^{3}$ & $0.5 \mathrm{mg} / \mathrm{L}$ & .. \\
\hline Japan & $0 \mathrm{mg} / \mathrm{L}$ & $10 \mathrm{mg} / \mathrm{kg}$ & $0.01 \mathrm{mg} / \mathrm{L}$ & $0.01 \mathrm{mg} / \mathrm{L}$ & $0.0005 \mathrm{mg} / \mathrm{L}$ & $\begin{array}{c}470-1316 \\
\mathrm{mg} / \mathrm{m}^{3}\end{array}$ &..$(4)$ & $0.1 \mathrm{mg} / \mathrm{L}$ & $0.005 \mathrm{mg} / \mathrm{L}$ \\
\hline New Zealand & $5 \mathrm{mg} / \mathrm{L}$ & $10 \mathrm{mg} / \mathrm{kg}$ & $0.01 \mathrm{mg} / \mathrm{L}$ & $0.01 \mathrm{mg} / \mathrm{L}$ & $0.007 \mathrm{mg} / \mathrm{L}$ & .. & .. & $10 \mathrm{mg} / \mathrm{L} \mathrm{(5)}$ & 0 mg/L (5) \\
\hline Norway & $5 \mathrm{mg} / \mathrm{L}$ & $50 \mathrm{mg} / \mathrm{kg}$ & $0.01 \mathrm{mg} / \mathrm{L}$ & $0.01 \mathrm{mg} / \mathrm{L}$ & $0.0005 \mathrm{mg} / \mathrm{L}$ & $\begin{array}{c}200-400 \\
\mathrm{mg} / \mathrm{m}^{3}\end{array}$ & $50 \mathrm{mg} / \mathrm{m}^{3}$ & $0.5 \mathrm{mg} / \mathrm{L}$ & .. \\
\hline Turkey & $5 \mathrm{mg} / \mathrm{L}$ & $10 \mathrm{mg} / \mathrm{kg}$ & $0.01 \mathrm{mg} / \mathrm{L}$ & $0.01 \mathrm{mg} / \mathrm{L}$ & $0.001 \mathrm{mg} / \mathrm{L}$ & $\begin{array}{c}200-400 \\
\mathrm{mg} / \mathrm{m}^{3}\end{array}$ & $50 \mathrm{mg} / \mathrm{m}^{3}$ & $0.5 \mathrm{mg} / \mathrm{L}$ & $0.05 \mathrm{mg} / \mathrm{L}$ \\
\hline United States & $13.2 \mathrm{mg} / \mathrm{L}$ & $15 \mathrm{mg} / \mathrm{kg}$ & $0.01 \mathrm{mg} / \mathrm{L}$ & $0.015 \mathrm{mg} / \mathrm{L}$ & $0.002 \mathrm{mg} / \mathrm{L}$ & $\begin{array}{c}263-470 \\
\mathrm{mg} / \mathrm{m}^{3}\end{array}$ & $11-144 \mathrm{mg} / \mathrm{m}^{3}$ & $0.69 \mathrm{mg} / \mathrm{L}$ & .. \\
\hline
\end{tabular}

Notes: ".." denotes missing data. (1) Northern Territory; (2) New South Wales; (3) British Columbia and Ontario; (4) Varies by region and height of smokestack; (5) Auckland Metropolitan Area.

This table is provided to illustrate the discussion above on actual environmental regulations in certain sectors. As such, it only intends to show the extent to which certain guidelines or binding concentration limits vary across selected OECD members. It does not rank countries or attempt to assess the stringency of their environmental regulations.

Sources: OECD based on a web search of countries' legislation. 


\section{Technical Appendix.}

\section{Data sources and detailed results}

\section{Trade data}

Data on bilateral trade in CLEG products were taken from the UN Comtrade database using the six-digit level of the 2007 version of the Harmonized System (HS 2007). Values are all expressed in current USD. To cover the years 2002 to 2012, the HS codes listed on the CLEG were converted from HS 2007 into HS 2002 by the OECD, taking into account the environmental relevance of the different HS lines where necessary.

As explained in the main body of the report, indicators of revealed comparative advantage (RCA) were calculated using the following formula:

$$
R C A_{i k}=100 \times\left(\left(X_{i k} / X_{w k}\right) /\left(X_{i .} / X_{w .}\right)\right)
$$

where $X_{i k}$ denotes country $i$ 's exports of product $k, X_{w k}$ denotes world exports of product $k$,

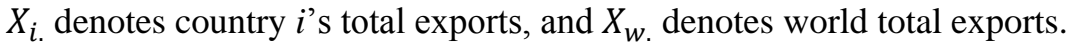

\section{Indicators of the stringency of environmental regulations}

The EPS index

The index of Environmental Policy Stringency (EPS) was constructed in the context of related OECD work on environmental policies and productivity growth (OECD, 2014a). It is a composite measure of the relative stringency of different regulatory instruments applying to a selection of pollutants, industries, and media, with the underlying assumption being that a stringent approach to the latter is indicative of "a general preoccupation with environmental issues across all domains" (ibid.: 13). For each instrument included in the composite EPS index, the information collected was normalised and scored on a 0-6 scale, and subsequently aggregated using equal weights to arrive at a single value for each country and year (see Figure 4). The resulting data are available for 26 OECD countries over most of the period 1990-2012, though the analysis in the present report only covers the years 2002 to 2012 due to data limitations on the trade side. More information on the construction and the coverage of the index can be found in Annex 2 of the cited report (OECD, 2014a).

\section{Waste indicator}

Estimates of the share of municipal solid waste landfilled in OECD and European countries come from OECD and Eurostat. Additional data points for selected emerging and developing countries were sourced from the Environmental Indicators of the United Nations' Statistics Division and from the World Bank (Hoornweg and Bhada-Tata, 2012). National sources were also used in the case of Brazil.

To balance the panel more and improve coverage, the OECD then estimated a few missing data points using a generalised linear model of the binomial family with a logit link, which forces predicted values for the dependent variable to take on values comprised between 0 and 1 (as is the case for the share of MSW landfilled). The explanatory variables used for 
this exercise were GDP per capita, GDP growth, population density, country dummies, and a time trend.

\section{Water indicator}

Estimates of the share of the population connected to wastewater systems using at least secondary treatment (the TRT indicator) were taken from OECD and Eurostat. Because the resulting data are not consistently available for every year - and given the linear trend observed in most OECD countries towards more advanced treatment of wastewater - certain missing values were linearly interpolated where possible. Care was then taken to verify that the data points thus obtained are plausible.

Data were not available from the OECD in the particular case of Australia. Instead, information at the utility level was obtained from the National Water Commission (www.nwc.gov.au) and combined with population statistics from the World Bank's WDI database to arrive at a set of annual country-wide estimates $\left(T R T_{A U S, t}\right)$. This was done using the following weighting formula:

$$
T R T_{A U S, t}=\sum_{u}\left(W T R_{u, t} \times \frac{p o p_{u, t}}{\sum_{u} p o p_{u, t}}\right) \times u r b_{A U S, t}
$$

where $W T R_{u, t}$ denotes the share of wastewater volume that undergoes at least secondary treatment by utility $u$ in year $t$; $p o p_{u, t}$ denotes the population served by utility $u$ in year $t$; and $u r b_{A U S, t}$ denotes the share of urban inhabitants in the total population of Australia in year $t$. This procedure yields annual estimates of the TRT indicator for Australia that are plausible and consistent with information for countries of comparable size and level of development.

\section{Control variables}

Data on the share of the population with at least secondary education were all taken from the World Bank's WDI database. The capital-labour ratio was obtained by combining estimates for each country's capital stock with readily available data on the size of the labour force (from the WDI database as well). Estimates of the capital stock were calculated by the OECD using the perpetual-inventory method. To that end, annual data on each country's gross fixed capital formation (in constant 2005 USD) were assembled from WDI. A 15-year expected service life was then assumed for fixed capital assets and implemented through a straight-line depreciation rule.

The degree of export diversification was measured using UNCTAD's concentration index for merchandise exports. This indicator is available by country and year, and measures the extent to which particular products account for a country's total merchandise exports. The formula used by UNCTAD to calculate the index follows that for a normalised HerfindahlHirschmann index taking values between 0 and 1 (with 1 corresponding to the maximum concentration, i.e. minimum diversification).

\section{Import tariffs}

Data on effectively applied import tariffs were obtained from the UNCTAD's TRAINS database for each country pair, year, and HS line listed on the CLEG. The data were complemented by adding zero values for intra-EU import tariffs, taking into account each EU member state's year of accession. 


\section{Econometric specification}

Econometric results were obtained using ordinary least squares (OLS) regressions with standard errors clustered by country. All specifications include year dummies and take the form:

$$
\ln R C A_{i, t}=\beta_{0}+\beta_{1} \ln S T R_{i, t}+\gamma \mathrm{X}+\delta_{t}+\varepsilon_{i, t}
$$

where $S T R_{i, t}$ denotes a particular measure of regulatory stringency characterising country $i$ in year $t$; X represents a set of control variables; $\delta_{t}$ denotes the year fixed effects; and $\varepsilon_{i, t}$ is the random-error term. Variants of this model are then used in different settings to estimate the relationship between the selected measures of stringency and revealed comparative advantage in environmental products.

In the particular case of the municipal-solid-waste sector, two outliers (Finland and Italy) were dropped from the estimation sample since the calculated values for their RCA-SWM index were implausibly high. The sensitivity of the results to that change is, however, small.

Pairwise correlation coefficients

\begin{tabular}{|c|c|c|c|c|c|c|c|c|}
\hline & EPS & Landfill & TRT & $\begin{array}{l}\text { GDP per } \\
\text { capita }\end{array}$ & $\begin{array}{l}\text { Export } \\
\text { conc. }\end{array}$ & $K / L$ & $\begin{array}{l}\text { 2ry edu. } \\
\text { ratio }\end{array}$ & Tariff \\
\hline EPS & 1 & & & & & & & \\
\hline Landfill & $-0.5379^{\star}$ & 1 & & & & & & \\
\hline TRT & $0.6088^{*}$ & $-0.6487^{*}$ & 1 & & & & & \\
\hline $\begin{array}{l}\text { GDP per } \\
\text { capita }\end{array}$ & $0.3039^{*}$ & $-0.7311^{*}$ & $0.5212^{*}$ & 1 & & & & \\
\hline $\begin{array}{l}\text { Export } \\
\text { conc. }\end{array}$ & -0.0613 & $0.1734^{*}$ & $-0.2807^{*}$ & $-0.2394^{*}$ & 1 & & & \\
\hline$K / L$ & $0.3959^{*}$ & $-0.7659^{\star}$ & $0.3943^{*}$ & $0.9118^{*}$ & $-0.2019^{*}$ & 1 & & \\
\hline $\begin{array}{l}2 \text { ry edu. } \\
\text { ratio }\end{array}$ & $0.3721^{*}$ & $-0.1792^{*}$ & $0.3719^{\star}$ & $0.3271^{*}$ & -0.0478 & $0.2661^{*}$ & 1 & \\
\hline Tariff & $-0.1504^{*}$ & $0.3664^{*}$ & -0.0553 & $-0.4942^{*}$ & $0.1837^{*}$ & $-0.4775^{\star}$ & $-0.2080^{\star}$ & 1 \\
\hline \multicolumn{9}{|c|}{ Note: "*” denotes statistical significance at the $5 \%$ level. } \\
\hline \multicolumn{9}{|c|}{ Summary statistics } \\
\hline Variable & \multicolumn{2}{|c|}{ Observations } & Mean & \multicolumn{2}{|r|}{ Std. Dev. } & \multicolumn{3}{|r|}{ Max } \\
\hline EPS & \multicolumn{2}{|r|}{273} & 2.518109 & \multicolumn{2}{|r|}{0.8923729} & \multicolumn{3}{|r|}{4.675} \\
\hline Landfill & \multicolumn{2}{|r|}{472} & 65.36482 & \multicolumn{2}{|r|}{34.307} & \multicolumn{3}{|r|}{100} \\
\hline TRT & \multicolumn{2}{|r|}{303} & 61.96976 & \multicolumn{2}{|r|}{28.21873} & \multicolumn{3}{|r|}{100} \\
\hline \multicolumn{2}{|l|}{ Export conc. } & 585 & 0.2104239 & \multicolumn{2}{|r|}{0.1579304} & 0.0515172 & \multicolumn{2}{|r|}{0.8959615} \\
\hline \multicolumn{2}{|l|}{$K / L$} & 1014 & 80416.13 & \multicolumn{2}{|r|}{94818.18} & 684.0853 & \multicolumn{2}{|r|}{556267.3} \\
\hline \multicolumn{2}{|l|}{ 2ry edu. ratio } & 633 & 67.62291 & \multicolumn{2}{|r|}{19.57387} & \multicolumn{3}{|r|}{97.1} \\
\hline \multicolumn{2}{|l|}{ Tariff } & 417 & 1.763525 & \multicolumn{2}{|r|}{2.894725} & \multicolumn{3}{|r|}{23.97746} \\
\hline
\end{tabular}


62 - THE STRINGENCY OF ENVIRONMENTAL REGULATIONS AND TRADE IN ENVIRONMENTAL GOODS

Table A.2. The EPS index and other determinants of RCA in CLEG products

\begin{tabular}{|c|c|c|c|c|c|}
\hline & $\begin{array}{l}\text { (1) RCA } \\
\text { All CLEG }\end{array}$ & $\begin{array}{l}\text { (2) RCA } \\
\text { All CLEG }\end{array}$ & $\begin{array}{l}\text { (3) RCA } \\
\text { All CLEG }\end{array}$ & $\begin{array}{l}\text { (4) RCA } \\
\text { All CLEG }\end{array}$ & $\begin{array}{l}\text { (5) RCA } \\
\text { All CLEG }\end{array}$ \\
\hline EPS index & $\begin{array}{c}0.664^{* * *} \\
(2.98)\end{array}$ & $\begin{array}{c}0.691^{\star * *} \\
(3.21)\end{array}$ & $\begin{array}{c}0.641^{* * *} \\
(3.08)\end{array}$ & & \\
\hline EPS index (3-year lag) & & & & $\begin{array}{c}0.606^{* * *} \\
(2.94)\end{array}$ & \\
\hline EPS index (5-year lag) & & & & & $\begin{array}{c}0.609^{* * *} \\
(2.93)\end{array}$ \\
\hline Export concentration index & $\begin{array}{c}-0.648^{* * *} \\
(-5.70)\end{array}$ & $\begin{array}{c}-0.629^{\star * *} \\
(-5.38)\end{array}$ & $\begin{array}{c}-0.637^{\star \star *} \\
(-5.34)\end{array}$ & $\begin{array}{c}-0.627^{* * *} \\
(-4.63)\end{array}$ & $\begin{array}{c}-0.660^{\star * *} \\
(-4.41)\end{array}$ \\
\hline Capital-labour ratio & & $\begin{array}{l}-0.110 \\
(-0.60)\end{array}$ & $\begin{array}{l}-0.161 \\
(-1.00)\end{array}$ & $\begin{array}{l}-0.194 \\
(-1.17)\end{array}$ & $\begin{array}{l}-0.252 \\
(-1.54)\end{array}$ \\
\hline Secondary education or more (\% labour force) & & & $\begin{array}{l}0.389^{*} \\
(1.95)\end{array}$ & $\begin{array}{c}0.512^{\star \star} \\
(2.52)\end{array}$ & $\begin{array}{c}0.588^{* * *} \\
(3.00)\end{array}$ \\
\hline Constant & $\begin{array}{c}2.783^{\star * *} \\
(8.42)\end{array}$ & $\begin{array}{l}4.113^{*} \\
(1.86)\end{array}$ & $\begin{array}{l}3.040 \\
(1.47)\end{array}$ & $\begin{array}{l}2.769 \\
(1.25)\end{array}$ & $\begin{array}{l}3.194 \\
(1.49)\end{array}$ \\
\hline Year dummies & Yes & Yes & Yes & Yes & Yes \\
\hline Observations & 254 & 254 & 224 & 160 & 116 \\
\hline Adjusted R-squared & 0.512 & 0.518 & 0.598 & 0.610 & 0.631 \\
\hline F Statistic & 11.22 & 10.87 & 30.12 & 15.98 & 13.79 \\
\hline
\end{tabular}

Note: All models are estimated using year dummies. Standard errors are clustered by country and t statistics indicated in parentheses below each estimated coefficient. Asterisks denote the level of statistical significance (*** at the $1 \%$ level, ${ }^{* *}$ at the $5 \%$ level, and * at the $10 \%$ level). The dependent variable is the log of the RCA index for all 248 CLEG products listed in Annex 1. Explanatory variables are all expressed as logs. 
Table A.3. Additional results for CLEG products using the EPS index and average import tariffs

\begin{tabular}{|c|c|c|c|c|c|}
\hline & $\begin{array}{l}\text { (1) RCA } \\
\text { All CLEG }\end{array}$ & $\begin{array}{l}\text { (2) RCA } \\
\text { All CLEG }\end{array}$ & $\begin{array}{l}\text { (3) RCA } \\
\text { All CLEG }\end{array}$ & $\begin{array}{l}\text { (4) RCA } \\
\text { All CLEG }\end{array}$ & $\begin{array}{l}\text { (5) RCA } \\
\text { All CLEG }\end{array}$ \\
\hline EPS index & $\begin{array}{c}0.593^{* * *} \\
(2.83)\end{array}$ & $\begin{array}{c}0.614^{* * *} \\
(3.07)\end{array}$ & $\begin{array}{c}0.574^{* * *} \\
(2.84)\end{array}$ & & \\
\hline EPS index (3-year lag) & & & & $\begin{array}{c}0.502^{* *} \\
(2.41)\end{array}$ & \\
\hline EPS index (5-year lag) & & & & & $\begin{array}{c}0.498^{* *} \\
(2.48)\end{array}$ \\
\hline Export concentration index & $\begin{array}{c}-0.765^{\star * *} \\
(-5.35)\end{array}$ & $\begin{array}{c}-0.763^{* * *} \\
(-5.57)\end{array}$ & $\begin{array}{c}-0.795^{* * *} \\
(-5.50)\end{array}$ & $\begin{array}{c}-0.832^{* * *} \\
(-5.23)\end{array}$ & $\begin{array}{c}-0.919^{* * *} \\
(-6.71)\end{array}$ \\
\hline Average import tariff applied on CLEG products & $\begin{array}{c}-0.0174^{* *} \\
(-2.50)\end{array}$ & $\begin{array}{c}-0.0215^{\star *} \\
(-2.72)\end{array}$ & $\begin{array}{c}-0.0214^{* *} \\
(-2.76)\end{array}$ & $\begin{array}{c}-0.0249^{* * *} \\
(-2.99)\end{array}$ & $\begin{array}{c}-0.0297^{* * *} \\
(-3.85)\end{array}$ \\
\hline Capital-labour ratio & & $\begin{array}{l}-0.180 \\
(-0.93)\end{array}$ & $\begin{array}{l}-0.246 \\
(-1.45)\end{array}$ & $\begin{array}{c}-0.320^{*} \\
(-1.97)\end{array}$ & $\begin{array}{c}-0.443^{\star \star *} \\
(-3.85)\end{array}$ \\
\hline Secondary education or more (\% labour force) & & & $\begin{array}{c}0.381^{* *} \\
(2.46)\end{array}$ & $\begin{array}{c}0.545^{\star * *} \\
(3.64)\end{array}$ & $\begin{array}{c}0.645^{\star * *} \\
(5.39)\end{array}$ \\
\hline \multirow[t]{2}{*}{ Constant } & $2.538^{\star * *}$ & $4.648^{*}$ & $3.739^{*}$ & $3.767^{\star}$ & $4.746^{\star * *}$ \\
\hline & $(6.85)$ & $(2.06)$ & $(1.98)$ & $(1.99)$ & (3.22) \\
\hline Year dummies & Yes & Yes & Yes & Yes & Yes \\
\hline Observations & 248 & 248 & 219 & 158 & 115 \\
\hline Adjusted R-squared & 0.547 & 0.565 & 0.654 & 0.681 & 0.742 \\
\hline F Statistic & 9.931 & 17.69 & 20.15 & 21.02 & 37.17 \\
\hline
\end{tabular}

Note: All models are estimated using year dummies. Standard errors are clustered by country and t statistics indicated in parentheses below each estimated coefficient. Asterisks denote the level of statistical significance ${ }^{* * *}$ at the $1 \%$ level, ${ }^{* *}$ at the $5 \%$ level, and ${ }^{*}$ at the $10 \%$ level). The dependent variable is the log of the RCA index for all 248 CLEG products listed in Annex 1. Explanatory variables are all expressed as logs. 
64 - THE STRINGENCY OF ENVIRONMENTAL REGULATIONS AND TRADE IN ENVIRONMENTAL GOODS

Table A.4. The EPS index and other determinants of RCA in core CLEG products

\begin{tabular}{|c|c|c|c|c|c|}
\hline & $\begin{array}{c}\text { (1) RCA } \\
\text { Core CLEG }\end{array}$ & $\begin{array}{c}\text { (2) RCA } \\
\text { Core CLEG }\end{array}$ & $\begin{array}{c}\text { (3) RCA } \\
\text { Core CLEG }\end{array}$ & $\begin{array}{c}\text { (4) RCA } \\
\text { Core CLEG }\end{array}$ & $\begin{array}{c}\text { (5) RCA } \\
\text { Core CLEG }\end{array}$ \\
\hline EPS index & $\begin{array}{c}0.778^{\star *} \\
(2.68)\end{array}$ & $\begin{array}{c}0.628^{* *} \\
(2.67)\end{array}$ & $\begin{array}{l}0.441^{*} \\
(2.01)\end{array}$ & & \\
\hline EPS index (3-year lag) & & & & $\begin{array}{l}0.389^{*} \\
(1.90)\end{array}$ & \\
\hline EPS index (5-year lag) & & & & & $\begin{array}{l}0.348 \\
(1.69)\end{array}$ \\
\hline Export concentration index & $\begin{array}{c}-0.545^{\star *} \\
(-2.48)\end{array}$ & $\begin{array}{c}-0.653^{* * *} \\
(-2.89)\end{array}$ & $\begin{array}{c}-0.787^{\star * *} \\
(-3.50)\end{array}$ & $\begin{array}{c}-0.769^{* * *} \\
(-3.72)\end{array}$ & $\begin{array}{c}-0.774^{* * *} \\
(-4.06)\end{array}$ \\
\hline Capital-labour ratio & & $\begin{array}{c}0.602^{* * *} \\
(3.33)\end{array}$ & $\begin{array}{c}0.639^{\star * *} \\
(4.27)\end{array}$ & $\begin{array}{c}0.558^{\star * *} \\
(3.08)\end{array}$ & $\begin{array}{c}0.524^{* *} \\
(2.64)\end{array}$ \\
\hline Secondary education or more (\% labour force) & & & $\begin{array}{c}1.316^{\star \star \star} \\
(5.90)\end{array}$ & $\begin{array}{c}1.470^{\star * *} \\
(4.58)\end{array}$ & $\begin{array}{c}1.629^{* * *} \\
(4.48)\end{array}$ \\
\hline Constant & $\begin{array}{c}2.809^{\star * *} \\
(5.81)\end{array}$ & $\begin{array}{l}-4.457^{*} \\
(-2.06)\end{array}$ & $\begin{array}{c}-10.67^{* * *} \\
(-4.65)\end{array}$ & $\begin{array}{c}-10.84^{* * *} \\
(-3.54)\end{array}$ & $\begin{array}{c}-10.97^{\star \star *} \\
(-3.22)\end{array}$ \\
\hline Year dummies & Yes & Yes & Yes & Yes & Yes \\
\hline Observations & 254 & 254 & 224 & 160 & 116 \\
\hline Adjusted R-squared & 0.267 & 0.404 & 0.577 & 0.561 & 0.560 \\
\hline F Statistic & 2.492 & 8.105 & 21.48 & 10.03 & 16.62 \\
\hline
\end{tabular}

Note: All models are estimated using year dummies. Standard errors are clustered by country and t statistics indicated in parentheses below each estimated coefficient. Asterisks denote the level of statistical significance ${ }^{* * *}$ at the $1 \%$ level, ${ }^{* *}$ at the $5 \%$ level, and ${ }^{*}$ at the $10 \%$ level). The dependent variable is the log of the RCA index for the Asterisks denote the level of statistical significance ${ }^{* * *}$ at the $1 \%$ level, ${ }^{* *}$ at the $5 \%$ level, and
11 Core products listed in Annex 1 . Explanatory variables are all expressed as logs. 
Table A.5. The EPS index and other determinants of RCA in core CLEG+ products

\begin{tabular}{|c|c|c|c|c|c|}
\hline & $\begin{array}{c}\text { (1) RCA } \\
\text { Core CLEG+ }\end{array}$ & $\begin{array}{c}\text { (2) RCA } \\
\text { Core CLEG+ }\end{array}$ & $\begin{array}{c}\text { (3) RCA } \\
\text { Core CLEG+ }\end{array}$ & $\begin{array}{c}\text { (4) RCA } \\
\text { Core CLEG+ }\end{array}$ & $\begin{array}{c}\text { (5) RCA } \\
\text { Core CLEG+ }\end{array}$ \\
\hline EPS index & $\begin{array}{c}0.642^{* \star \star} \\
(3.91)\end{array}$ & $\begin{array}{c}0.588^{* * \star} \\
(3.49)\end{array}$ & $\begin{array}{c}0.467^{\star *} \\
(2.75)\end{array}$ & & \\
\hline EPS index (3-year lag) & & & & $\begin{array}{c}0.408^{* *} \\
(2.16)\end{array}$ & \\
\hline EPS index (5-year lag) & & & & & $\begin{array}{l}0.351^{*} \\
(1.80)\end{array}$ \\
\hline Export concentration index & $\begin{array}{c}-0.491^{\star \star *} \\
(-4.88)\end{array}$ & $\begin{array}{c}-0.530^{\star \star \star} \\
(-5.63)\end{array}$ & $\begin{array}{c}-0.580^{\star \star *} \\
(-6.29)\end{array}$ & $\begin{array}{c}-0.548^{* * *} \\
(-4.97)\end{array}$ & $\begin{array}{c}-0.551^{* * *} \\
(-4.69)\end{array}$ \\
\hline Capital-labour ratio & & $\begin{array}{l}0.216^{*} \\
(1.74)\end{array}$ & $\begin{array}{c}0.245^{\star *} \\
(2.14)\end{array}$ & $\begin{array}{l}0.250^{*} \\
(1.92)\end{array}$ & $\begin{array}{l}0.284^{*} \\
(2.03)\end{array}$ \\
\hline Secondary education or more (\% labour force) & & & $\begin{array}{c}0.720^{\star * *} \\
(4.21)\end{array}$ & $\begin{array}{c}0.799^{\star \star *} \\
(3.60)\end{array}$ & $\begin{array}{c}0.877^{\star \star \star} \\
(3.76)\end{array}$ \\
\hline Constant & $\begin{array}{c}3.175^{\star \star \star} \\
(15.56)\end{array}$ & $\begin{array}{l}0.563 \\
(0.37)\end{array}$ & $\begin{array}{l}-2.879 \\
(-1.63)\end{array}$ & $\begin{array}{l}-3.486 \\
(-1.60)\end{array}$ & $\begin{array}{c}-4.099^{*} \\
(-1.74)\end{array}$ \\
\hline Year dummies & Yes & Yes & Yes & Yes & Yes \\
\hline Observations & 254 & 254 & 224 & 160 & 116 \\
\hline Adjusted R-squared & 0.466 & 0.504 & 0.620 & 0.586 & 0.572 \\
\hline F Statistic & 12.63 & 16.01 & 16.55 & 20.65 & 9.778 \\
\hline
\end{tabular}

Note: All models are estimated using year dummies. Standard errors are clustered by country and $t$ statistics indicated in parentheses below each estimated coefficient.

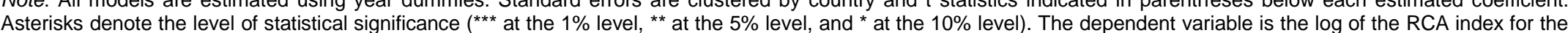
40 Core CLEG+ products listed in Annex 1. Explanatory variables are all expressed as logs. 
Table A.6. The EPS index and other determinants of RCA in energy-related CLEG products

\begin{tabular}{|c|c|c|c|c|c|}
\hline & $\begin{array}{l}\text { (1) RCA } \\
\text { Energy }\end{array}$ & $\begin{array}{l}\text { (2) RCA } \\
\text { Energy }\end{array}$ & $\begin{array}{c}\text { (3) RCA } \\
\text { Energy }\end{array}$ & $\begin{array}{l}\text { (4) RCA } \\
\text { Energy }\end{array}$ & $\begin{array}{c}\text { (5) RCA } \\
\text { Energy }\end{array}$ \\
\hline EPS index & $\begin{array}{c}0.675^{\star \star \star} \\
(2.83)\end{array}$ & $\begin{array}{c}0.686^{\star * *} \\
(3.01)\end{array}$ & $\begin{array}{c}0.571^{* *} \\
(2.80)\end{array}$ & & \\
\hline EPS index (3-year lag) & & & & $\begin{array}{c}0.572^{\star \star *} \\
(2.92)\end{array}$ & \\
\hline EPS index (5-year lag) & & & & & $\begin{array}{c}0.621^{* * *} \\
(3.27)\end{array}$ \\
\hline Export concentration index & $\begin{array}{c}-0.505^{* * *} \\
(-4.09)\end{array}$ & $\begin{array}{c}-0.497^{* * *} \\
(-3.97)\end{array}$ & $\begin{array}{c}-0.537^{* * *} \\
(-5.15)\end{array}$ & $\begin{array}{c}-0.519^{* * *} \\
(-4.78)\end{array}$ & $\begin{array}{c}-0.551^{* * *} \\
(-4.70)\end{array}$ \\
\hline Capital-labour ratio & & $\begin{array}{c}-0.0431 \\
(-0.18)\end{array}$ & $\begin{array}{c}-0.0855 \\
(-0.43)\end{array}$ & $\begin{array}{l}-0.151 \\
(-0.76)\end{array}$ & $\begin{array}{l}-0.260 \\
(-1.40)\end{array}$ \\
\hline Secondary education or more (\% labour force) & & & $\begin{array}{c}0.798^{* * *} \\
(3.70)\end{array}$ & $\begin{array}{c}0.913^{\star \star \star *} \\
(4.35)\end{array}$ & $\begin{array}{c}0.926^{\star * \star} \\
(4.70)\end{array}$ \\
\hline Constant & $\begin{array}{c}3.007^{\star \star *} \\
(8.58)\end{array}$ & $\begin{array}{l}3.527 \\
(1.24)\end{array}$ & $\begin{array}{l}0.577 \\
(0.23)\end{array}$ & $\begin{array}{l}0.681 \\
(0.26)\end{array}$ & $\begin{array}{l}1.959 \\
(0.79)\end{array}$ \\
\hline Year dummies & Yes & Yes & Yes & Yes & Yes \\
\hline Observations & 254 & 254 & 224 & 160 & 116 \\
\hline Adjusted R-squared & 0.341 & 0.339 & 0.501 & 0.527 & 0.571 \\
\hline F Statistic & 5.429 & 5.251 & 9.723 & 10.84 & 9.200 \\
\hline
\end{tabular}

Note: All models are estimated using year dummies. Standard errors are clustered by country and t statistics indicated in parentheses below each estimated coefficient. Asterisks denote the level of statistical significance $\left(^{* *}\right.$ at the $1 \%$ level, ${ }^{* *}$ at the $5 \%$ level, and ${ }^{*}$ at the $10 \%$ level). The dependent variable is the log of the RCA index for 103 CLEG products related to the energy sector and listed in Annex 1 under the media "APC", "MON", and "REP". Explanatory variables are all expressed as logs. 
Table A.7. The share of MSW landfilled and other determinants of RCA in solid-waste-related products

\begin{tabular}{|c|c|c|c|c|c|}
\hline & $\begin{array}{c}\text { (1) RCA } \\
\text { SWM }\end{array}$ & $\begin{array}{c}\text { (2) RCA } \\
\text { SWM }\end{array}$ & $\begin{array}{c}\text { (3) RCA } \\
\text { SWM }\end{array}$ & $\begin{array}{c}\text { (4) RCA } \\
\text { SWM }\end{array}$ & $\begin{array}{c}\text { (5) RCA } \\
\text { SWM }\end{array}$ \\
\hline MSW landfilled (\% MSW generation) & $\begin{array}{c}-0.0635^{\star \star \star} \\
(-4.08)\end{array}$ & $\begin{array}{c}-0.0510^{* * *} \\
(-3.68)\end{array}$ & $\begin{array}{c}-0.0414^{\star \star *} \\
(-3.89)\end{array}$ & & \\
\hline MSW landfilled (3-year lag) & & & & $\begin{array}{c}-0.0379^{* * *} \\
(-3.48)\end{array}$ & \\
\hline MSW landfilled (5-year lag) & & & & & $\begin{array}{c}-0.0415^{\star \star \star} \\
(-3.64)\end{array}$ \\
\hline Export concentration index & $\begin{array}{c}-0.830^{* * *} \\
(-2.97)\end{array}$ & $\begin{array}{c}-0.832^{* * *} \\
(-2.88)\end{array}$ & $\begin{array}{c}-0.760^{* *} \\
(-2.62)\end{array}$ & $\begin{array}{c}-0.724^{* *} \\
(-2.69)\end{array}$ & $\begin{array}{c}-0.790^{* * *} \\
(-2.94)\end{array}$ \\
\hline Capital-labour ratio & & $\begin{array}{l}0.163 \\
(1.21)\end{array}$ & $\begin{array}{l}0.190 \\
(1.40)\end{array}$ & $\begin{array}{l}0.205 \\
(1.42)\end{array}$ & $\begin{array}{l}0.232 \\
(1.58)\end{array}$ \\
\hline Secondary education or more (\% labour force) & & & $\begin{array}{c}0.888^{* *} \\
(2.28)\end{array}$ & $\begin{array}{c}0.982^{* *} \\
(2.60)\end{array}$ & $\begin{array}{c}0.906^{* *} \\
(2.71)\end{array}$ \\
\hline Constant & $\begin{array}{c}2.616^{\star \star *} \\
(4.11)\end{array}$ & $\begin{array}{l}0.709 \\
(0.54)\end{array}$ & $\begin{array}{l}-3.313 \\
(-1.21)\end{array}$ & $\begin{array}{l}-3.640 \\
(-1.25)\end{array}$ & $\begin{array}{l}-3.793 \\
(-1.37)\end{array}$ \\
\hline Year dummies & Yes & Yes & Yes & Yes & Yes \\
\hline Observations & 356 & 336 & 303 & 203 & 140 \\
\hline Adjusted R-squared & 0.360 & 0.378 & 0.430 & 0.404 & 0.428 \\
\hline F Statistic & . & . & 11.31 & 9.395 & 7.370 \\
\hline
\end{tabular}

Note: All models are estimated using year dummies. Standard errors are clustered by country and t statistics indicated in parentheses below each estimated coefficient Asterisks denote the level of statistical significance $\left(^{* * *}\right.$ at the $1 \%$ level, ${ }^{* *}$ at the $5 \%$ level, and ${ }^{*}$ at the $10 \%$ level). The dependent variable is the log of the RCA index for all CLEG products classified under the "SWM" heading (see Annex 1). Explanatory variables are all expressed as logs. 
$\mathbf{6 8}$ - THE STRINGENCY OF ENVIRONMENTAL REGULATIONS AND TRADE IN ENVIRONMENTAL GOODS

Table A.8. The TRT indicator and other determinants of RCA in water-related products

\begin{tabular}{|c|c|c|c|c|c|}
\hline & $\begin{array}{c}\text { (1) RCA } \\
\text { WAT }\end{array}$ & $\begin{array}{c}\text { (2) RCA } \\
\text { WAT }\end{array}$ & $\begin{array}{c}\text { (3) RCA } \\
\text { WAT }\end{array}$ & $\begin{array}{c}\text { (4) RCA } \\
\text { WAT }\end{array}$ & $\begin{array}{c}\text { (5) RCA } \\
\text { WAT }\end{array}$ \\
\hline TRT indicator & $\begin{array}{c}0.279^{\star \star} \\
(2.19)\end{array}$ & $\begin{array}{c}0.457^{\star * *} \\
(5.78)\end{array}$ & $\begin{array}{c}0.452^{\star \star *} \\
(5.16)\end{array}$ & & \\
\hline TRT indicator (3-year lag) & & & & $\begin{array}{c}0.585^{\star * *} \\
(7.20)\end{array}$ & \\
\hline TRT indicator (5-year lag) & & & & & $\begin{array}{c}0.604^{* * *} \\
(7.72)\end{array}$ \\
\hline Export concentration index & $\begin{array}{c}-0.685^{\star * *} \\
(-4.53)\end{array}$ & $\begin{array}{c}-0.503^{\star * *} \\
(-4.31)\end{array}$ & $\begin{array}{c}-0.477^{\star * *} \\
(-4.68)\end{array}$ & $\begin{array}{c}-0.445^{\star \star *} \\
(-3.86)\end{array}$ & $\begin{array}{c}-0.415^{\star \star \star} \\
(-2.92)\end{array}$ \\
\hline Capital-labour ratio & & $\begin{array}{l}-0.115 \\
(-1.26)\end{array}$ & $\begin{array}{l}-0.117 \\
(-1.22)\end{array}$ & $\begin{array}{l}-0.153 \\
(-1.52)\end{array}$ & $\begin{array}{l}-0.121 \\
(-1.12)\end{array}$ \\
\hline Secondary education or more (\% labour force) & & & $\begin{array}{c}0.0306 \\
(0.14)\end{array}$ & $\begin{array}{c}0.0476 \\
(0.17)\end{array}$ & $\begin{array}{l}0.197 \\
(0.48)\end{array}$ \\
\hline Constant & $\begin{array}{c}1.976^{\star \star \star} \\
(3.83)\end{array}$ & $\begin{array}{c}2.976^{\star \star \star} \\
(2.78)\end{array}$ & $\begin{array}{c}2.916^{* *} \\
(2.05)\end{array}$ & $\begin{array}{l}2.857 \\
(1.61)\end{array}$ & $\begin{array}{l}1.776 \\
(0.74)\end{array}$ \\
\hline Year dummies & Yes & Yes & Yes & Yes & Yes \\
\hline Observations & 271 & 248 & 223 & 175 & 127 \\
\hline Adjusted R-squared & 0.481 & 0.551 & 0.559 & 0.701 & 0.753 \\
\hline F Statistic & 9.612 & 32.74 & 23.71 & 40.91 & 40.62 \\
\hline
\end{tabular}

Note: All models are estimated using year dummies. Standard errors are clustered by country and t statistics indicated in parentheses below each estimated coefficient. Asterisks denote the level of statistical significance ${ }^{* * *}$ at the $1 \%$ level, ${ }^{* *}$ at the $5 \%$ level, and ${ }^{*}$ at the $10 \%$ level). The dependent variable is the log of the RCA index for all CLEG products classified under the "WAT" heading (see Annex 1). Explanatory variables are all expressed as logs. 